In cooperation with DuPage County Department of Economic Development and Planning, Stormwater Management Division

\title{
Development and Analysis of a Meteorological Database, Argonne National Laboratory, Illinois
}

Open-File Report 2010-1220 
Cover image was selected from the Sag Bridge 7.5-minute quadrangle topographic map downloaded from US Topo at: http://nationalmap.gov/ustopo/index.html. 


\section{Development and Analysis of a Meteorological Database, Argonne National Laboratory, Illinois}

By Thomas M. Over, Thomas H. Price, and Audrey L. Ishii

In cooperation with DuPage County Department of Economic

Development and Planning, Stormwater Management Division

Open-File Report 2010-1220 


\title{
U.S. Department of the Interior \\ KEN SALAZAR, Secretary \\ U.S. Geological Survey \\ Marcia K. McNutt, Director
}

\section{U.S. Geological Survey, Reston, Virginia: 2010}

\author{
For more information on the USGS — the Federal source for science about the Earth, its natural and living resources, \\ natural hazards, and the environment, visit http://www.usgs.gov or call 1-888-ASK-USGS \\ For an overview of USGS information products, including maps, imagery, and publications, \\ visit http://www.usgs.gov/pubprod \\ To order this and other USGS information products, visit http://store.usgs.gov
}

Any use of trade, product, or firm names is for descriptive purposes only and does not imply endorsement by the U.S. Government.

Although this report is in the public domain, permission must be secured from the individual copyright owners to reproduce any copyrighted materials contained within this report.

Suggested citation:

Over, T.M., Price, T.H., and Ishii, A.L., 2010, Development and analysis of a meteorological database, Argonne National Laboratory, Illinois: U.S. Geological Survey Open File Report 2010-1220, 67 p. 


\section{Contents}

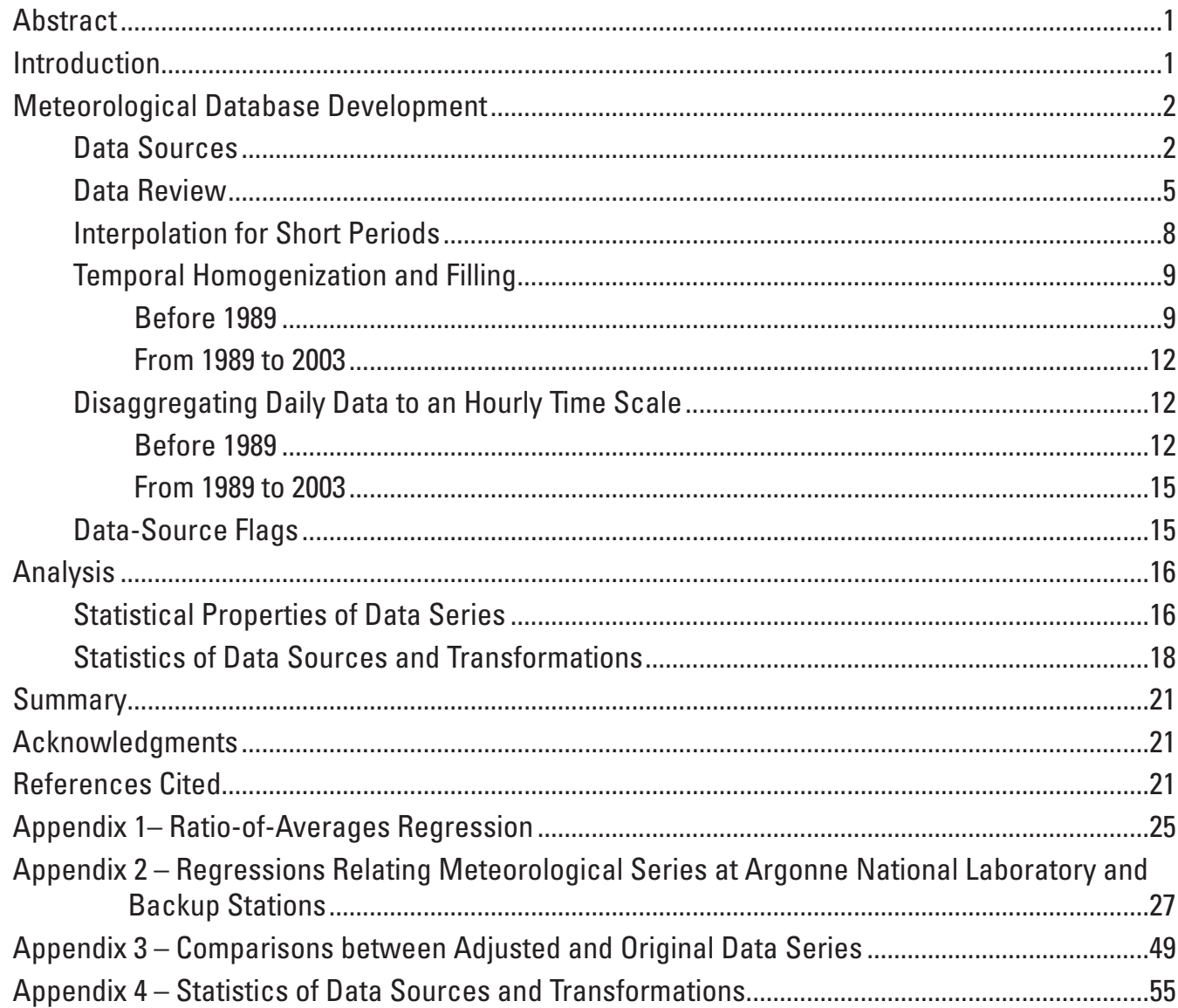

\section{Figures}

1. Map showing locations of Argonne National Laboratory and other meteorological data-collection sites in northeastern Illinois used in this report.

2. Graph showing air temperature data periods at Argonne National Laboratory (ANL), Wheaton (WHT), and St. Charles (STC), Illinois, 1948-2003.

3. Graph showing dewpoint temperature data periods at Argonne National Laboratory (ANL) and O'Hare International Airport (OH), Illinois, 1948-2003

4. Graph showing wind travel data periods at Argonne National Laboratory (ANL), O'Hare International Airport (OH), and St. Charles (STC), Illinois, 1948-2003..

5. Graph showing solar radiation data periods at Argonne National Laboratory (ANL), O'Hare International Airport (OH), and St. Charles (STC), Illinois, 1948-2003

6. Graphs showing average daily values for the period January 1, 1948, through September 30, 2003, of meteorological data series at Argonne National Laboratory in this study [A: temperature, $B$ : dewpoint, $C$ : wind, $D$ : solar radiation, $E$ : solar radiation as a fraction of extraterrestrial solar radiation, F: computed potential evapotranspiration (PET)] ....17

7. Graphs showing average annual values, estimated trends, and average values of meteorological data series for water years 1949 through 2003 at Argonne National Laboratory in this study [A: temperature, $B$ : dewpoint, $C$ : wind, $D$ : solar radiation, $E$ : computed potential evapotranspiration (PET)] 


\section{Tables}

1. Basic information about the meteorological stations used in this study ..........................5

2. Data period designations used in this study.

3. Instruments used to record meteorological data at Argonne National Laboratory, Illinois used in this study

4. Regression equations and statistics relating pre-1989 daily Argonne National Laboratory and concurrent backup data in this study.

5. Regression equations and statistics relating daily 1989-2003 Argonne National Laboratory and pre-1989 backup data series and used to fill missing and erroneous backup data in this study.

6. Equations and statistics relating daily ANL_DAT and WHT_col air temperature series and used to fill missing and erroneous WHT_col air temperature data in this study.....12

7. Equations and statistics relating daily pre-1989 and 1989-2003 Argonne National Laboratory data and used to convert pre-1989 data to the 1989-2003 statistical base in this study.

8. Regression equations and statistics relating daily 1989-2003 Argonne National Laboratory and backup data used to fill missing and erroneous Argonne National Laboratory data in this study

9. Data-source flag " $x$ " codes indicating Argonne National Laboratory data status in this study......

10. Data-source flag " $y$ " codes indicating method used for filling or fixing missing or erroneous data in this study

11. Statistics of annual averages of filled and adjusted Argonne data series and computed potential evapotranspiration for water years 1949 through 2003 in this study.................18

12. Pearson correlation coefficients between annual averages of filled and adjusted Argonne data series and computed potential evapotranspiration and their significance for water years 1949 through 2003 in this study 


\section{Conversion Factors, Abbreviations, Datums}

Inch/Pound to SI

\begin{tabular}{|c|c|c|}
\hline Multiply & By & To obtain \\
\hline \multicolumn{3}{|c|}{ Length } \\
\hline inch (in.) & 2.54 & centimeter $(\mathrm{cm})$ \\
\hline inch (in.) & 25.4 & millimeter $(\mathrm{mm})$ \\
\hline foot $(\mathrm{ft})$ & 0.3048 & meter $(\mathrm{m})$ \\
\hline mile (mi) & 1.609 & kilometer $(\mathrm{km})$ \\
\hline \multicolumn{3}{|c|}{ Energy density } \\
\hline Langleys (Lg) & 41,840 & Joules per square meter $\left(\mathrm{J} / \mathrm{m}^{2}\right)$ \\
\hline
\end{tabular}

Temperature in degrees Fahrenheit $\left({ }^{\circ} \mathrm{F}\right)$ may be converted to degrees Celsius $\left({ }^{\circ} \mathrm{C}\right)$ as follows:

${ }^{\circ} \mathrm{C}=\left({ }^{\circ} \mathrm{F}-32\right) / 1.8$

Vertical coordinate information is referenced to the National Geodetic Vertical Datum of 1929 (NGVD 29).

Horizontal coordinate information is referenced to the North American Datum of 1983 (NAD 83). 



\title{
Development and Analysis of a Meteorological Database, Argonne National Laboratory, Illinois
}

\author{
By Thomas M. Over, Thomas H. Price, and Audrey L. Ishii
}

\section{Abstract}

A database of hourly values of air temperature, dewpoint temperature, wind speed, and solar radiation from January 1, 1948, to September 30, 2003, primarily using data collected at the Argonne National Laboratory station, was developed for use in continuous-time hydrologic modeling in northeastern Illinois. Missing and apparently erroneous data values were replaced with adjusted values from nearby stations used as "backup". Temporal variations in the statistical properties of the data resulting from changes in measurement and datastorage methodologies were adjusted to match the statistical properties resulting from the data-collection procedures that have been in place since January 1, 1989. The adjustments were computed based on the regressions between the primary data series from Argonne National Laboratory and the backup series using data obtained during common periods; the statistical properties of the regressions were used to assign estimated standard errors to values that were adjusted or filled from other series. Each hourly value was assigned a corresponding data-source flag that indicates the source of the value and its transformations. An analysis of the data-source flags indicates that all the series in the database except dewpoint have a similar fraction of Argonne National Laboratory data, with about 89 percent for the entire period, about 86 percent from 1949 through 1988, and about 98 percent from 1989 through 2003. The dewpoint series, for which observations at Argonne National Laboratory did not begin until 1958, has only about 71 percent Argonne National Laboratory data for the entire period, about 63 percent from 1948 through 1988, and about 93 percent from 1989 through 2003, indicating a lower reliability of the dewpoint sensor.

A basic statistical analysis of the filled and adjusted data series in the database, and a series of potential evapotranspiration computed from them using the computer program LXPET (Lamoreux Potential Evapotranspiration) also was carried out. This analysis indicates annual cycles in solar radiation and potential evapotranspiration that follow the annual cycle of extraterrestrial solar radiation, whereas temperature and dewpoint annual cycles are lagged by about 1 month relative to the solar cycle. The annual cycle of wind has a late summer minimum, and spring and fall maximums. At the annual time scale, the filled and adjusted data series and computed potential evapotranspiration have significant serial correlation and possibly have significant temporal trends. The inter-annual fluctuations of temperature and dewpoint are weakest, whereas those of wind and potential evapotranspiration are strongest.

\section{Introduction}

High quality meteorological data series are required for continuous-time hydrologic modeling. In northeastern Illinois, applications of continuous-time hydrologic modeling have included floodplain management studies (Soong and others, 2005; Duncker and Melching, 1998; Price, 1994, 1996; Price and Dreher, 1991) and real-time flood forecasting (Ishii and others, 1998) with runoff being simulated by the Hydrologic Simulation Program - FORTRAN (HSPF) model (Bicknell and others, 1997; Donigian and others, 1995). HSPF requires hourly inputs of precipitation, air temperature, dewpoint temperature, wind travel, and solar radiation. This study focuses on the inputs other than precipitation which are used to compute potential evapotranspiration and snowmelt/ ablation. Other continuous-time hydrologic models, such as the Precipitation-Runoff Modeling System (Leavesley and Stannard, 1995) and the Soil and Water Assessment Tool (Arnold and Fohrer, 2005), require similar meteorological input data. Previous continuous-time hydrologic modeling in northeastern Illinois made use of a database developed by the Northeastern Illinois Planning Commission (NIPC; now incorporated into the Chicago Metropolitan Agency for Planning) from measurements made primarily at O'Hare International Airport $(\mathrm{OH})$ by the National Weather Service (NWS). Recent conversion of the OH station to a new Automated Surface Observation System (ASOS) station (National Weather Service, 1998) created a discontinuity in the record and motivated consideration of data sources other than $\mathrm{OH}$ (Price, 1998). The largest data concern was solar radiation, which was never measured directly at $\mathrm{OH}$, but instead for the NIPC database was estimated daily as a function of cloud cover. The new ASOS station at $\mathrm{OH}$ changed the cloud-cover measurement system requiring a new empirical cloud coverradiation relation, which was not immediately available. The other primary concern was the convenience of near real-time availability of the data in digital form, which is relatively 
low at NWS stations, including the new ASOS station at $\mathrm{OH}$. These concerns prompted the consideration of the use of an alternative meteorological station operated by Argonne National Laboratory (ANL) on the grounds of its facility in southeastern DuPage County, which has been operating since July 1, 1949 (Moses and Bogner, 1967), and provides all of the desired measurements including measured solar radiation, digitally on the World-Wide Web (WWW) (ANL, 2005) with only a short delay.

As a result, the U.S. Geological Survey (USGS), in cooperation with DuPage County Department of Economic Development and Planning, Stormwater Management Division, undertook the development of a database consisting of air temperature, dewpoint temperature, wind travel, and solar radiation, based on measurements at ANL. This effort involved applying a series of checks to the ANL data to identify apparently erroneous values, replacing missing values and values deemed to be erroneous with values from the NIPC database and other sources, and removing temporal non-homogeneities in the series. The result is a complete database with dates ranging from January 1, 1948, to September 30, 2003, called the Argonne meteorological database. The statistical properties of the database are those of the measurement regime at ANL as of January 1, 2003, where the measurement regime is the set of measurement practices, including what instruments are used, where they are located, and how the data are processed, that exert statistically significant control over the measured values that are reported. Within the database, each value has a flag that allows the user to determine its source and processing. The flag identifies the origin of the data, and the transformations applied to convert the data value to the present ANL measurement regime. The database is available both as a "flat file" of ASCII values and in the standard Watershed Data Management (WDM) database format used by HSPF. The database is available on the WWW at http://pubs.water.usgs. gov/wdril05 and distributed on CD-ROM as part of the annual data report of the Illinois Water Science Center of the USGS (LaTour and others, 2006) for water year (WY) 2005, where a water year is defined to run from October 1 of the previous calendar year to September 30 of the calendar year.

The approach for the quality control of the data in the development of this database shares many features with other approaches taken to the quality control of meteorological data (Alexandersson, 1986; Allen and DeGaetano, 2000; Allen and DeGaetano, 2001; DeGaetano, 1997; DeGaetano and others, 2002; Easterling and Peterson, 1995; Graybeal and others, 2004a; Graybeal and others, 2004b; Karl and Williams, 1987; Kunkel and others, 1998; Meek and Hatfield, 1994; Peterson and Easterling, 1994; Peterson and others, 1998; Potter, 1981; Rhoades and Salinger, 1993). These shared features include comparison with a homogeneous reference data series, homogeneity tests for periods demarcated by changes in instrumentation and station location, use of differences to test for homogeneity of temperature data, and ratios to test for homogeneity of precipitation data (applied here to wind travel and solar radiation data), evaluation of the temporal sequence of the data series, comparison with other related data series, application of physical principles, and estimating missing data by means of regression. The full implementation of the methodology of complex quality control of meteorological data (Gandin, 1988; Collins, 2001), however, was beyond the scope of this study.

This report consists of two parts. In the first, the methods used to develop the database are presented. The database development included checking the data; filling in missing and erroneous values; adjusting data to achieve temporal homogeneity; disaggregating daily to hourly; and constructing data-source flags. In the second, a summary of the statistical properties of the data, showing some climatological features and the number and percentage of values in the database from each source and transformation, is presented.

\section{Meteorological Database Development}

The following section describes the development of the Argonne meteorological database. A description of the data sources and how the data were reviewed, filled, temporally homogenized, and disaggregated from daily to hourly time scales are presented. In addition, the data-source flags that accompany each data value in the database, identifying the source and transformations of the data value are described.

\section{Data Sources}

Basic information about the meteorological stations used in this study is provided in table 1 , and the locations of the stations are shown in figure 1. ANL, which was founded in 1946 and began operations at its present site in southeast DuPage County in 1948 (Holl, 1997, ch. 1 \& 2), built and instrumented a tower with sensors for measuring wind speed and direction, air temperature, dewpoint temperature, solar radiation, precipitation, barometric pressure, and soil temperature for the purpose of monitoring weather in support of research on diffusion and transport of airborne contaminants (Holl, 1997, ch. 3, p. 101; Moses and Kulhanek, 1962; Moses and Bogner, 1967). The first available measurements are from July 1, 1949. Wind speed and direction, air temperature, dewpoint temperature, and soil temperature were and are measured at several levels. The original and current ANL meteorological towers are located about 23 miles southwest from The Loop in downtown Chicago. The NWS weather station at $\mathrm{OH}$ is located about 16 miles northwest from downtown Chicago. The earliest digital data available at $\mathrm{OH}$ is from October 30,1958, and data from this station comprise air temperature, dewpoint temperature, precipitation, wind speed and direction, atmospheric pressure, and, for certain years before conversion of the station from a first-order station (staffed by NWS personnel) to an automated surface observation station (ASOS) on February 1, 1996, cloud cover and hours of daily sunshine. The earliest digital data available from the NWS cooperative station at Wheaton (WHT) is from January 1, 1948, and comprise daily minimum 


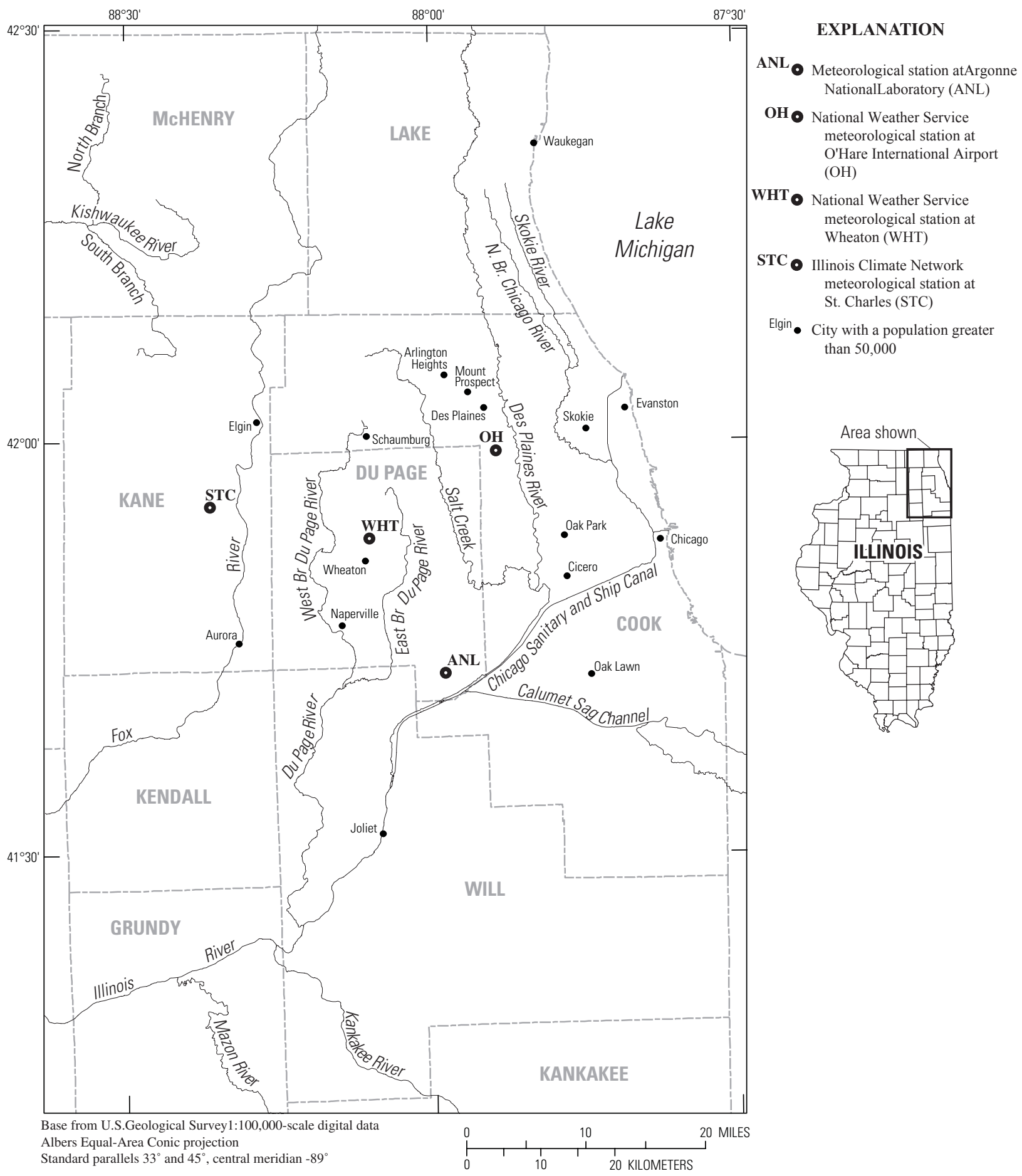

Figure 1. Locations of Argonne National Laboratory and other meteorological data-collection sites in northeastern Illinois used in this report.

and maximum temperature and precipitation data. The station originally was located at Wheaton College, but since June, 1966, has been located at Morton Arboretum nearby. Both locations are about 25 miles west from downtown Chicago. The St. Charles (STC) station has been operated by the Illinois State Water Survey (ISWS) as part of the Water and Atmospheric Resources Monitoring Program/Illinois Climate
Network (WARM/ICN) (Hollinger and others, 1994) since January, 1989, near St. Charles, Illinois, in east-central Kane County, about 39 miles west from downtown Chicago. ICN stations provide hourly measurements of wind speed and direction, air temperature, dewpoint temperature, solar radiation, precipitation, barometric pressure, and soil temperature. 


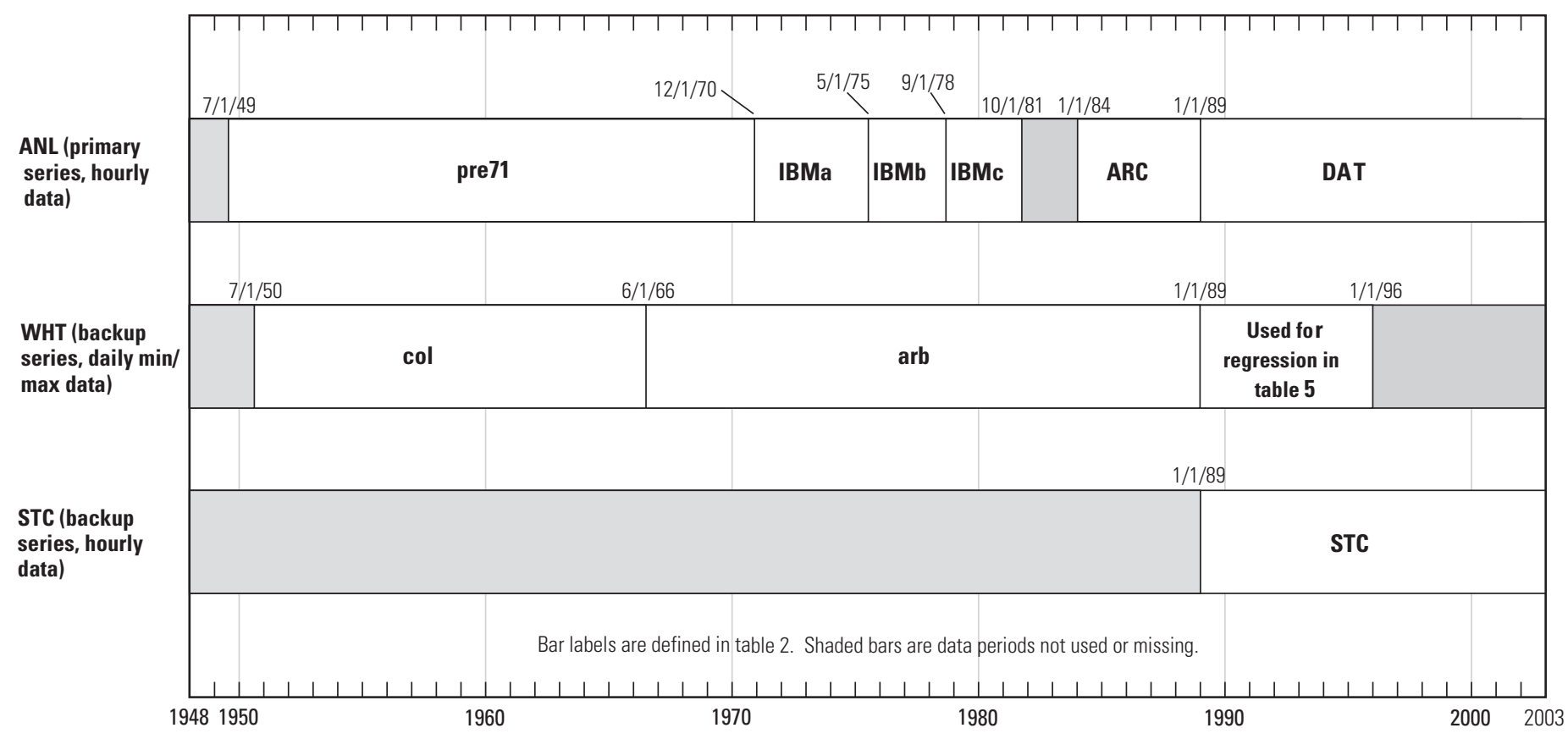

Figure 2. Air temperature data periods at Argonne National Laboratory (ANL), Wheaton (WHT), and St. Charles (STC), Illinois, 1948-2003.



Figure 3. Dewpoint temperature data periods at Argonne National Laboratory (ANL) and O'Hare International Airport (OH), Illinois, 1948-2003.

The ANL dataset is the primary source for the database. Data from $\mathrm{OH}$, WHT, and STC were used as backup series to ANL data for filling missing and erroneous periods in the primary series. NIPC provided the $\mathrm{OH}$ and WHT datasets to the USGS. These two datasets make up the primary sources of the NIPC database. NIPC also provided the ANL data before December 1, 1970, which were entered by NIPC from paper and microfiche records. Data from December 1, 1970, to September 30, 2003, were downloaded from the ANL website at http://www.atmos.anl.gov/ANLMET/.

The data in the primary series were divided into periods based on changes in instrumentation, and data storage format, and at long breaks in the record. Evidence for changes in statistical properties between these periods was sought by 
Table 1. Basic information about the meteorological stations used in this study.

[ANL, Argonne National Laboratory; ', degrees; ' , minutes; OH, O’Hare International Airport; NWS, National Weather Service; ASOS, Automated Surface Observing System; WHT, Wheaton; COOP, cooperative; STC, St. Charles; ISWS, Illinois State Water Survey; WARM/ICN, Water and Atmospheric Resources Monitoring - Illinois Climate Network]

\begin{tabular}{|c|c|c|c|c|c|}
\hline Location & Operator / type & Latitude & Longitude & Elevation & $\begin{array}{c}\text { Period of record used } \\
\text { in this study (month/ } \\
\text { day/year) }\end{array}$ \\
\hline \multicolumn{6}{|c|}{ Argonne National Laboratory (ANL) } \\
\hline ANL, "181" tower & ANL & $41^{\circ} 42^{\prime}$ & $87^{\circ} 59^{\prime}$ & 734.9 & $7 / 1 / 49$ to $12 / 31 / 88$ \\
\hline ANL, Building 487 tower & ANL & $41^{\circ} 42^{\prime}$ & $88^{\circ} 00^{\prime}$ & 754.6 & $1 / 1 / 89$ to present \\
\hline \multicolumn{6}{|c|}{ O'Hare International Airport $(\mathrm{OH})$} \\
\hline $\mathrm{OH}$ & NWS / first-order ${ }^{\mathrm{a}}$ & $41^{\circ} 59^{\prime}$ & $87^{\circ} 54^{\prime}$ & 658 & $10 / 30 / 58$ to $3 / 7 / 85$ \\
\hline $\mathrm{OH}$ & NWS / first-order & $41^{\circ} 59^{\prime}$ & $87^{\circ} 54^{\prime}$ & 658 & $3 / 7 / 85$ to $1 / 19 / 89$ \\
\hline $\mathrm{OH}$ & NWS / first-order & $42^{\circ} 00^{\prime}$ & $87^{\circ} 53^{\prime}$ & 658 & $1 / 19 / 89$ to $2 / 1 / 96$ \\
\hline $\mathrm{OH}$ & NWS / ASOS & $41^{\circ} 59^{\prime}$ & $87^{\circ} 54^{\prime}$ & 658 & $2 / 1 / 96$ to present \\
\hline \multicolumn{6}{|c|}{ Wheaton (WHT) } \\
\hline WHT (Wheaton College) & NWS / COOPa & $41^{\circ} 52^{\prime}$ & $88^{\circ} 06^{\prime}$ & 751 & $1 / 1 / 48$ to $6 / 30 / 55$ \\
\hline WHT (Wheaton College) & NWS / COOP & $41^{\circ} 52^{\prime}$ & $88^{\circ} 06^{\prime}$ & 771 & $7 / 1 / 55$ to $5 / 31 / 66$ \\
\hline WHT (Morton Arboretum) & NWS / COOP & $41^{\circ} 49^{\prime}$ & $88^{\circ} 04^{\prime}$ & 679 & $6 / 1 / 66$ to present \\
\hline \multicolumn{6}{|c|}{ St. Charles (STC) } \\
\hline STC & ISWS / WARM-ICN & $41^{\circ} 54^{\prime}$ & $88^{\circ} 22^{\prime}$ & 741 & $1 / 1 / 89$ to present \\
\hline
\end{tabular}

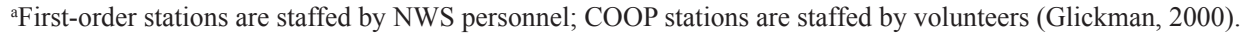

examination of the time series of ratios (in the case of wind and solar radiation) or differences (in the case of temperature and dewpoint temperature) between the ANL and backup series. The backup series were assumed to have been already temporally homogenized. The origin of primary and backup data sources used in the development of the database and the designated names for each period are listed in table 2; these periods are shown schematically in figures 2 through 5 .

The instrumentation used to measure each variable in the database at the old and new ANL locations are listed in table 3. At both ANL towers wind and temperature were measured at a minimum of two levels. In the case of ANL data beginning in 1989, wind and temperature were measured at 10 and $60 \mathrm{~m}$, whereas before 1989, wind was measured at 1.5, 6.0, and $44.5 \mathrm{~m}$, but temperature only at 1.5 (approximately) and $6.0 \mathrm{~m}$. After review of the record available at each level, only the wind data at $6.0 \mathrm{~m}$ and the temperature data at $1.5 \mathrm{~m}$ were used for the pre-1989 period.

\section{Data Review}

Various techniques were applied to check for possibly erroneous values in the primary and backup data series. The basic test was to identify outliers in a plot of differences (for air and dewpoint temperatures) or ratios (for wind and solar radiation) between the primary and backup series at the daily and hourly (if available) timescales. Outliers were identified visually as points lying outside the cloud around the central tendency of the plots. These difference and ratio plots also were used to check for temporal trends in the relations between the primary and backup series. Comparisons were carried out using differences for temperatures and ratios for wind and solar radiation because these operations tend to provide approximately symmetric clouds of points around a central tendency for these two groups of meteorological variables.

To plot the differences between the ANL and WHT temperature series, daily minima and maxima of the ANL series were computed from hourly values for comparison with the daily air-temperature series from WHT. To compute the daily minima and maxima of the ANL series, day $\tau$ was defined as beginning at 7:00 p.m. on date $\tau-1$ and ending at 6:00 p.m. on date $\tau$. These times were chosen to correspond to the values in the WHT series because the temperature at WHT generally was read late in the afternoon, according to records at the Midwestern Regional Climate Center.

In the second test, the ANL series were checked for unrealistic data jumps from one hour to the next. In the third test, where available, comparisons with data series at additional stations were made. For example, minimum and maximum daily air-temperature data from the Aurora NWS-COOP station were used to clarify conflicts between the ANL and backup temperatures.

The fourth test was to use comparisons against known physical constraints to identify erroneous data. This test was applied to dewpoint and air temperature series using the criterion that dewpoint temperature cannot exceed air temperature. This test also was applied to solar radiation data. Solar radiation received at the earth's surface at a certain observation location cannot exceed the solar radiation at the top of the atmosphere incident on a plane tangent to the earth's surface 
Table 2. Data period designations used in this study.

[ANL, Argonne National Laboratory; N/A, not applicable; WHT, Wheaton; STC, St. Charles; OH, O’Hare International Airport]

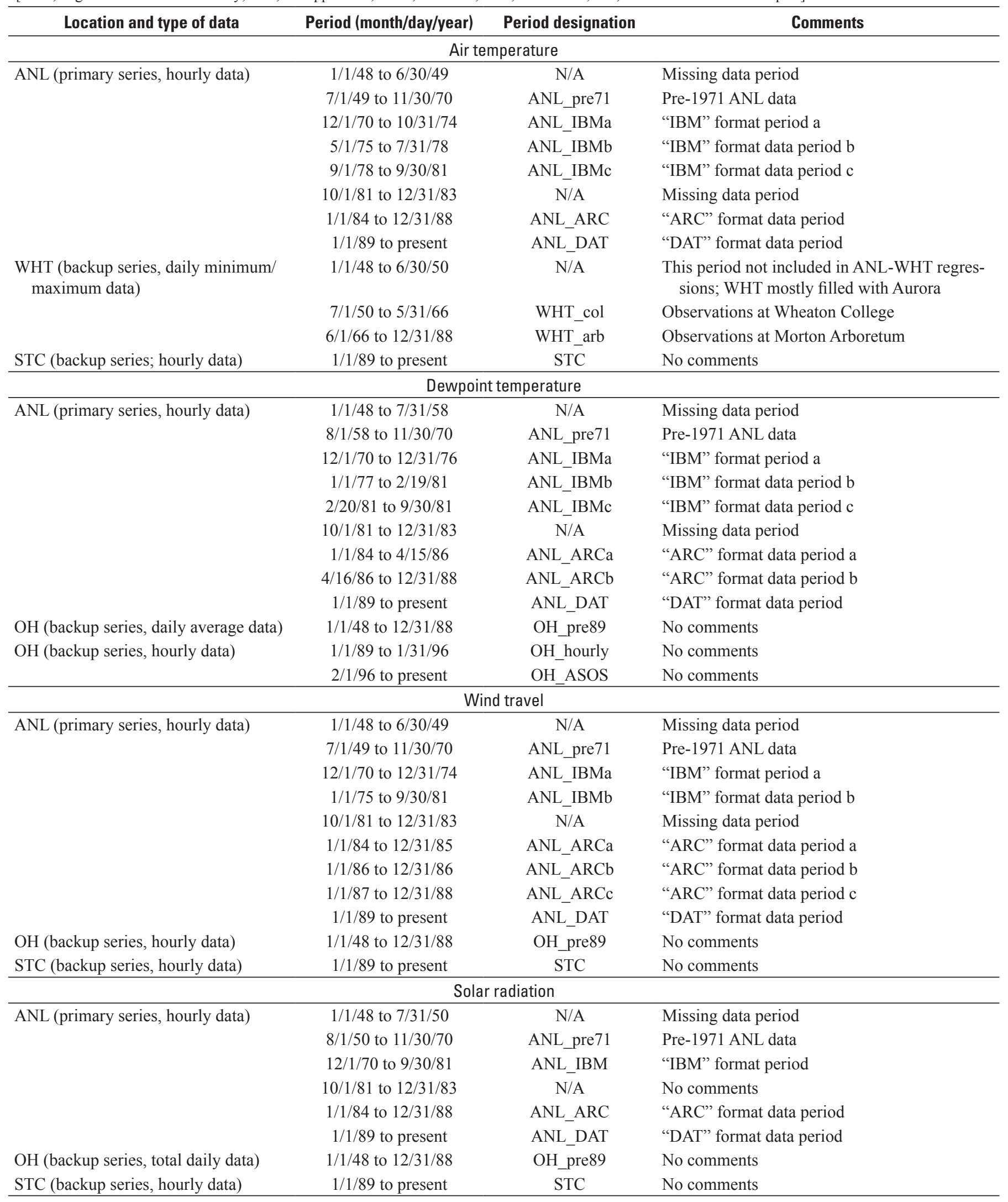




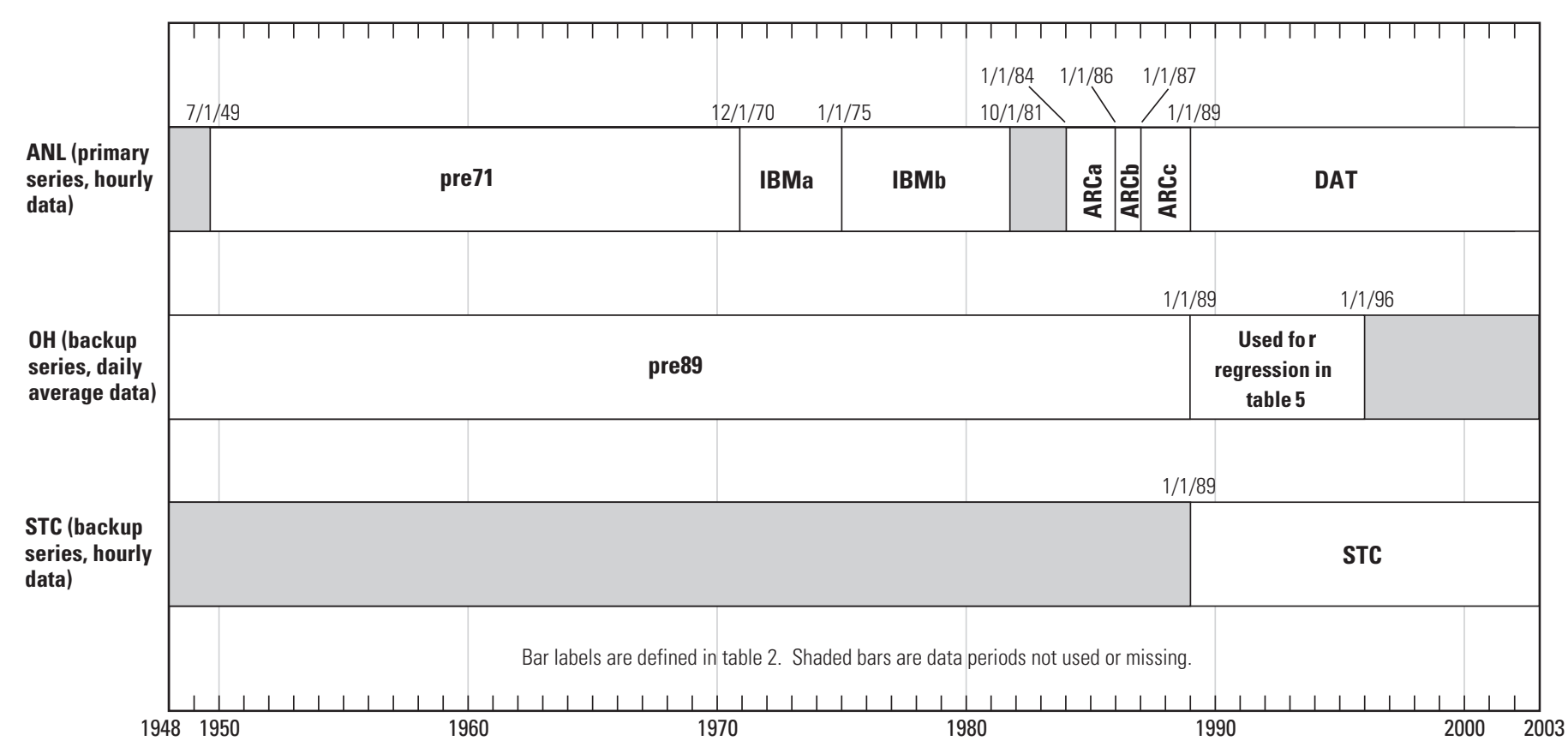

Figure 4. Wind travel data periods at Argonne National Laboratory (ANL), O'Hare International Airport (OH), and St. Charles (STC), Illinois, 1948-2003.

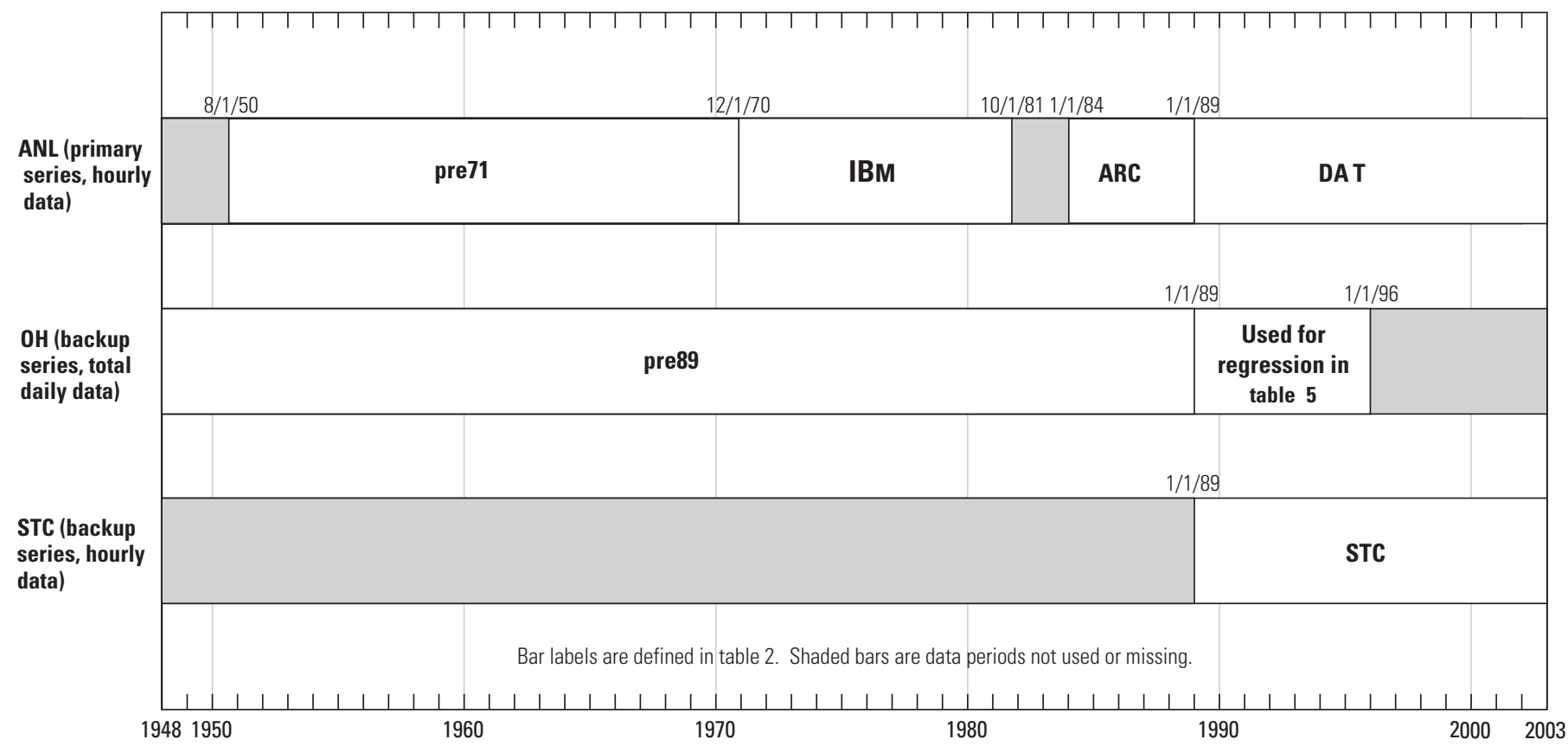

Figure 5. Solar radiation data periods at Argonne National Laboratory (ANL), O'Hare International Airport (OH), and St. Charles (STC), Illinois, 1948-2003.

at the observation location, except during periods near sunrise and sunset when indirect (diffuse) solar radiation may dominate the radiation received; therefore, hourly or daily values exceeding the incident top-of-atmosphere (extraterrestrial) solar radiation (calculated as in Dingman, 1994, Appendix E) were deemed erroneous, except for small values during hours near sunrise or sunset.
Two systematic errors were identified and corrected as a result of the data review process. The two errors were: (1) the WHT maximum temperature series, which was used as a backup air-temperature series, was determined to have been shifted back 1 day for most years, apparently because of an erroneous understanding of the time of measurement, and (2) negative signs had been mistakenly dropped from many 
Table 3. Instruments used to record meteorological data at Argonne National Laboratory, Illinois used in this study.

[The information in this table was provided by David R. Cook of Argonne National Laboratory; m, meters.]

\begin{tabular}{|c|c|c|c|}
\hline Series & Period (month/day/year) & $\begin{array}{l}\text { Height (feet above } \\
\text { land surface) }\end{array}$ & Instrument \\
\hline \multirow[t]{3}{*}{ Air temperature } & $1 / 1 / 50$ to $6 / 30 / 51$ & $5.0(1.5 \mathrm{~m})$ & Friez Hygrothermograph \\
\hline & $8 / 5 / 52$ to $1 / 17 / 62$ & $5.0(1.5 \mathrm{~m})$ & $\begin{array}{l}\text { 5/junction copper/constantan Thermopile No. } 36 \text { wire and } \\
\text { Honeywell Electronik Potentiometer }\end{array}$ \\
\hline & $1 / 1 / 89$ to $8 / 25 / 03^{a}$ & $32.8(10 \mathrm{~m})$ & $\begin{array}{l}\text { Minco } 100 \mathrm{ohm} \text {, tip sensitive platinum resistance temperature } \\
\text { detector (PRTD) }\end{array}$ \\
\hline Dewpoint temperature & $3 / 12 / 58$ to $12 / 1 / 60$ & $5.5(1.7 \mathrm{~m})$ & Foxboro Dewcell \\
\hline \multirow[t]{3}{*}{ Wind speed } & $1 / 1 / 50$ to $12 / 31 / 60$ & $18.75(6 \mathrm{~m})$ & Friez Aerovane \\
\hline & $12 / 1 / 60$ to $12 / 31 / 88$ & $18.75(6 \mathrm{~m})$ & Belfort 3-cup anemometer Model No. 339-A \\
\hline & $1 / 1 / 89$ to present & $32.8(10 \mathrm{~m})$ & Met One Instruments, Model 10B \\
\hline \multirow[t]{2}{*}{ Solar radiation } & $1 / 1 / 50$ to $12 / 31 / 88$ & $6.0(1.8 \mathrm{~m})$ & Eppley 50-junction Model 8-48 pyranometer \\
\hline & $1 / 1 / 89$ to present & $32.8(10 \mathrm{~m})$ & Eppley 50-junction Model 8-48 pyranometer \\
\hline
\end{tabular}

\footnotetext{
${ }^{a}$ The air and dewpoint temperature probes were replaced on August 26, 2003, with a Vaisala HMP45A, which also was placed at the $10 \mathrm{~m}$ level. Possible
} changes in the associated data series were not possible to assess at the time of the publication of this report.

periods in the ANL_pre71 air and dewpoint temperature series that were digitized for the first time for this project. The second error was recognized during comparison of the ANL series with the backup series (which contains both minimum and maximum daily temperature), and when the ANL temperature series would rise without physical justification after approaching zero. Once this error was corrected in the ANL temperature series, it also was identified and corrected in the dewpoint temperature data using air temperature as an upper boundary.

The data review process also showed the ANL and STC dewpoint series to have inconsistent relation, whereas the relation between the ANL and OH dewpoint series was observed to be consistent (except for May through October 1989, during which time the ANL series was deemed erroneous). It was concluded that it was preferable to use the $\mathrm{OH}$ dewpoint series as backup in the post-1989 period, as opposed to the more convenient STC dewpoint series.

\section{Interpolation for Short Periods}

Short periods (up to a few hours) of missing or clearly erroneous values were filled by interpolation and flagged according to the scheme described in the sub-section entitled "Data-Source Flags". Judgment was used to determine how many hours could be interpolated. One particular factor that led to the extension of the interpolation period is that when non-linear transformations were used to convert pre-1989 backup series data to the present base as described in the subsection entitled "Temporal Homogenization and Filling", a day with missing hours needed to be replaced entirely; therefore, interpolating a few hours instead of replacing the entire day prevented discarding good data.

Linear interpolation was used for filling air temperature, dewpoint temperature, and wind series data, using the two values immediately before and after the missing or erroneous period. Equation 1 shows the numerical formula used to obtain the interpolated value at missing hour $t, X(t)$ :

$$
X(t)=\frac{\left(t_{b}-t\right) X\left(t_{a}\right)+\left(t-t_{a}\right) X\left(t_{b}\right)}{t_{b}-t_{a}}, t=t_{a}+1, \ldots, t_{b}-1,
$$

where $t_{a}$ and $t_{b}$ are the hours before and after the period being filled, respectively.

When solar radiation data were to be filled by interpolation, the ratio of measured solar radiation to the incident extraterrestrial solar radiation (ETsolar) at the hours bounding the missing period was linearly interpolated across the missing period. The missing hours were filled with product of the interpolated ratio and the ETsolar. When one value of the measured solar radiation bounding the missing period was zero, the ratio at the other bounding value was used throughout the missing period. The numerical formula used to obtain the ratio of the 
interpolated actual to incident extraterrestrial solar radiation at missing hour $\tau$, was:

$$
R(t)=\frac{\left(t_{b}-t\right) R\left(t_{a}\right)+\left(t-t_{a}\right) R\left(t_{b}\right)}{t_{b}-t_{a}}, t=t_{a}+1, \ldots, t_{b}-1,
$$

where $t_{a}$ and $t_{b}$ are the hours before and after the period being filled, $R\left(t_{a}\right)=X\left(t_{a}\right) / E$ Esolar $\left(t_{a}\right)$, and $R\left(t_{a}\right)=X\left(t_{b}\right) / \operatorname{ETsolar}\left(t_{b}\right)$. Equation (2) applies except when ETsolar $\left(t_{d}\right)$ or ETsolar $\left(t_{b}\right)$, in which case $R(t)=R\left(t_{b}\right)$ or $R(t)=R\left(t_{a}\right)$. In any case, once $R(t)$ is computed, the interpolated value $X(t), t=t_{a}+1, \ldots ., t_{b}-1$, is computed as $X(t)+R(t) *$ ETsolar.

\section{Temporal Homogenization and Filling}

Because of changes in instrumentation and data processing methods, it was expected that the data from ANL would have different statistical properties, relative to the actual weather, during different periods; that is, it was expected to be temporally non-homogeneous. Removing this property constitutes temporal homogenization. The ANL data also are incomplete; in addition to the short periods filled by interpolation as described above, there are a number of long gaps that needed to be filled using the backup series. The description of the application of these two procedures, temporal homogenization and filling, are described in this section. The section is divided into two sub-sections, one focusing on the data before 1989, and the other on the data beginning in 1989. It is divided because somewhat different methods are applied for the two periods, as the statistical properties of the ANL data for the period beginning in 1989 are taken as the "base" or standard for the final database.

\section{Before 1989}

The basic strategy used to accomplish temporal homogenization and filling for the data collected before the beginning of the ANL_DAT base series (1989) was to develop regression equations at the daily time scale that relate the backup series to the pre-and post-1989 ANL data (ANL_OLD and ANL_DAT, respectively). This strategy is feasible because, the backup series are temporally homogeneous, and they overlap with the ANL_OLD and ANL_DAT series. The exception to the presence of overlap is the WHT temperature series before June 1, 1966 (WHT_col), which does not overlap with ANL_DAT. The handling of this period follows the same general strategy (the use of overlap with the backup series); the details are given below. For the other series, the equations relating the ANL_OLD series and its backup, and that relating the ANL_DAT series and its backup were solved for an equation giving ANL_DAT in terms of ANL_OLD. This equation allowed conversion of the ANL_OLD series to the ANL_DAT time base. The equation relating the ANL_DAT series and its backup then were used directly to convert the backup series to the ANL_DAT time base.
To develop the equations described above, different types of regression relations were tested to find a good relation between each period in the ANL data and its concurrent backup series. These types of regression included: (1) ordinary least squares (OLS) regression with and without a non-zero intercept, (2) maintenance-of-variance-extension type 1 (MOVE.1) regression or "line of organic correlation" (Hirsch, 1982; Hirsch and Gilroy, 1984), (3) OLS regression applied to non-linear functions of the independent series, (4) multiple regression on the backup series plus time as an additional independent variable, and (5) "ratio-of-averages" regression (see appendix 1 for description), a technique that preserves the averages and maintains a zero intercept. Criteria considered in choosing the type of regression to be used for each equation included minimization of mean square error (MSE) of fit, preservation of the average for the air and dewpoint temperature series, preservation of the total for the wind and solar radiation series, a zero intercept, prevention of negative values for the wind and solar radiation series, and approximate preservation of standard deviation and serial correlation statistics.

The selected regression equations are given in tables 4-5. The selected type of regression and resulting regression equations relating the pre-1989 ANL data with the concurrent backup series and the associated regression standard error (SE) are presented in table 4; the corresponding scatterplots with regression-based prediction lines are given in appendix 2, figures A2-1 $A-F, \mathrm{~A} 2-2 A-F, \mathrm{~A} 2-3 A-G$, A2-4A-F, and A2-5A-C. In table 4 , the first column gives the time period used in the regression; the second column gives the regression equation; the third column gives the type of regression used; the fourth column gives the SE of the regression; the fifth column gives the SE of ordinary least squares (OLS) regression applied to the same data; and the sixth and last column gives the figure number of the scatterplot of the data used in the regression with the regression-based prediction line. Using MOVE.1 regression results in only a slight degradation of the standard error of prediction (SE) compared to the SE resulting from using OLS regression (table 4). Including an additional parameter, such as in the case of dewpoint temperature from August 1, 1958, to November 30, 1970, results in a slight improvement of the SE. The SE value obtained from the ratio-of-averages regression was only slightly larger or smaller than the SE value from OLS regression. Similar results from comparing SE values resulting from different types of regression were observed for all the regression analyses done in this study.

The type of regression selected and the resulting regression equations relating the ANL_DAT period (1989 to present) to the backup series used before 1989 and the associated regression SE are presented in table 5; the corresponding scatterplots with regression-based prediction lines are given in figures $\mathrm{A} 2-1 G, \mathrm{~A} 2-2 G, \mathrm{~A} 2-3 G, \mathrm{~A} 2-4 G$, and $\mathrm{A} 2-5 D$ in appendix 2. In table 5, the first column gives the period of applicability of the regression relation for filling missing and erroneous data in the ANL data series. The second column gives the period of the data used in computing the regression 
Table 4. Regression equations and statistics relating pre-1989 daily Argonne National Laboratory and concurrent backup data in this study.

[SE, standard error; OLS, ordinary least squares; ${ }^{\circ} \mathrm{F}$, degrees Fahrenheit; MOVE.1, maintenance-of-variance extension type $1 ; t$, time in days beginning January 1, 1900. Variable names used in the equations are the period designations presented in table 2]

\begin{tabular}{|c|c|c|c|c|c|}
\hline $\begin{array}{l}\text { Period of data used in } \\
\text { regression analysis } \\
\text { (month/day/year) }\end{array}$ & Equation & Regression type & $\begin{array}{c}\text { Regression } \\
\text { SE }\end{array}$ & $\begin{array}{l}\text { OLS Regres- } \\
\text { sion SE }\end{array}$ & $\begin{array}{l}\text { Correspond- } \\
\text { ing figure }\end{array}$ \\
\hline \multicolumn{6}{|c|}{ Air temperature - daily minimum ( $\left.{ }^{\circ} \mathrm{F}\right)$} \\
\hline $7 / 1 / 50$ to $5 / 31 / 66$ & ANL_pre71a $=1.0123 *$ WHT_col -0.721 & MOVE.1 & 2.462 & 2.457 & $\mathrm{~A} 2-1 A$ \\
\hline $6 / 1 / 66$ to $11 / 30 / 70$ & ANL_pre71b $=1.0111 *$ WHT_arb +0.657 & MOVE.1 & 2.922 & 2.914 & $\mathrm{~A} 2-1 B$ \\
\hline $12 / 1 / 70$ to $10 / 31 / 74$ & $\mathrm{ANL}$ IBMa $=1.0038 *$ WHT_arb +1.928 & MOVE.1 & 2.724 & 2.717 & $\mathrm{~A} 2-1 C$ \\
\hline $5 / 1 / 75$ to $7 / 31 / 78$ & $\mathrm{ANL} \_\mathrm{IBMb}=1.0082 * \mathrm{WHT} \_\mathrm{arb}+3.080$ & MOVE.1 & 3.103 & 3.095 & $\mathrm{~A} 2-1 D$ \\
\hline $9 / 1 / 78$ to $9 / 30 / 81$ & ANL_IBMc $=0.9999 *$ WHT_arb +1.627 & MOVE.1 & 2.959 & 2.951 & A2-1E \\
\hline $1 / 1 / 84$ to $12 / 31 / 88$ & $\mathrm{ANL} \_\mathrm{ARC}=0.9785^{*} \mathrm{WHT} \_$arb +2.250 & MOVE.1 & 2.900 & 2.891 & $\mathrm{~A} 2-1 F$ \\
\hline \multicolumn{6}{|c|}{ Air temperature - daily maximum ( $\left.{ }^{\circ} \mathrm{F}\right)$} \\
\hline $7 / 1 / 50$ to $5 / 31 / 66$ & ANL_pre71a $=0.9707 *$ WHT_col -0.812 & MOVE.1 & 2.720 & 2.715 & $\mathrm{~A} 2-2 A$ \\
\hline $6 / 1 / 66$ to $11 / 30 / 70$ & ANL_pre71b $=0.9699 *$ WHT_arb -1.511 & MOVE.1 & 2.708 & 2.702 & $\mathrm{~A} 2-2 B$ \\
\hline $12 / 1 / 70$ to $10 / 31 / 74$ & ANL_IBMa $=0.9792 * W H T \_a r b-1.312$ & MOVE.1 & 2.995 & 2.987 & $\mathrm{~A} 2-2 \mathrm{C}$ \\
\hline $5 / 1 / 75$ to $7 / 31 / 78$ & $\mathrm{ANL} \_\mathrm{IBMb}=0.9809 * \mathrm{WHT}$ arb -1.316 & MOVE.1 & 3.094 & 3.086 & A2-2D \\
\hline $9 / 1 / 78$ to $9 / 30 / 81$ & ANL_IBMc $=0.9907 *$ WHT_arb -2.378 & MOVE.1 & 3.101 & 3.094 & A2-2E \\
\hline $1 / 1 / 84$ to $12 / 31 / 88$ & ANL_ARC $=0.9744 *$ WHT_arb -1.903 & MOVE.1 & 3.089 & 3.081 & A2-2F \\
\hline \multicolumn{6}{|c|}{ Dewpoint temperature - daily average ( $\left.{ }^{\circ} \mathrm{F}\right)$} \\
\hline $8 / 1 / 58$ to $11 / 30 / 70$ & ANL_pre71 $=0.3018 *(\mathrm{OH}+100)^{1.2}-73.505$ & $\mathrm{OLS}^{\mathrm{a}}$ & 1.740 & 1.784 & $\mathrm{~A} 2-3 A$ \\
\hline $12 / 1 / 70$ to $12 / 31 / 76$ & ANL_IBMa $=0.9508 * \mathrm{OH}+1.401$ & MOVE.1 & 1.860 & 1.857 & $\mathrm{~A} 2-3 B$ \\
\hline $1 / 1 / 77$ to $2 / 19 / 81$ & $\mathrm{ANL} \_\mathrm{IBMb}=1.0309^{*} \mathrm{OH}-0.003666 t+102.25$ & Multiple OLS & 2.352 & 2.845 & A2-3C, $D$ \\
\hline $2 / 20 / 81$ to $9 / 30 / 81$ & $\mathrm{ANL} \_\mathrm{IBMc}=0.9596 * \mathrm{OH}+1.799$ & MOVE.1 & 1.388 & 1.386 & $\mathrm{~A} 2-3 E$ \\
\hline $1 / 1 / 84$ to $4 / 15 / 86$ & $\mathrm{ANL} \_\mathrm{ARCa}=0.09753 *(\mathrm{OH}+100)^{1.4}-57.452$ & $\mathrm{OLS}^{\mathrm{a}}$ & 1.751 & 1.855 & $\mathrm{~A} 2-3 F$ \\
\hline $4 / 16 / 86$ to $12 / 31 / 88$ & $\mathrm{ANL} \_\mathrm{ARCb}=0.5317 *(\mathrm{OH}+100)^{1.1}-81.797$ & $\mathrm{OLS}^{\mathrm{a}}$ & 2.967 & 2.974 & $\mathrm{~A} 2-3 G$ \\
\hline \multicolumn{6}{|c|}{ Wind travel - daily total (miles) } \\
\hline $7 / 1 / 49$ to $11 / 30 / 70$ & ANL_pre71 $=0.9358 * \mathrm{OH}^{0.960}$ & Ratio-of-averages & 27.83 & 27.86 & $\mathrm{~A} 2-4 A$ \\
\hline $12 / 1 / 70$ to $12 / 31 / 74$ & $\mathrm{ANL} \_\mathrm{IBMa}=0.3382 * \mathrm{OH}^{1.179}$ & Ratio-of-averages & 31.83 & 31.89 & $\mathrm{~A} 2-4 B$ \\
\hline $1 / 1 / 75$ to $9 / 30 / 81$ & ANL_IBMb $=1.5694 * \mathrm{OH}^{0.936}$ & Ratio-of-averages & 26.16 & 26.04 & $\mathrm{~A} 2-4 C$ \\
\hline $1 / 1 / 84$ to $12 / 31 / 85$ & $\mathrm{ANL} \_\mathrm{ARCa}=2.6999 * \mathrm{OH}^{0.887}$ & Ratio-of-averages & 33.69 & 33.71 & $\mathrm{~A} 2-4 D$ \\
\hline $1 / 1 / 86$ to $12 / 31 / 86$ & $\mathrm{ANL} \_\mathrm{ARCb}=2.0715^{*} \mathrm{OH}^{0.924}$ & Ratio-of-averages & 33.27 & 33.22 & $\mathrm{~A} 2-4 E$ \\
\hline $1 / 1 / 87$ to $12 / 31 / 88$ & $\mathrm{ANL} \_\mathrm{ARCc}=5.8097 * \mathrm{OH}^{0.791}$ & Ratio-of-averages & 41.94 & 41.65 & $\mathrm{~A} 2-4 F$ \\
\hline \multicolumn{6}{|c|}{ Solar radiation - daily total (Langleys) } \\
\hline $8 / 1 / 50$ to $11 / 30 / 70$ & ANL_pre71 $=1.5645^{*} \mathrm{OH}^{0.93}$ & Ratio-of-averages & 83.00 & 83.08 & $\mathrm{~A} 2-5 A$ \\
\hline $12 / 1 / 70$ to $9 / 30 / 81$ & $\mathrm{ANL} \_\mathrm{IBM}=1.4424 * \mathrm{OH}^{0.93}$ & Ratio-of-averages & 77.46 & 77.61 & A2-5B \\
\hline $1 / 1 / 84$ to $12 / 31 / 88$ & $\mathrm{ANL} \_\mathrm{ARC}=1.4587^{*} \mathrm{OH}^{0.94}$ & Ratio-of-averages & 84.11 & 84.04 & $\mathrm{~A} 2-5 \mathrm{C}$ \\
\hline
\end{tabular}

${ }^{a}$ The exponent that minimizes the mean-square error was determined by trial-and-error; the slope and intercept were determined by OLS.

relation, and the third column gives the resulting regression equation. These regression equations were used to convert the data from the backup series to the ANL_DAT base for filling missing and erroneous data during the indicated period of applicability. The fourth column gives the "z" code, which is the part of the data-source flag identifying the transformation applied to a given data value (see the Data-Source Flags section for further information). The fifth column of table 5 gives the type of regression used, the sixth column gives its SE, and the seventh gives the SE of ordinary least squares (OLS) regression applied to the same data. The eighth column gives the figure number in appendix 2 containing a scatterplot of the data used in the regression with the regression-based prediction line, followed by the figure number in appendix 
Table 5. Regression equations and statistics relating daily 1989-2003 Argonne National Laboratory and pre-1989 backup data series and used to fill missing and erroneous backup data in this study.

[" $z$ " code, portion of the data source flag identifying the transformation applied to the data; SE, standard error; OLS, ordinary least squares; ${ }^{\circ} \mathrm{F}$, degrees Fahrenheit; MOVE.1, maintenance-of-variance extension type 1. Variable names used in the equations are the period designations presented in table 2]



3 of a graph showing the difference (for air temperature and dewpoint temperature) or ratio (for wind travel and solar radiation) between the original and adjusted data series for the period indicated in the first column. The averages of these differences or ratios between the original and adjusted data for the period in the first column are given in the final column.

There was no temporal overlap between WHT_col and ANL_DAT temperature data. Thus, equations for the conversion of WHT_col data to the ANL_DAT base for filling the WHT_col series were obtained using the ANL_pre71 data that overlapped the WHT_col and WHT_arb data periods. The sequence of transformations used is as follows. For the minimum temperature, the first two equations in table 4 were used to obtain WHT_col in terms of WHT_arb. The resulting equation was used with the first equation in table 5 to solve for ANL_DAT as a function of WHT_col, yielding the first equation in table 6. Likewise, the maximum temperature equation given in table 6 was obtained by solving the first two maximum temperature equations in table 4 for WHT_col as a function of WHT_arb, and then plugging the resulting equation into the maximum temperature equation in table 5 to solve for ANL_DAT as a function of WHT_col. These equations were used to convert WHT_col minimum and maximum temperature data to the ANL_DAT base. In this case, the multiple transformations involved increased the SE of the estimated values.

The results of these transformations are presented in table 6 . In table 6 , the first column gives the period of applicability of the equation in the second column, which was derived algebraically as discussed above, and does not represent a new regression relation. The third column gives an estimate of the SE of the equation and the fourth column the " $z$ " code that signifies the transformation as part of the data-source flag. The fifth column gives the average difference between the original and adjusted data series for the period indicated in the first column, and the sixth and final column gives the figure number in appendix 3, where the original and adjusted data series are compared graphically.

The backup series from the pre-1989 period were converted to the ANL_DAT base for filling in missing data during the pre-1989 period using the equations given in tables 5 and 6. Equations used to convert the pre-1989 primary series data (generically ANL_OLD) to the ANL_DAT base were obtained by combining the equations in tables 4 and 5 . The equation in 
Table 6. Equations and statistics relating daily ANL_DAT and WHT_col air temperature series and used to fill missing and erroneous WHT_col air temperature data in this study.

[SE, standard error; "z" code, portion of the data source flag identifying the transformation applied to the data; ${ }^{\circ} \mathrm{F}$, degrees Fahrenheit. Variable names used in the equations are the period designations presented in table 2]

\begin{tabular}{|c|c|c|c|c|c|}
\hline $\begin{array}{l}\text { Period of applicability of regres- } \\
\text { sion equation for filling backup } \\
\text { data series (month/day/year) }\end{array}$ & Equation & $\begin{array}{c}\text { Approximate } \\
\text { SE }\end{array}$ & $\begin{array}{l}\text { "z" } \\
\text { code }\end{array}$ & $\begin{array}{l}\text { Average difference } \\
\text { between adjusted } \\
\text { and original data }\end{array}$ & $\begin{array}{l}\text { Corresponding } \\
\text { figure }\end{array}$ \\
\hline $1 / 1 / 48$ to $5 / 31 / 66$ & ANL_DAT $=0.9975 *$ WHT_col +1.157 & 5.2 & 1 & 1.058 & $\mathrm{~A} 3-1 B$ \\
\hline \multicolumn{6}{|c|}{ Air Temperature - daily maximum ( $\left.{ }^{\circ} \mathrm{F}\right)$} \\
\hline
\end{tabular}

${ }^{a}$ Appromixate $S E$ was computed as $S E=\sqrt{\sum_{i} S E_{i}^{2}}$, where $S E_{i}$ are the $\mathrm{SE}$ of the regression relations used to derive the given equation.

table 4 was solved for the backup series and substituted for the backup series in the equation in table 5 . The resulting equations, which provide the method used to convert the pre-1989 ANL data to the ANL_DAT base, are given in table 7 .

For example, for the pre-1971 period in wind travel, the appropriate equation from table 4, ANL_pre71 $=0.9358^{*}$ $\mathrm{OH}^{0.960}$, may be solved for $\mathrm{OH}$ as:

$\mathrm{OH}=\left(\mathrm{ANL} \_ \text {pre } 71 / 0.9358\right)^{(1 / 0.96)}=1.0716^{*} \mathrm{ANL} \_$pre $71^{1.0417}$.

This equation may be substituted for $\mathrm{OH}$ in the appropriate equation from table 5, ANL_DAT $=0.6190 * \mathrm{OH}^{1.080}$, yielding:

$$
\begin{aligned}
& \mathrm{ANL} \_\mathrm{DAT}=0.6190 *\left(1.0716^{*} \mathrm{ANL} \text { _pre } 71^{1.0417}\right)^{1.080}= \\
& 0.667^{*} \mathrm{ANL} \_ \text {pre } 71^{1.125}=0.667^{*} \mathrm{ANL} \_\mathrm{OLD}{ }^{1.125}
\end{aligned}
$$

which gives the pre-1971 (1/1/48 to $11 / 30 / 70)$ wind travel equation in table 7 . The figures corresponding to the equations in table 7 (figures A3-1A, A3-2A, A3-3A, and A3-4A in appendix 3 ) show the differences or ratios of the original and adjusted data. As in table 6, the multiple transformations increased the SE of estimation of the missing values. The columns of table 7 have the same meaning as those in table 6 .

\section{From 1989 to 2003}

From 1989 to 2003, the ANL data are already in the desired ANL DAT base, so no transformation of that data is needed; however, the concurrent backup series still must be converted to the ANL_DAT base in order to be used to fill in missing and erroneous ANL data periods. This conversion was done using regression equations relating the 1989-2003 ANL data series to the concurrent backup series, and the regression equations and the results of their application are presented in table 8 , and in the figures cited in table 8 . The column structure of table 8 is the same as that of table 5, starting with the periods of applicability and the period used in the regression in columns 1 and 2, followed by the regression equation in column 3 , and the "z" code in column 4 . Columns 5, 6, and 7 give the regression type, the SE of the regression, and the SE of an OLS regression of the same data, to show the effect of the use of alternative regressions. Column 8 gives the figure number in appendix 2 where the corresponding scatterplot with regression-based prediction line is given, and the figure number in appendix 3 where the difference or ratio of original and adjusted data are plotted. The final column gives the average difference or ratio of the original and adjusted data.

\section{Disaggregating Daily Data to an Hourly Time Scale}

As discussed in previous sections, the temporal homogenization and filling were done at the daily time scale. To obtain hourly series, the daily values had to be disaggregated to hourly values. This disaggregation was done utilizing different methods for each series and time period, depending on the properties of the series and time period.

\section{Before 1989}

To obtain temporal homogeneity for data before 1989 , the primary and backup series were converted at the daily time scale to the ANL_DAT base. Thus, for data from this period, both data series have to be disaggregated to hourly values.

Air Temperature. Before 1989, the primary temperature series is hourly, and temporally homogeneous daily minimum and maximum primary and backup temperature series in the ANL_DAT base were available. The daily minimum and maximum values from the backup series were used to create an hourly backup series using the standard disaggregation technique associated with HSPF (Lumb and Kittle, 1995), where the minimum temperature is assumed to occur at 6:00 a.m. and the maximum temperature at 4:00 p.m. The primary hourly series was converted to the ANL_DAT base using the converted daily minimum and maximum by shifting and linear stretching between the measured and converted daily minimum and maximum. In other words, for each "day" (recall 
Table 7. Equations and statistics relating daily pre-1989 and 1989-2003 Argonne National Laboratory data and used to convert pre1989 data to the 1989-2003 statistical base in this study.

[SE, standard error; " $z$ " code, portion of the data source flag identifying the transformation applied to the data; ANL_DAT, 1989-2003 Argonne National Laboratory data; ANL_OLD, pre-1989 Argonne National Laboratory data; ${ }^{\circ} \mathrm{F}$, degrees Fahrenheit; $t$, time in days beginning January $\left.1,1900.\right]$

\begin{tabular}{|c|c|c|c|c|c|}
\hline $\begin{array}{l}\text { Period of applicability } \\
\text { (month/day/year) }\end{array}$ & Equation & $\begin{array}{l}\text { Approximate } \\
\text { SE }^{\mathrm{a}}\end{array}$ & "z" code & $\begin{array}{c}\text { Average difference } \\
\text { (temperatures) or ratio } \\
\text { (wind and solar radia- } \\
\text { tion) between adjusted } \\
\text { and original data }\end{array}$ & $\begin{array}{l}\text { Corresponding } \\
\text { figure }\end{array}$ \\
\hline \multicolumn{6}{|c|}{ Air temperature - daily minimum ( $\left.{ }^{\circ} \mathrm{F}\right)$} \\
\hline $7 / 1 / 49$ to $11 / 30 / 70$ & ANL_DAT $=0.9853^{*}$ ANL_OLD +1.867 & 4.6 & 1 & 1.283 & \multirow[t]{4}{*}{$\mathrm{A} 3-1 A$} \\
\hline $5 / 1 / 75$ to $7 / 31 / 78$ & ANL_DAT $=0.9882 * A N L \_O L D-0.529$ & 4.7 & 3 & 1.253 & \\
\hline $9 / 1 / 78$ to $9 / 30 / 81$ & ANL_DAT $=0.9964 * A N L \_O L D+0.894$ & 4.6 & 4 & 1.276 & \\
\hline $1 / 1 / 84$ to $12 / 31 / 88$ & ANL_DAT $=1.0182 * A N L \_O L D+0.225$ & 4.6 & 5 & 1.259 & \\
\hline \multicolumn{6}{|c|}{ Air Temperature - daily maximum ( $\left.{ }^{\circ} \mathrm{F}\right)$} \\
\hline $7 / 1 / 49$ to $11 / 30 / 70$ & ANL_DAT $=1.0016^{*}$ ANL_OLD -0.515 & 4.1 & 1 & -0.421 & \multirow[t]{2}{*}{$\mathrm{A} 3-1 A$} \\
\hline $1 / 1 / 84$ to $12 / 31 / 88$ & ANL_DAT $=0.9971^{*}$ ANL_OLD -0.132 & 4.3 & 5 & -.419 & \\
\hline \multicolumn{6}{|c|}{ Dewpoint temperature - daily average $\left({ }^{\circ} \mathrm{F}\right)$} \\
\hline $1 / 1 / 48$ to $11 / 30 / 70$ & $\begin{array}{l}\text { ANL_DAT }=2.7064 *\left(A N L \_O L D+\right. \\
73.505)^{(1 / 1.2)}-99.90\end{array}$ & 2.3 & 1 & -0.583 & \multirow[t]{5}{*}{ A $3-2 A$} \\
\hline $12 / 1 / 70$ to $12 / 31 / 76$ & ANL_DAT $=1.0489^{*}$ ANL_OLD -1.638 & 2.4 & 2 & .266 & \\
\hline $1 / 1 / 77$ to $2 / 19 / 81$ & $\begin{array}{l}\text { ANL_DAT }=0.9674 * A N L \_O L D+ \\
\quad .003547 t-98.917\end{array}$ & 2.8 & 3 & 2.193 & \\
\hline $2 / 20 / 81$ to $9 / 30 / 81$ & ANL_DAT $=1.0393^{*}$ ANL_OLD -2.039 & 2.1 & 4 & -.112 & \\
\hline $1 / 1 / 84$ to $4 / 15 / 86$ & $\begin{array}{l}\text { ANL_DAT }=5.258 *\left(A N L \_O L D+\right. \\
57.452)^{(1 / 1.4)}-99.90\end{array}$ & 2.4 & 5 & -2.031 & \\
\hline $1 / 1 / 84$ to $12 / 31 / 85$ & $\mathrm{ANL} \_\mathrm{DAT}=0.185^{*} \mathrm{ANL} \_\mathrm{OLD}{ }^{1.218}$ & 47 & 4 & .614 & \multirow{3}{*}{ A3-3A } \\
\hline $1 / 1 / 86$ to $12 / 31 / 86$ & ANL_DAT $=0.264 * A N L \_O L D^{1.169}$ & 47 & 5 & .664 & \\
\hline $1 / 1 / 87$ to $12 / 31 / 88$ & ANL_DAT $=0.0561 *$ ANL_OLD $^{1.365}$ & 53 & 6 & .473 & \\
\hline \multicolumn{6}{|c|}{ Solar radiation - daily total (Langleys) } \\
\hline $1 / 1 / 48$ to $11 / 30 / 70$ & ANL_DAT $=1.171 * A N L \_O L D D^{0.973}$ & 120 & 1 & 1.008 & \multirow[t]{3}{*}{ A $3-4 A$} \\
\hline $12 / 1 / 70$ to $9 / 30 / 81$ & ANL_DAT $=1.267 * \mathrm{ANL}^{\prime} \mathrm{OLD}^{0.973}$ & 110 & 2 & 1.094 & \\
\hline $1 / 1 / 84$ to $12 / 31 / 88$ & $\mathrm{ANL} \_\mathrm{DAT}=1.258 * \mathrm{ANL} \_\mathrm{OLD}{ }^{0.963}$ & 120 & 3 & 1.025 & \\
\hline
\end{tabular}

${ }^{a}$ Appromixate $\mathrm{SE}$ was computed as $\mathrm{SE}=\sqrt{\sum_{i} S E_{i}^{2}}$, where $S E_{i}$ are the $\mathrm{SE}$ of the regression relations used to derive the given equation. 
Table 8. Regression equations and statistics relating daily 1989-2003 Argonne National Laboratory and backup data used to fill missing and erroneous Argonne National Laboratory data in this study.

[" $z$ " code, portion of the data source flag identifying the transformation applied to the data; SE, standard error; OLS, ordinary least squares; ${ }^{\circ} \mathrm{F}$, degrees Fahrenheit; MOVE.1, maintenance-of-variance extension type 1. Variable names used in the equations are the period designations presented in table 2]

\begin{tabular}{|c|c|c|c|c|c|c|c|c|}
\hline $\begin{array}{c}\text { Period of } \\
\text { applicability }\end{array}$ & $\begin{array}{l}\text { Priod } \\
\text { used in } \\
\text { regression } \\
\text { (month/day/ } \\
\text { year) }\end{array}$ & Equation & $\begin{array}{l}\text { "z" } \\
\text { code }\end{array}$ & $\begin{array}{l}\text { Regression } \\
\text { type }\end{array}$ & $\begin{array}{l}\text { Regres- } \\
\text { sion SE }\end{array}$ & $\begin{array}{l}\text { OLS Re- } \\
\text { gression } \\
\text { SE }\end{array}$ & $\begin{array}{l}\text { Corre- } \\
\text { sponding } \\
\text { figures }\end{array}$ & $\begin{array}{c}\text { Average differ- } \\
\text { ence (tempera- } \\
\text { tures) or ratio } \\
\text { (wind and solar } \\
\text { radiation) be- } \\
\text { tween adjusted } \\
\text { and original } \\
\text { data }\end{array}$ \\
\hline $\begin{array}{l}1 / 1 / 89 \text { to } \\
\text { present }\end{array}$ & $\begin{array}{l}1 / 1 / 89 \text { to } \\
12 / 31 / 00\end{array}$ & $\begin{array}{l}\text { ANL_DAT }=1.0092 * \mathrm{STC}+ \\
0.998\end{array}$ & 3 & MOVE.1 & 1.744 & 1.742 & $\begin{array}{l}\text { A2- } 6 A, \\
\text { A3- } 1 C\end{array}$ & 1.442 \\
\hline \multicolumn{9}{|c|}{ Dewpoint temperature - daily average ( $\left.{ }^{\circ} \mathrm{F}\right)$} \\
\hline $\begin{array}{r}1 / 1 / 48 \text { to } \\
\text { present }\end{array}$ & $\begin{array}{l}1 / 1 / 89 \text { to } \\
12 / 31 / 00 \\
\end{array}$ & $\begin{array}{l}\text { ANL_DAT }=0.9973 * \mathrm{OH}- \\
0.1689\end{array}$ & 1 & MOVE.1 & 1.578 & 1.577 & $\begin{array}{l}\text { A2- } 6 B, \\
\text { A3- } 2 C\end{array}$ & .277 \\
\hline \multicolumn{9}{|c|}{ Solar radiation - daily total (Langleys) } \\
\hline $\begin{array}{l}1 / 1 / 89 \text { to } \\
\text { present }\end{array}$ & $\begin{array}{l}1 / 1 / 89 \text { to } \\
12 / 31 / 00\end{array}$ & ANL_DAT $=1.2808 * \mathrm{STC}^{0.96}$ & 2 & $\begin{array}{l}\text { ratio-of- } \\
\text { averages }\end{array}$ & 37.36 & 37.59 & $\begin{array}{l}\text { A2-6D, } \\
\text { A3-4C }\end{array}$ & 1.027 \\
\hline
\end{tabular}

that for day $\tau$, the hourly values begin with the 7 p.m. value on the date $\tau$ - 1 and continue to the 6 p.m. value on date $\tau$ ),

$$
A R G_{D A T}(t)=a(\tau) *\left[A R G_{O L D}(t)-A R G_{O L D}^{M I N}(\tau)\right]+A R G_{D A T}^{M I N}(\tau)
$$

where:

$$
a(\tau)=\frac{A R G_{D A T}^{M A X}(\tau)-A R G_{D A T}^{M I N}(\tau)}{A R G_{O L D}^{M A X}(\tau)-A R G_{O L D}^{M I N}(\tau)}
$$

and $A R G_{x}^{M I N}$ and $A R G_{x}^{M A X}$ are the minimum and maximum on day $\tau$ of the ANL series in base $x$, respectively; $x$ refers to "DAT" or any of the prior "OLD" bases. Because the daily minima and maxima were converted separately, it is possible that $\mathrm{ARG}_{D A T}^{M I N}(\tau)$ exceeds $A R G_{D A T}^{M A X}(\tau)$, and, thus, $\tau$ is negative. In this case, the entire day is set to the average of $A R G_{D A T}^{M I N}(\tau)$ and $A R G_{D A T}^{M A X}(\tau)$. Days with missing values were replaced completely with the converted, distributed hourly backup series data.

Dewpoint Temperature. Before 1989, the primary dewpoint data series is hourly, and the backup series is daily; therefore, the missing hours in each day, if any, are filled with the converted daily average value of the backup series for that day. The hourly values of the converted primary series were obtained by applying the same equations as were used for the daily values. In the case of non-linear relations, this application introduces a negligible error.

Wind. Before 1989, the primary and backup wind travel data series are hourly. The relations at the daily time scale between the primary and backup series are non-linear. It was determined that by not accounting for the non-linearity, significant error would be introduced. Similarly, the converted daily values of the primary series in the ANL_DAT base also are related non-linearly to their original values. Thus, a technique had to be developed that would preserve the total wind travel through the disaggregation from a daily to an hourly time scale. Assumptions are made that the daily values are related as, $Y=b X^{a}$, and the hourly values as, $y_{i}=c x_{i}^{a}$, with the same exponent $a$. Using these assumptions, taking $c=b X^{a} / \sum_{i} x_{i}^{a}$ conserves total wind travel; that is, the computed hourly values $y^{i}$ summed over the day result in the original daily value $Y$; therefore, the hourly values $y^{i}$ are computed as,

$$
y_{i}=\frac{b X^{a}}{\sum_{i} x_{i}^{\mathrm{a}}} x_{i}^{a}, i=1,2 \ldots, 24 .
$$

For example, for wind travel from 1949 to 1970, on days when no ANL values are missing, equation (7) is applied with $X$ being the daily ANL value (unconverted), $x$ is an hourly ANL value, and $a=1.125$ and $b=0.667$ (table 7). When ANL values are missing, equation (7) is applied with $X$ being the daily $\mathrm{OH}$ value, $x$ is an hourly $\mathrm{OH}$ value, and $a=1.080$ and $b=0.6190$ (see table 5). Because of the non-linear regression relations, days containing missing or erroneous hours not filled by interpolation were replaced entirely.

Solar Radiation. Before 1989, the primary solar radiation data series is hourly, and the backup series is daily. The standard daily-to-hourly disaggregation technique associated with HSPF (Lumb and Kittle, 1995) for solar radiation was considered inadequate because changes in day length with 
day-of-year are overlooked. Thus, a new technique, based on the incident extraterrestrial solar radiation, was developed to distribute the converted values of the backup series to hourly estimates. Hourly values were computed as the fraction of the daily total incident extraterrestrial solar radiation in that hour. This computation is represented mathematically as:

$$
X(t)=\frac{X(\tau)}{\operatorname{ETsolar}(\tau)} * \operatorname{ETsolar}(t),
$$

where $\tau$ is the day, $t$ is an hour during the same day as $\tau, X$ is the converted backup series, and ETsolar is the incident extraterrestrial solar radiation.

Because of non-linearities, the converted daily values of the primary solar radiation series, in the ANL_DAT base, were distributed to hourly values utilizing the same technique applied in converting the wind values. Because of non-linearities, days with missing values were replaced with the converted and disaggregated hourly backup series data.

\section{From 1989 to 2003}

During 1989-2003, the primary series are in the ANL DAT base; therefore, only the backup series are converted. The backup series are converted to the ANL_DAT base at the daily time scale and needs to be disaggregated where the conversion relation is non-linear.

Air and Dewpoint Temperatures. During 1989-2003, the backup series for air and dewpoint temperature are hourly; therefore, it is not necessary to work with daily minimum and maximum values, and the daily conversion equations are in terms of daily averages. Because the daily conversion equations are in terms of daily averages and are linear, the same regression equation that applies to the daily averages applies to the hourly values, and daily-to-hourly disaggregation is not necessary; furthermore, only the missing hours are filled, rather than entire days.

Wind. During 1989-2003, the daily relations between the primary and backup wind series are non-linear as in the pre1989 case; therefore, converted daily values from the backup series must be disaggregated using equation 7 , as discussed in the pre-1989 section on wind. Because the primary series does not need to be converted, only the missing hours are filled with the backup series rather than entire days.

Solar Radiation. During 1989-2003, the daily relations between the primary and backup solar radiation series are nonlinear, and hourly values of the backup series are available; therefore, disaggregation of converted daily values from the backup series was carried out in the same way as the disaggregation technique used in the wind data series. Because the primary series does not need to be converted, only the missing hours were filled with the backup series data.

\section{Data-Source Flags}

An hourly data-source flag series was created to document the multiple data sources and various conversions applied to the data. These flags provide complete information regarding the origin and transformations of each hourly value in the database using a three-digit code in the form "xyz".

The " $x$ " code describes the status of the corresponding ANL data value. The possible values for this code and its meaning are given in table 9 .

When the " $y$ " code does not have the value 3 , the " $z$ " code refers to the transformation used to convert pre-1989 ANL data to the ANL_DAT base, where applicable. The " $z$ " codes and corresponding transformations in this case are listed in table 7 , except the case $\mathrm{z}=0$. The $\mathrm{z}=0$ case corresponds to no transformation; in other words, the original ANL data are in the ARG_DAT base, which holds for ANL data during 1989-2003. When " $y$ " has the value 3, "z" refers to the transformation used to convert the backup series to the ANL_DAT base. These " $\mathrm{z}$ " codes and corresponding transformations

Table 9. Data-source flag " $x$ " codes indicating Argonne National Laboratory data status in this study.

[QA/QC, quality-assured, quality-controlled; ANL, Argonne National Laboratory]

\begin{tabular}{cc}
\hline $\begin{array}{c}\text { "x" } \\
\text { code }\end{array}$ & Description \\
\hline 0 & Original ANL QA/QC data were used \\
1 & ANL data were missing \\
2 & ANL data were deemed erroneous \\
3 & Raw (not yet QA/QC'd) ANL data were considered prefer- \\
& able \\
4 & $\begin{array}{c}\text { Original ANL QA/QC data had to be filled because of er- } \\
\end{array}$ \\
& roneous data at another time during the day \\
\hline
\end{tabular}

Table 10. Data-source flag " $y$ " codes indicating method used for filling or fixing missing or erroneous data in this study.

[ANL, Argonne National Laboratory]

\begin{tabular}{cl}
$\begin{array}{c}\text { "y" } \\
\text { code }\end{array}$ & \multicolumn{1}{c}{ Method of Filling } \\
\hline 0 & No filling or replacement (corresponds to $\mathrm{x}=0$ or $\mathrm{x}=3$ ) \\
1 & By linear interpolation of data before and after \\
2 & Not used in this study \\
3 & By use of data from another series \\
4 & By interpolation of ratios of measured to extraterrestrial \\
& solar radiation \\
5 & Solar radiation set to zero for a nighttime hour \\
6 & By inserting a missing negative sign \\
7 & By extrapolation (1-2 hours to finish out a day in the \\
8 & Bewpoint series) \\
\hline${ }^{a}$ Available at http://www.atmos.anl.gov/ANLMET/text/.
\end{tabular}


are listed in tables 5, 6, and 8 in the Temporal Homogenization and Filling section. Numerous examples of data-source codes and their corresponding meanings and frequency of occurrence in the dataset are given in appendix 4, tables A4-1 through A4-12, and are discussed in the sub-section, Statistics of Data Sources and Transformations in this report.

\section{Analysis}

Two types of analyses of the homogenized and filled data series, covering 1948-2003, resulting from the application of the methodology described in this report, for ANL air temperature, dewpoint temperature, wind travel, and solar radiation data were carried out. One type of analysis examines the statistical properties of the data and a potential evapotranspiration (PET) data series computed from it, looking at the annual cycle, annual trends, and inter-annual variability. This analysis was carried out to help the hydrologic modeler using these data to be aware how the meteorological input data driving their continuous-time hydrologic model varies from year to year, and over the course of a year. The other analysis considers the frequency of occurrence of the different data-source codes, which is equivalent to an examination of the frequency of use of the various data sources and the transformations applied to them. This second analysis was carried out to help users of the data to recognize the uncertainties that result from filling and homogenizing a data series and what fraction of the data are subject to these uncertainties.

\section{Statistical Properties of Data Series}

Statistics and plots of the filled and homogenized ANL data (temperature, dewpoint, wind, and solar radiation) and PET computed using the ANL data are given in tables 11 and 12, and in figures 6 and 7. PET was calculated using the LXPET program, which is based on a modification by Lamoreux of the Penman equation (Murphy, 2005). The average annual cycles of the data series and their variability are presented in figure 6 . The time series of annual averages of the data series are presented in figure 7. The results of a statistical analysis of the average annual values, allowing a characterization of the long-term trends and inter-annual variability of the individual series and cross-correlations between them, are presented in table 12.

The average and standard deviations of the daily values of the data series computed using data from January 1, 1948, through September 30, 2003, as a function of the day-of-year are shown in figure 6 . The annual cycle of mean daily solar radiation (figure $6 D$ ) is perhaps the most predictable, with a minimum in late December and a maximum in late June, the same timing for the extremes as the extraterrestrial solar radiation; however, as figure $6 E$ shows, the ratio of observed to extraterrestrial solar radiation, which depends inversely on cloudiness, has a distinct annual cycle, with smaller values in November and December and larger values in July and August. The annual cycles of mean daily temperature and dewpoint temperature (figures $6 A-B$ ) have extremes that are lagged somewhat relative to the solar radiation cycle; both show a minimum period from late December through January and a maximum on about day 200 of the year (mid-July). This mid-July maximum is followed by a 40 -day period of only slightly lower temperature and dewpoint values. The annual cycle of computed PET (figure $6 F$ ) is similar to the solar radiation cycle, with a maximum in late June and a minimum in late December. The normalized amplitude (defined as the difference of the annual maximum and annual minimum divided by the average) of the annual cycle of PET is somewhat larger than the solar radiation cycle. The annual cycle of the average wind speed (figure 6C) is different from all the others; it shows a single, well-defined minimum in mid-August, and a pair of relatively weaker maxima, one in late March-early April and the other in late November-early December. This annual cycle of wind speed generally is applicable to the entire United States east of the Rocky Mountains (Klink, 1999). Annual cycles of standard deviations indicate how much variability around the average can be expected at different times of the year. As can be seen in figure 6, the daily standard deviations vary with the daily averages, for some cases increasing as the average increases (in phase), but for other cases decreasing as the average increases (opposite phase). For example, the annual cycles of average and standard deviation of temperature and dewpoint are of opposite phase; the standard deviation decreases to a minimum in the summer as the average reaches its maximum and increases to a maximum in the winter as the average reaches its minimum. Meanwhile, the annual cycles of the average and standard deviations of solar radiation and PET are in phase; the standard deviation increases with the average to a maximum in the summer. The annual cycle of average and standard deviation of the wind travel are, like that of the solar radiation and PET, in phase: like the average, the standard deviation has a relatively strong mid-August minimum and a pair of weaker spring and fall maximums.

Average annual data series for water years 1949-2003, created from the filled and adjusted Argonne data series, and the PET computed from them, are shown in figure 7 . The trend lines were fitted by ordinary least-squares linear regression (solid lines), and the 1949-2003 average is shown as a dotted line. Basic statistics of these series, including average, standard deviation, coefficient of variation (CV), serial correlation, and the slope of the temporal trend, are given in table 11. Trends are apparent in all the annual series. The temperature, dewpoint, wind, and PET trends are positive, whereas the solar radiation trend is negative. Because the regression slopes in figure 7 exceed their standard deviations by a factor of about two or more in all cases, these trends may be considered statistically significant. However, the validity and significance of these trends should be treated with caution because: (1) numerous adjustments were involved in developing the data series, and (2) significant serial correlation in the annual data series (see the column headed by " $r(1)$ " in 

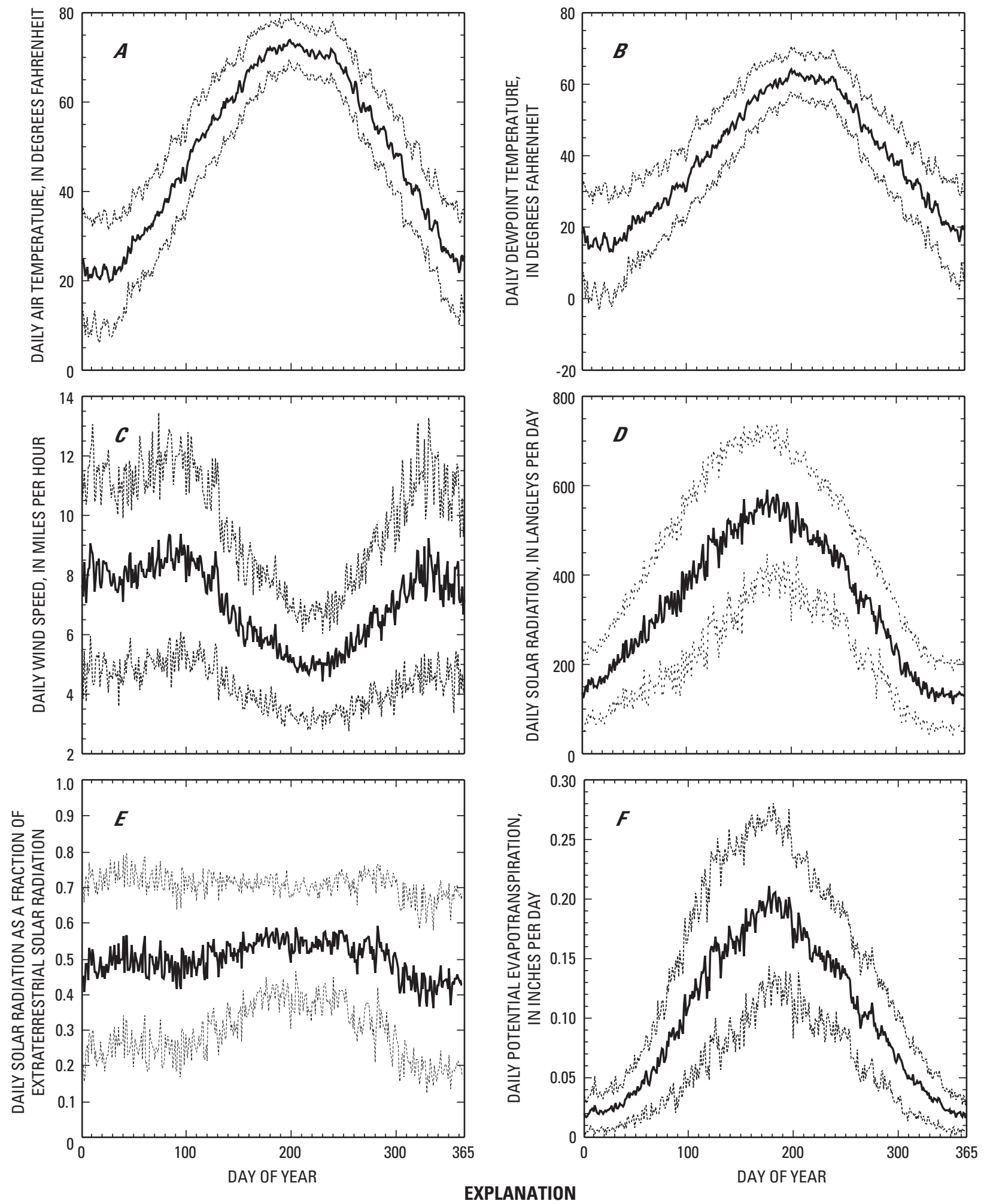

\section{EXPLANATION}

Average daily value
Average daily value + /- daily standard deviation

Figure 6. Average daily values for the period January 1, 1948, through September 30, 2003, of meteorological data series at Argonne National Laboratory in this study [A: temperature, $B$ : dewpoint, $C$ : wind, $D$ : solar radiation, $E$ : solar radiation as a fraction of extraterrestrial solar radiation, $F$ : computed potential evapotranspiration (PET)]. Note: extraterrestrial solar radiation was computed as in Dingman (1994), Appendix E. 
Table 11. Statistics of annual averages of filled and adjusted Argonne data series and computed potential evapotranspiration for water years 1949 through 2003 in this study.

$\left[\mathrm{CV}\right.$, coefficient of variation; r(1), serial correlation coefficient at a lag of one year; +/-, plus or minus; ${ }^{\circ} \mathrm{F}$, degrees Fahrenheit; mph, miles per hour; Lg/day, Langleys per day; in/day, inches per day; PET, potential evapotranspiration]

\begin{tabular}{|c|c|c|c|c|c|c|}
\hline Series & Average & $\begin{array}{l}\text { Standard } \\
\text { deviation }\end{array}$ & $\mathrm{CV}^{\mathrm{a}}$ & $r(1)$ & $\begin{array}{l}\text { Statistical sig- } \\
\text { nificance of } r(1)^{b}\end{array}$ & Slope of trend $+/-$ its standard deviation \\
\hline Temperature & $48.79^{\circ} \mathrm{F}$ & $1.518^{\circ} \mathrm{F}$ & 0.0311 & 0.319 & 0.991 & $0.0425+/-0.0115^{\circ} \mathrm{F}$ per year \\
\hline Wind speed & $7.011 \mathrm{mph}$ & $.433 \mathrm{mph}$ & .0617 & .453 & .9997 & $0.0122+/-0.0033 \mathrm{mph}$ per year \\
\hline Solar radiation & 341.4 Lg/day & $15.10 \mathrm{Lg} /$ day & .0443 & .343 & .994 & $-0.258+/-0.123 \mathrm{Lg} /$ day per year \\
\hline
\end{tabular}

aThe coefficient of variation $(\mathrm{CV})$ is defined as the standard deviation divided by the mean.

${ }^{\mathrm{b}}$ Computed using a t-test as described in Helsel and Hirsch (2002), pages 218-219; a large value indicates a significant correlation.

table 11) implies that the significance of trends computed by linear regression will be over-estimated (Helsel and Hirsch, 2002 , p. 250-252). The observation of increasing long-term temperatures from 1948-2003 in the ANL record, especially since the 1970s and in an urban area, is consistent with other results for this period in this region (Changnon and others, 2004; Stone, 2007) and throughout the United States and Canada (Whitewood and Phillips, 2008; Heim and others, 2008). Decreasing long-term solar radiation in the ANL record is consistent with observed world-wide trends in the second half of the 20th century (see, for example, Stanhill, 2007, and references therein).

The basic statistics presented in table 11 show that temperature, followed by dewpoint temperature and solar radiation, have the smallest inter-annual variability (as measured by the $\mathrm{CV}$ ), followed by wind and PET. It is perhaps surprising that solar radiation does not have the smallest inter-annual variability because it is the most directly tied to the annual cycle of the sun. PET, which is computed from the other four data series, has the largest inter-annual variability.

The Pearson correlation coefficients of the five annual series and their statistical significance are presented in table 12 . The values of statistical significance presented in table 12 have not been adjusted for serial correlation in the annual data series, which is significant (table 11), and therefore, they over-estimate the true significance. Such adjustments can be rather complex (see, for example, Ebisuzaki, 1997), and the authors feel the adjustment would not sufficiently add to the quality of the results to make it worthwhile. According to the correlations presented, temperature is strongly correlated with dewpoint temperature and PET at the annual time scale, and dewpoint is strongly correlated only with temperature. Wind is moderately correlated with PET and only weakly with the other series. Solar radiation is strongly correlated only with PET. As previously mentioned, PET is strongly correlated with temperature and solar radiation, and moderately correlated with wind. Whitbeck (2005) discusses the sensitivity of computed PET to changes in the input time series, noting the theoretical limits and proportionate effects and interactions of changes implied by the equations used in the computation of PET by the program LXPET.

\section{Statistics of Data Sources and Transformations}

The fraction of the values in the database from the various sources and the transformations involved are given in appendix 4, tables A4-1 to A4-12. There are three tables for each data series for a total of 12 . The first table in each group of three covers the entire period of analysis from January 1,

Table 12. Pearson correlation coefficients between annual averages of filled and adjusted Argonne data series and computed potential evapotranspiration and their significance for water years 1949 through 2003 in this study.

[PET, potential evapotranspiration; R, Pearson correlation coefficient; Sig., statistical significance of the Pearson correlation coefficient; ----, redundant entry]

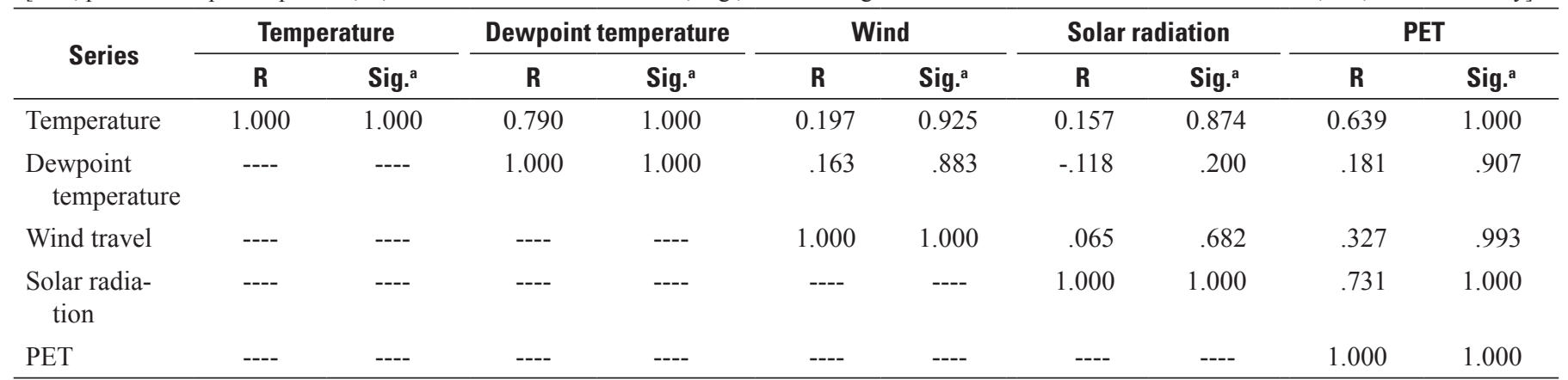

${ }^{a}$ Computed using a t-test as described in Helsel and Hirsch (2002), pages 218-219; a large value indicates a significant correlation. 



\section{EXPLANATION}

+ Average annual value

Trend line computed by least-squares linear regression Average value over all years

Figure 7. Average annual values, estimated trends, and average values of meteorological data series for water years 1949 through 2003 at Argonne National Laboratory in this study [A: temperature, $B$ : dewpoint, $C$ : wind, $D$ : solar radiation, $E$ : computed potential evapotranspiration (PET)]. 
1948, to September 30, 2003. The second covers the ANL OLD period, from January 1, 1948, to December 31, 1988. The third covers the remaining ANL_DAT period, January 1, 1989, to September 30, 2003. Each table contains the number and fraction of hourly data values during the indicated period having each data-source flag, along with a description of the data source and filling method, and in the first table of each group, the estimated standard error of the estimated data. These tables are primarily intended to show the fraction of data in the final dataset that came from each data source and filling method to give a user of the data an idea of the uncertainties that may be present in the data; for example, when a large fraction of the data has been filled using a backup series. The tables also provide a set of examples of data-source flags. In the discussion that follows, the values presented in the text usually are rounded from those in the tables.

The first group of tables in appendix 4 gives the datasource statistics and related results for the air temperature data series. They indicate that the transformations used to fill and homogenize daily minimum and maximum temperature data during 1948 through 1988 have estimated standard errors that range from 3.0 to $5.2^{\circ} \mathrm{F}$, whereas the transformation used during 1989 through 2003 to fill daily average temperature has an estimated standard error of $1.7^{\circ} \mathrm{F}$ (table A4-1). During 1948 through 1988, 12.9 percent of the temperature data were missing, 0.32 percent were considered erroneous, and 0.36 percent were filled because of missing or erroneous data at another time during the day, leaving 86.4 percent original (but transformed) ANL data in the database during this period (table A4-2). A particular source of erroneous temperature data during this period was missing negative signs, which were judged to have occurred for 919 values between 1948 and 1970 (table A4-1). During 1989 through 2003, 1.86 percent of the temperature data were missing, no data was considered erroneous, and no data were filled because of missing or erroneous data at another time during the day, leaving 98.1 percent original and non-transformed ANL data in the database during this period (table A4-3). For the entire period in the database, January 1, 1948, through September 30, 2003, 89.5 percent of the temperature series is ANL data, and the remainder was filled by interpolation or from the stations at O'Hare International Airport and St. Charles, Illinois (table A4-1).

The second set of tables in appendix 4 gives the datasource flag and related statistics for dewpoint temperature data. They show that the transformations used to fill and homogenize daily average dewpoint temperature data have estimated standard errors that range from 1.6 to $3.4^{\circ} \mathrm{F}$ (table A4-4). During 1948 through 1988, 36.15 percent of the dewpoint temperature data were missing, 0.45 percent were considered erroneous, and no data were filled because of missing or erroneous data at another time during the day, leaving 63.4 percent original (but transformed) ANL data in the database during this period (table A4-5). Missing negative signs also were detected in the dewpoint temperature data during this period, occurring for 1,189 values between 1948 and 1970 (tab1e A4-4). During 1989 through 2003, 3.15 percent of the dewpoint temperature data were missing, 3.48 percent of the data were considered erroneous, leaving 93.4 percent original and non-transformed ANL data in the database during this period (table A4-6). For the entire period in the database, January 1, 1948, through September 30, 2003, 71.3 percent of the dewpoint temperature series is ANL data, and the remainder was filled by interpolation or from the station at $\mathrm{OH}$ (table A4-4).

The third group of tables in appendix 4 gives the datasource flag and related results for the wind travel data series. They show that the transformations used to fill and homogenize daily total wind travel data have estimated standard errors that range from 29.6 to 53.4 miles per day (table A4-7). During 1948 through 1988, 13.4 percent of the wind travel data were missing, 0.11 percent were considered erroneous, and 0.86 percent was filled because of missing or erroneous data at another time during the day, leaving 85.6 percent original (but transformed) ANL data in the database during this period (table A4-8). During 1989 through 2003, 2.26 percent of the wind travel data were missing, 0.04 percent of the data were considered erroneous, leaving 97.7 percent original and nontransformed ANL data in the database during this period (table A4-9). For the entire period in the database, January 1, 1948, through September 30, 2003, 88.8 percent of the wind travel series is ANL data, and the remainder was filled by interpolation or from $\mathrm{OH}$ or STC data (table A4-7).

The fourth and final group of tables in appendix 4 gives the data-source flag and related results for the solar radiation data series. These show that the transformations used to fill and homogenize daily total solar radiation data have estimated standard errors that range from 37.4 to 117.4 Langleys per day (table A4-10). The lower end of this range is for filling from STC where, solar radiation was directly measured. The larger values (81.9 to 117.4 Langleys per day) are for different periods, during which the ANL data is being filled from the $\mathrm{OH}$ data, at which solar radiation is estimated using ancillary measurements (cloud cover). During 1948 through 1988, 13.6 percent of the solar radiation data were missing, 0.21 percent were considered erroneous, and 0.24 percent were filled because of missing or erroneous data at another time during the day, leaving 86.0 percent original (but transformed) ANL data in the database during this period (table A4-11). During 1989 through 2003, 1.37 percent of the solar radiation data were missing, 1.79 percent of the data were considered erroneous, leaving 96.8 percent original and non-transformed ANL data in the database during this period (table A4-12). During both periods, most of the erroneous values were because of small positive values recorded at night. For the entire period in the database, January 1, 1948, through September 30, 2003, 88.9 percent of the solar radiation series is ANL data, and the remainder was filled by interpolation or from the stations at $\mathrm{OH}$ and STC (table A4-10).

The fractions of missing and erroneous dewpoint temperature data are larger than the corresponding fractions of all the other data series for all periods for which these quantities were computed, usually by a multiple of at least 2 . As a 
consequence, the fraction of ANL dewpoint data in the database is much lower than the other data series $(71.3$ percent for the entire period compared to about 89 percent for the other series). This result reflects a shorter existing record of dewpoint temperature data at ANL, and more missing and erroneous data in the record during observed periods.

\section{Summary}

A database of hourly values of air temperature, dewpoint temperature, wind speed, and solar radiation at Argonne National Laboratory, Illinois, from January 1, 1948, to September 30, 2003, was developed by the U.S. Geological Survey in cooperation with DuPage County, Illinois, Department of Economic Development and Planning, Stormwater Management Division, for use in continuous-time hydrologic modeling in the northeastern Illinois region. Temporal variations in the statistical properties of the data resulting from changes in measurement and data-storage methodology were adjusted to match the statistical properties arising from the current data-collection procedures, which began in 1989 . Missing and apparently erroneous values were replaced with adjusted values from backup series data obtained at nearby stations at the O'Hare International Airport, St. Charles, and Wheaton, Illinois. The adjustments were computed based on regressions between the primary data series from Argonne National Laboratory and the backup series using data obtained during common periods. The regression-based adjustments were performed at a daily time scale; the adjusted daily values were disaggregated by techniques that preserve the daily average values. Each hourly value was assigned a corresponding three-digit flag that indicates the source of the value and the transformations it underwent.

The complete dataset is available as: (1) tab-separated ASCII tables in the 2005 annual data report CD, of the Illinois Water Science Center, of the U.S. Geological Survey (LaTour and others, 2006); (2) as part of an on-line annual data report (http://pubs.water.usgs.gov/wdril05); and (3) a Watershed Data Management (WDM; Lumb and Kittle, 1986) database file. Digital versions of the dataset may be requested from the USGS Illinois Water Science Center. Currently (2010), the dataset is being updated annually and is available through September, 2009.

\section{Acknowledgments}

The authors thank the Argonne National Laboratory staff who collected the primary data used in this study, the staff of the Northeastern Illinois Planning Commission who digitized some of the Argonne data from paper records and provided the O'Hare International Airport/Wheaton database, and Mr. Robert Scott of the Illinois State Water Survey, Champaign, Illinois, for providing the data from the station at St. Charles, Illinois.

\section{References Cited}

Alexandersson, H., 1986, A homogeneity test applied to precipitation data: Journal of Climatology, v. 6, p. 661-675.

Allen, R.J., and DeGaetano, A.T., 2000, A method to adjust long-term temperature extreme series of nonclimatic inhomogeneities: Journal of Climate, v. 13, p. 3,680-3,695.

Allen, R.J., and DeGaetano, A.T., 2001, Estimating missing daily temperature extremes using an optimized regression approach: International Journal of Climatology, v. 21, p. 1,305-1,321.

Argonne National Laboratory, Environmental Research Division, Atmospheric Research Section, 2005: accessed January 28, 2005 at URL http://www.atmos.anl.gov/ANLMET/.

Arnold, J.G., and Fohrer, N., 2005, SWAT2000: current capabilities and research opportunities in applied watershed modeling: Hydrological Processes, v. 19, p. 563-572.

Bicknell, B.R., Imhoff, J.C., Kittle, J.L., Jr., Donigian, A. S., Jr., and Johanson, R.C., 1997, Hydrological Simulation Program - Fortran, User's manual for version 11, EPA/600/R-97/080: Athens, Ga., U.S. Environmental Protection Agency, National Exposure Research Laboratory, $755 \mathrm{p}$.

Changnon, S.A., Angel, J.R., Kunkel, K.E., and Lehmann, C.M.B., 2004, Climate atlas of Illinois: Champaign, Ill., Illinois State Water Survey, 309 p.

Collins, W.G., 2001, The operational complex quality control of radiosonde heights and temperatures at the National Centers for Environmental Predictions. Part I: Description of the method: Journal of Applied Meteorology, v. 40, p. 137-151.

DeGaetano, A.T., 1997, A quality-control routine for hourly wind observations: Journal of Atmospheric and Oceanic Technology, v. 14, p. 308-317.

DeGaetano, A.T., Allen, R.T., and Gallo, K.P., 2002, A homogenized historical temperature extreme dataset for the United States: Journal of Atmospheric and Oceanic Technology, v. 19 , p. $1,267-1,284$.

Dingman, S.L., 1994, Physical Hydrology: Upper Saddle River, N.J., Prentice-Hall, 575 p.

Donigian, A.S. Jr., Bicknell, B.R., and Imhoff, J.C., 1995, Hydrological Simulation Program - FORTRAN (HSPF), in Singh, V.P., ed., Computer Models of Watershed Hydrology: Littleton, Colo., Water Resources Publications, p. 395-442.

Duncker, J.J., and Melching, C.S., 1998, Regional rainfallrunoff relations for simulation of streamflow for watersheds in DuPage County, Illinois: U.S. Geological Survey WaterResources Investigation Report 98-4035, 80 p. 
Easterling, D.R., and Peterson, T.C., 1995, A new method for detecting undocumented discontinuities in climatological time series: International Journal of Climatology, v. 15, p. 369-377.

Ebisuzaki, W., 1997, A method to estimate the statistical significance of a correlation when the data are serially correlated: Journal of Climate, v. 10, p. 2,147-2,153.

Gandin, L.S., 1988, Complex quality control of meteorological observations: Monthly Weather Review, v. 116, p. $1,137-1,156$.

Glickman, T.S., ed., 2000, Glossary of Meteorology (2d ed.): Boston, American Meteorological Society, 855 p.

Graybeal, D.Y., DeGaetano, A.T., and Eggleston, K.L., 2004a, Complex quality assurance of historical hourly surface airways meteorological data: Journal of Atmospheric and Oceanic Technology, v. 21, p. 1,156-1,169.

Graybeal, D.Y., DeGaetano, A.T., and Eggleston, K.L., 2004b, Improved quality assurance of historical hourly temperature and humidity: Development and application to environmental analysis: Journal of Applied Meteorology, v. 43, p. $1,722-1,735$.

Heim, R.R., Jr., Gleason, K.L., Kruk, M.C., Levinson, D.H., Sanchez-Lugo, A.M., Fritsch, R., Thoman, R., Papineau, J., and Lindsey, S., 2008, United States, in Levinson, D.H., and Lawrimore, J.H., eds., State of the Climate in 2007: Bulletin of the American Meteorological Society, v. 89, no. 7, p. S114-S120.

Helsel, D.R., and Hirsch, R.M., 2002, Statistical Methods in Water Resources: Techniques of Water-Resources Investigations of the United States Geological Survey, Book 4, Hydrologic Analysis and Interpretation, Chapter A3, 510 p.

Hirsch, R.M., 1982, A comparison of four streamflow record extension techniques: Water Resources Research, v. 18, no. 3 , p. $1,081-1,088$.

Hirsch, R.M., and Gilroy, E.J., 1984, Methods of fitting a straight line to data: Examples in water resources: Water Resources Bulletin, v. 20, no. 5, p. 705-711.

Holl, J.M., 1997, Argonne National Laboratory, 1946-1996: Urbana and Chicago, University of Illinois Press, 644 p.

Hollinger, S.E., Reinke, B.C., and Peppler, R.A., 1994, Illinois Climate Network: Site Descriptions, Instrumentation, and Data Management: Champaign, Ill., Illinois State Water Survey, $62 \mathrm{p}$.

Ishii, A.L., Charlton, T.J., Ortel, T.W., Vonnahme, C.C., 1998, Modeling system for near real-time flood simulation for Salt Creek in DuPage County, Illinois, in Proceedings of the First Federal Interagency Hydrologic Modeling Conference: Las Vegas, Nev., p. 8.51-8.58.
Karl, T.R., and Williams, Jr., C.N., 1987, An approach to adjusting climatological time series for discontinuous homogeneities: Journal of Climate and Applied Meteorology, v. 26, p. 1,744-1,763.

Klink, K., 1999, Climatological mean and interannual variance of United States surface wind speed, direction, and velocity: International Journal of Climatology, v. 19, p. 471-488.

Kunkel, K.E., Andsager, K., Conner, G., Decker, W.L., Hillaker, Jr., H.J., Knox, P.M., Nurnberger, F.V., Rogers, J.C., Scheeringa, K., Wendland, W.M., Zandlo, J., and Angel, J.R., 1998, An expanded digital daily database for climatic resources applications in the Midwestern United States: Bulletin of the American Meteorological Society, v. 79, p. 1,357-1,366.

LaTour, J.K., Weldon, E.A., Dupre, D.H., Halfar, T.M., 2006, Water Resources Data, Illinois, Water Year 2005: U.S. Geological Survey Water-Data Report IL-05 (CD-ROM).

Leavesley, G.H., and Stannard, L.G., 1995, The PrecipitationRunoff Modeling System - PRMS, in Singh, V.P., ed., Computer Models of Watershed Hydrology: Littleton, Colo., Water Resources Publications, p. 281-310.

Lumb, A.M., Kittle, J.L., Jr., 1986, Preliminary design of a data storage and retrieval system for hydrologic and hydraulic models (Watershed Data Management System, WDMS): Draft 6.0, $107 \mathrm{p}$.

Lumb, A.M. and Kittle, J.L., Jr., 1995, Users Manual for METCMP, a computer program for interactive computation of meteorologic time series, $88 \mathrm{p}$.

Meek, D.W., and Hatfield, J.L., 1994, Data quality checking for single station meteorological databases: Agricultural and Forest Meteorology, v. 69, p. 85-109.

Moses, H. and Bogner, M.A., 1967, Fifteen-Year Climatological Summary, January 1, 1950 - December 31, 1964, Argonne National Laboratory, DuPage County, Argonne, Illinois: Argonne National Laboratory Meteorology (TID4500) AEC Research and Development Report ANL-7084, $671 \mathrm{p}$.

Moses, H. and Kulhanek, F.C., 1962, Argonne meteorological data processing system: Journal of Applied Meteorology, v. 1, p. 69-80.

Murphy, E.A., 2005, Comparison of potential evapotranspiration calculated by the LXPET (Lamoreux Potential Evapotranspiration) Program and by the WDMUtil (Watershed Data Management Utility) Program: US Geological Survey Open-File Report 2005-1020, 20 p.

National Weather Service, 1998, ASOS User's Guide: Silver Spring, Maryland, $70 \mathrm{p}$. 
Peterson, T.C., and Easterling, D.R., 1994, Creation of homogenous composite climatological reference series: International Journal of Climatology, v. 14, p. 671-679.

Peterson, T.C., Easterling, D.R., Karl, T.R., Groisman, P., Nicholls, N., Plummer, N., Torok, S., Auer, I., Boehm, R., Gullett, D., Vincent, L., Heino, R., Tuomenvirta, H., Mestre, O., Szentimrey, T., Salinger, J., Forland, E., Hanssen-Bauer, I., Alexandersson, H., Jones, P., and Parker, D., 1998, Homogeneity adjustments of in situ atmospheric climate data: A review: International Journal of Climatology, v. 18, p. $1,493-1,517$.

Price, T.H., and Dreher, D.W., 1991, Investigation of hydrologic design methods for urban development in Northeastern Illinois: Chicago, Northeastern Illinois Planning Commission, 67 p. and appendixes.

Price, T.H., 1994, Meteorologic database update and hydrologic verification of HSPF Model for DuPage County: West Branch DuPage River at West Chicago, West Branch DuPage River at Warrenville, West Branch DuPage River at Naperville, East Branch DuPage River at Downers Grove, East Branch DuPage River at Bolingbrook, Salt Creek at Elmhurst, Salt Creek at Western Springs, Sawmill Creek near Lemont, St. Joseph Creek at Route 34, Kress Creek at West Chicago: Chicago, Northeastern Illinois Planning Commission, 19 p. and appendixes.

Price, T.H., 1996, Application guide for hydrologic modeling in DuPage County using hydrologic simulation program FORTRAN (HSPF): Model organization and use, data collection and processing, calibration: Chicago, Northeastern Illinois Planning Commission, 44 p. and appendixes.

Price, T.H., 1998, Comparison of Argonne and O'Hare meteorological data and resulting runoff and streamflows: Chicago, Northeastern Illinois Planning Commission, 6 p. and appendixes.
Potter, K.W., 1981, Illustration of a new test for detecting a shift in mean in precipitation series: Monthly Weather Review, v. 109, p. 2,040-2,045.

Rhoades, D.A., and Salinger, M.J., 1993, Adjustment of temperature and rainfall records for site changes: International Journal of Climatology, v. 13, p. 899-913.

Soong, D.T., Straub, T.D., and Murphy, E.A., 2005, Continuous hydrologic simulation and flood-frequency, hydraulic, and flood-hazard analysis of the Blackberry Creek Watershed, Kane County, Illinois: U.S. Geological Survey Scientific Investigations Report 2005-5270, 66 p.

Stanhill, G., 2007, A perspective on global warming, dimming, and brightening: Eos, Transactions, American Geophysical Union, v. 88, p. 58-59.

Stone, B., Jr., 2007, Urban and rural temperature trends in proximity to large US cities: 1951-2000: International Journal of Climatology, v. 27, p. 1,801-1,807.

Whitbeck, D.E., 2005, Sensitivity of potential evapotranspiration and simulated flow to varying meteorological inputs, Salt Creek watershed, DuPage County, Illinois: US Geological Survey Open-File Report 2005-1430, 18 p.

Whitewood, R., and Phillips, D., 2008, Canada, in Levinson, D.H., and Lawrimore, J.H., eds., State of the Climate in 2007: Bulletin of the American Meteorological Society, v. 89 , no. 7, p. S112-S114. 

Appendix 1-Ratio-of-Averages Regression 
A technique was needed to establish relations between variables that are governed by the following criteria: (1) both variables bounded below by zero (indicating the desirability of a fixed intercept at zero), (2) the variables are non-linearly related with a simple concave or convex shape, (3) the average or total of the dependent variable is preserved in the predictions, and (4) there is not a strong increase in variance with increasing values of the variables. In this study, these criteria apply to wind travel or solar radiation regressions between statistically distinct periods. The first two criteria are satisfied by a power-law relation $\left(Y=a X^{b}\right)$, but the last two criteria rule out the common technique of regressing the logarithms to estimate the parameters of the power-law relation; therefore, the technique described below, called here "ratio-of-averages regression", was developed.

A relation between the dependent variable $Y$ and the independent variable $X$ of the form $Y=b X^{a}$, where $b>0$, is assumed. Conservation of the total (and average) of $Y$ (meaning that the total of the predicted $Y$ values $\sum_{i} \hat{Y}_{i}$ equals the total of the original $Y$ values $\sum_{i} Y_{i}$ ) is obtained if the pre-factor $b$ is taken to be $\sum_{i} Y_{i} / \sum_{i} X_{i}^{a}$, because for this value of $b$, $\sum_{i} \hat{Y}_{i}=\sum b X_{i}^{a}=\left(\frac{\sum_{i} Y_{i}}{\sum_{i} X_{i}^{a}}\right) \sum_{i} X_{i}^{a}=\sum_{i} Y_{i}$. The exponent $a$ then is given the value that minimizes the mean-square-error (MSE) of prediction, where $(1 / N) \sum_{i=1}^{N}\left(\hat{Y}_{i}-Y_{i}\right)^{2}$. It can be seen from tables 4, 5 and 8 that, as applied here with exponents not far from unity, the resulting MSE is similar to that of an ordinaryleast-squares (OLS) regression with non-zero intercept. As a result, it also can be assumed that this technique leads to a reduction in the variance of the estimated values, as does OLS regression [but unlike maintenance-of-variance-extension (MOVE) techniques]. 


\section{Appendix 2-Regressions Relating Meteorological Series at Argonne National Laboratory and Backup Stations}




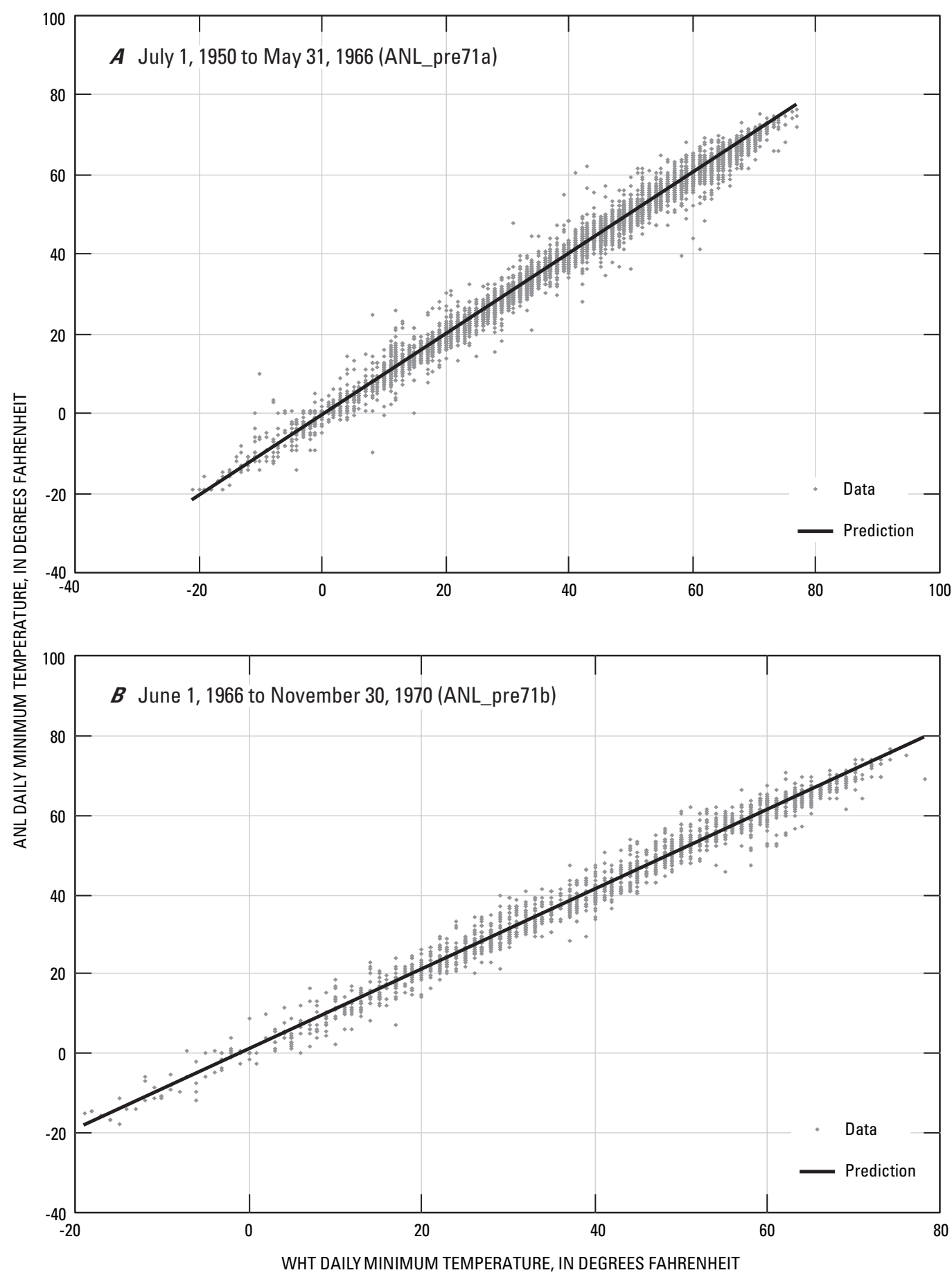

Figure A2-1. Regressions relating daily minimum air temperatures at Argonne National Laboratory (ANL) and Wheaton (WHT), Illinois (A: 1950-66, B: 1966-70). See tables 4 and 5 for regression types and statistics. 


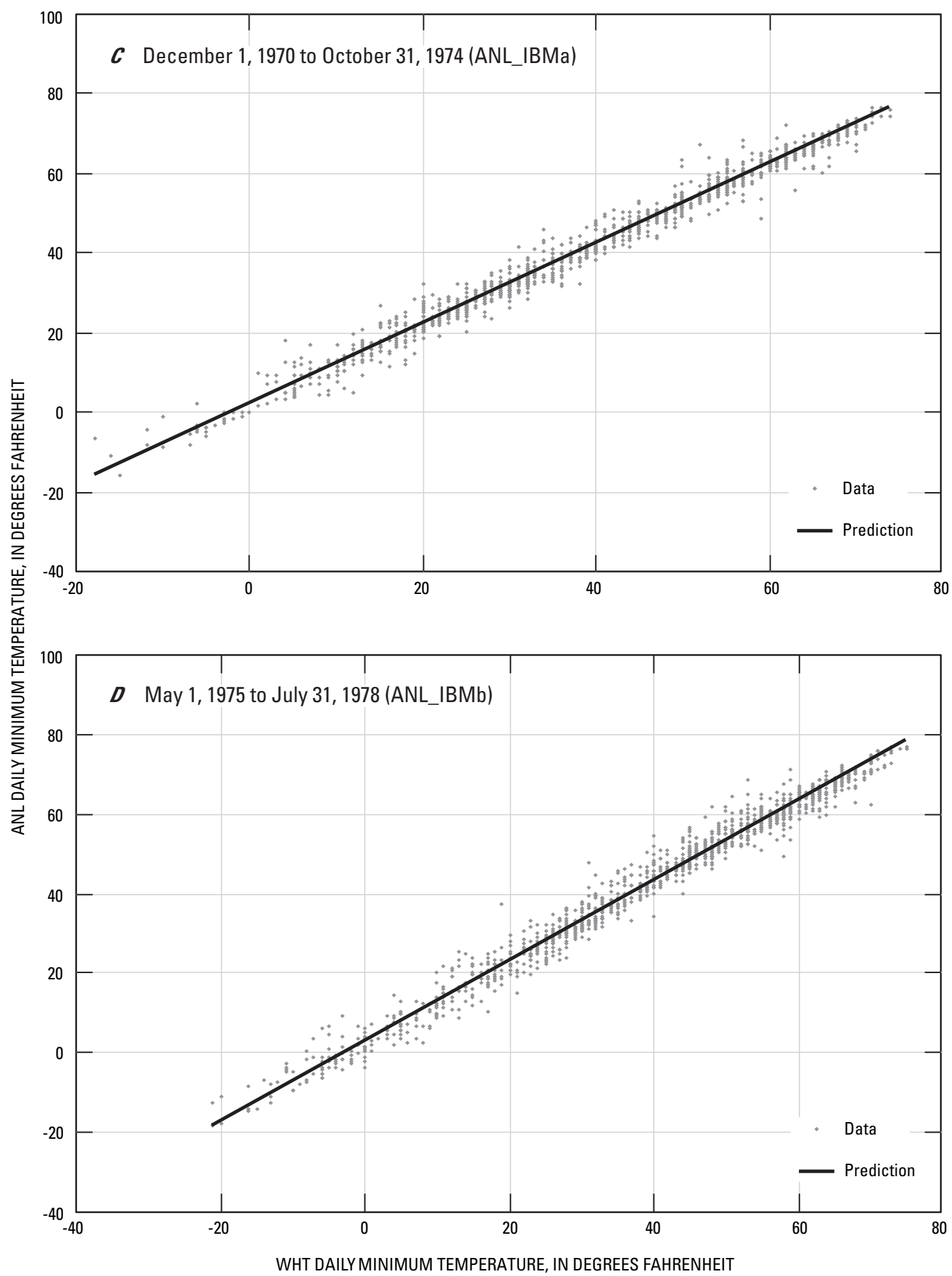

Figure A2-1. Regressions relating daily minimum air temperatu res at Argonne National Laboratory (ANL) and Wheaton (WHT), Illinois (C: 1970-74, D: 1975-78). See tables 4 and 5 for regression types and statistics.-Continued 


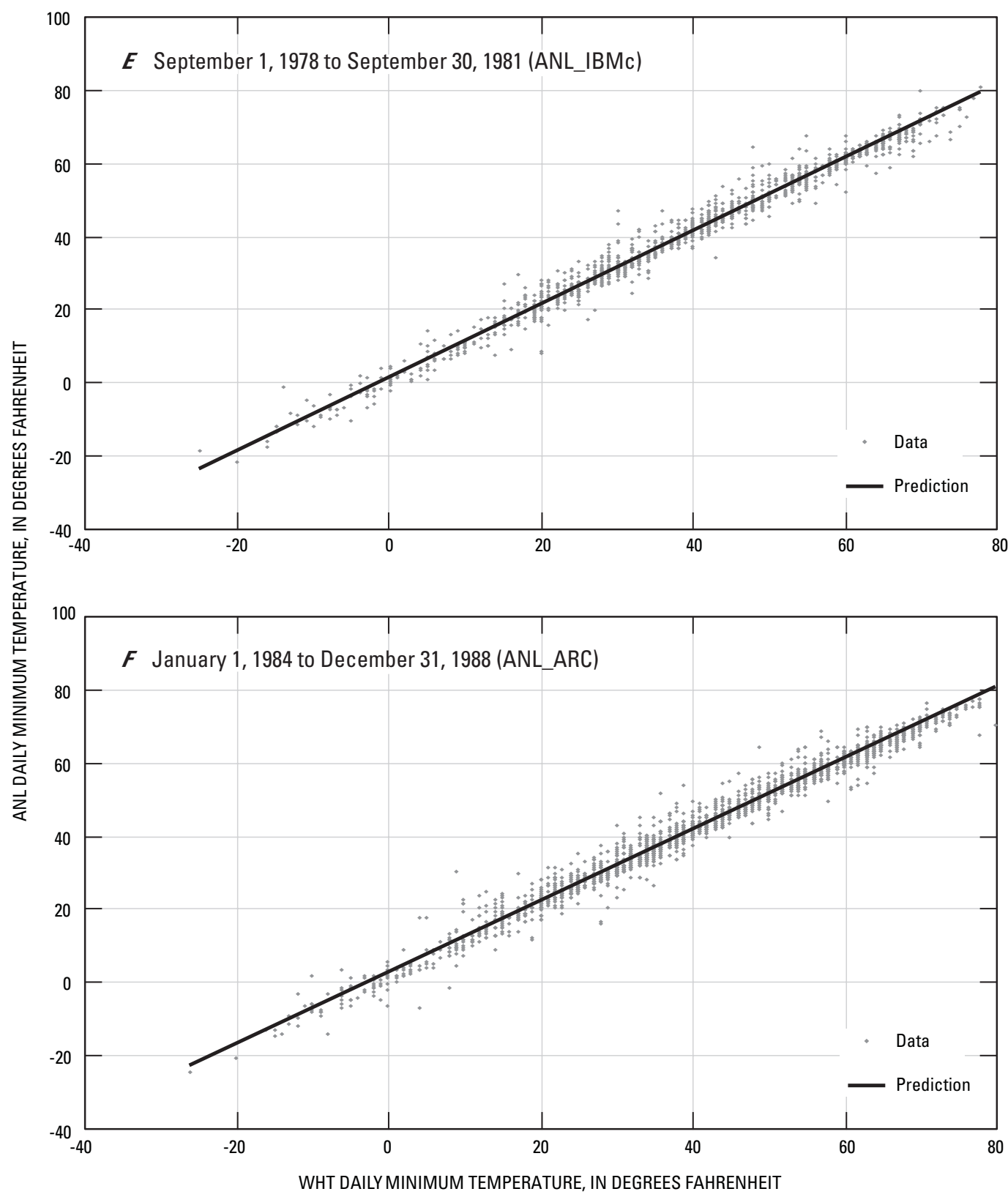

Figure A2-1. Regressions relating daily minimum air temperatures at Argonne National Laboratory (ANL) and Wheaton (WHT), Illinois (E: 1978-81, F: 1984-88). See tables 4 and 5 for regression types and statistics.-Continued 


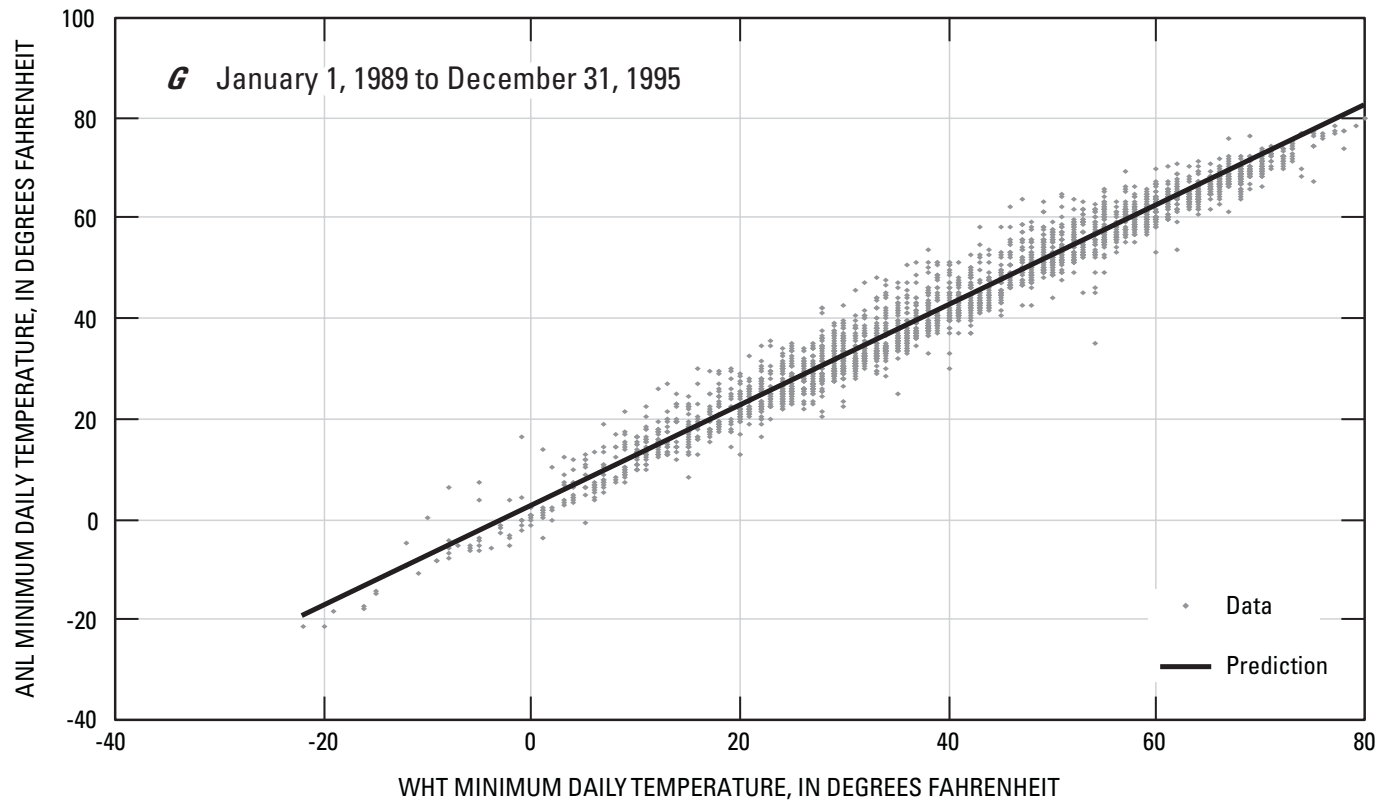

Figure A2-1. Regressions relating daily minimum air temperatures at Argonne National Laboratory (ANL) and Wheaton (WHT), Illinois (G: 1989-95). See tables 4 and 5 for regression types and statistics.

-Continued 




Figure A2-2. Regressions relating daily maximum air temperatures at Argonne National Laboratory (ANL) and Wheaton (WHT), Illinois (A: 1950-66, B: 1966-70). See tables 4 and 5 for regression types and statistics. 


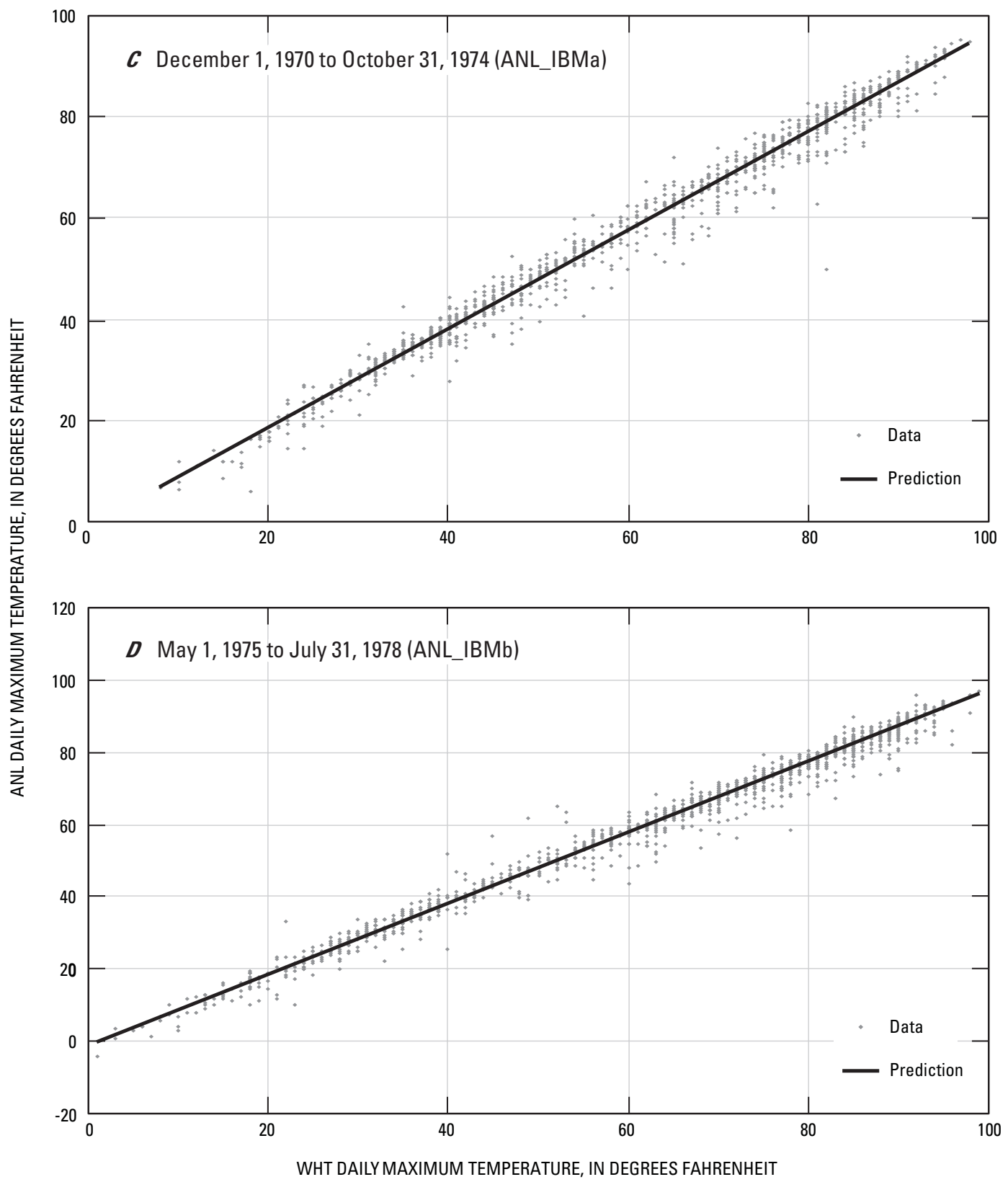

Figure A2-2. Regressions relating daily maximum air temperatures at Argonne National Laboratory (ANL) and Wheaton (WHT), Illinois (C: 1970-74, D: 1975-78). See tables 4 and 5 for regression types and statistics.-Continued 


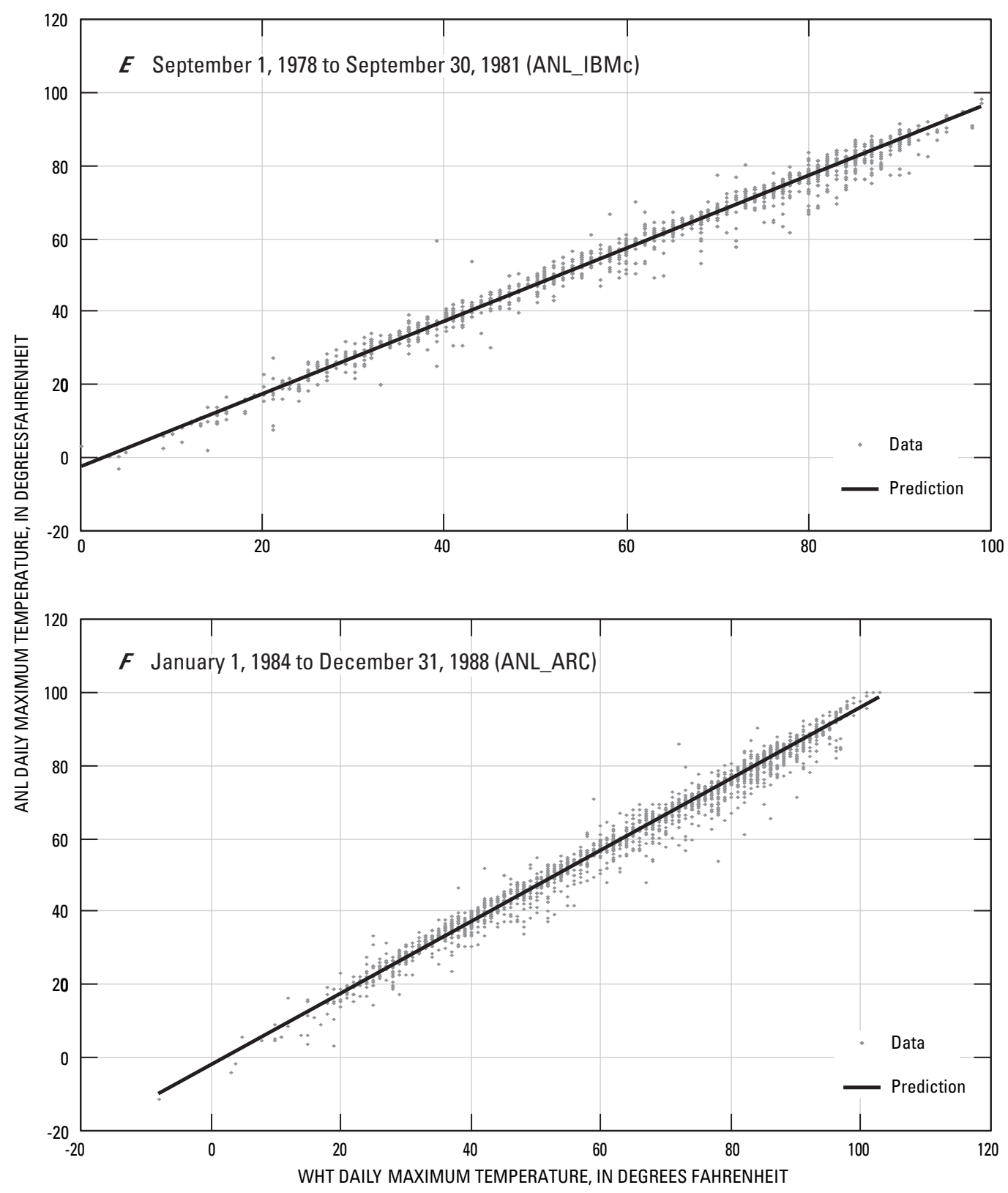

Figure A2-2. Regressions relating daily maximum air temperatures at Argonne National Laboratory (ANL) and Wheaton (WHT), Illinois (E: 1978-81, F: 1984-88). See tables 4 and 5 for regression types and statistics.-Continued 


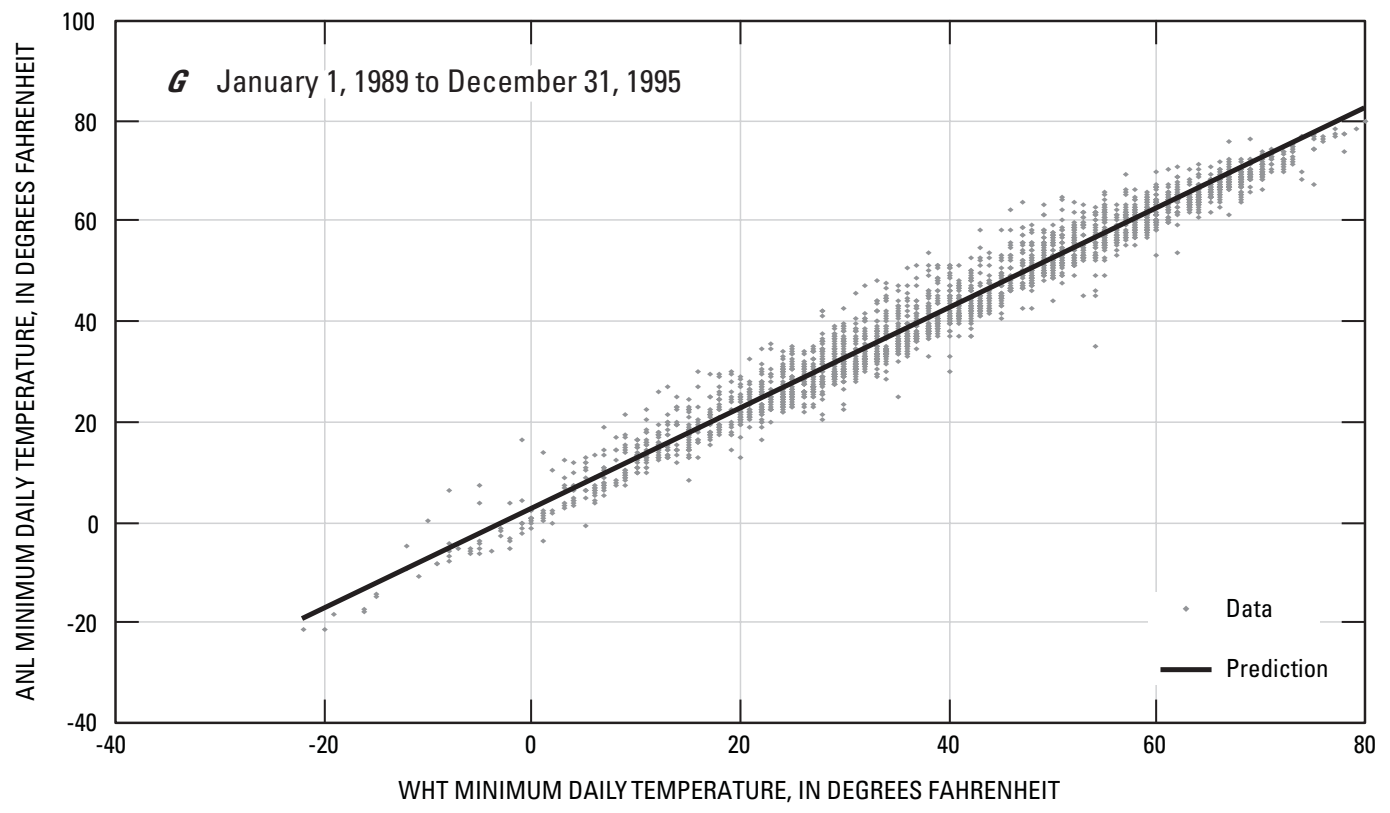

Figure A2-2. Regressions relating daily maximum air temperatures at Argonne National Laboratory (ANL) and Wheaton (WHT), Illinois (G:1989-95). See tables 4 and 5 for regression types and statistics. -Continued 


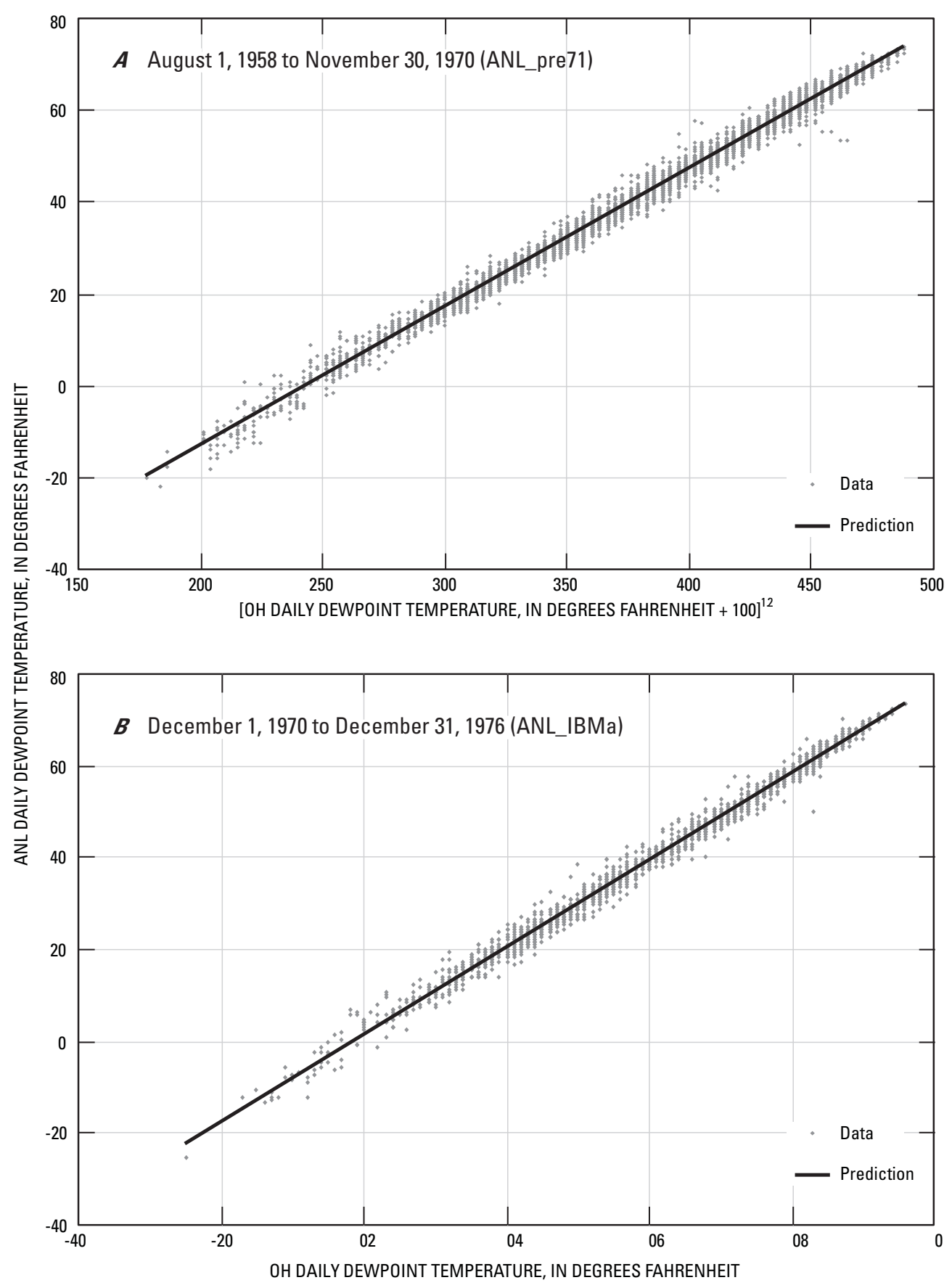

Figure A2-3. Regressions relating daily average dewpoint temperatures at Argonne National Laboratory (ANL) and O'Hare International Airport (OH), Illinois (A: 1958-70, B: 1970-76). See tables 4 and 5 for regression types and statistics. 



Figure A2-3. Regressions relating daily average dewpoint temperatures at Argonne National Laboratory (ANL) and O'Hare International Airport (OH), Illinois [C: 1977-2/19/81 (OH partial residuals), D: 1977-2/19/81 (date partial residuals)]. See Tables 4 and 5 for regression types and statistics. Note: The partial residuals and adjusted variables are defined as in Helsel and Hirsch (2002), p. 301.-Continued 

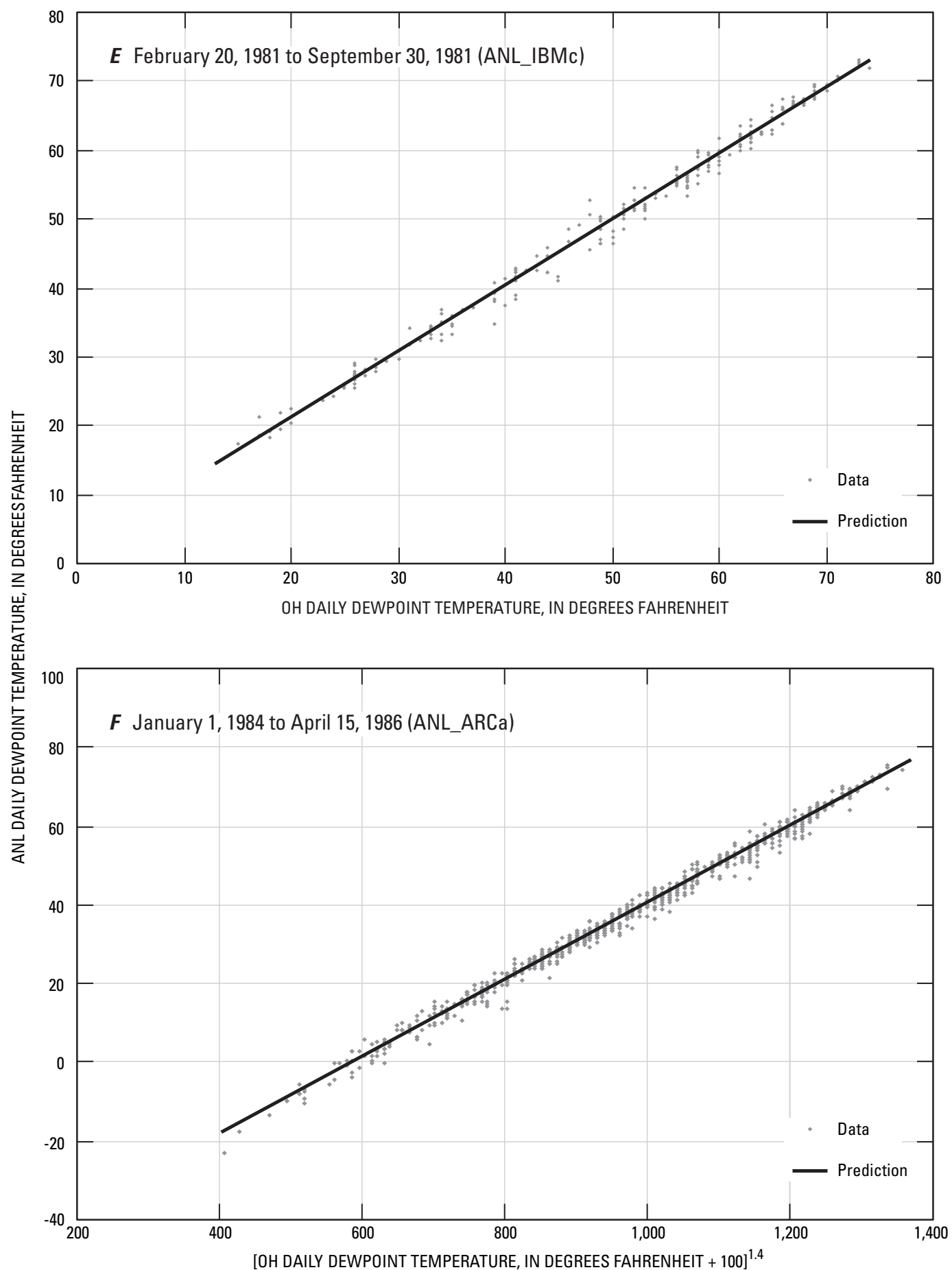

Figure A2-3. Regressions relating daily average dewpoint temperatures at Argonne National Laboratory (ANL) and O'Hare International Airport (OH), Illinois (E: 2/20/81-9/30/81, F: 1984-86). See tables 4 and 5 for regression types and statistics.-Continued 

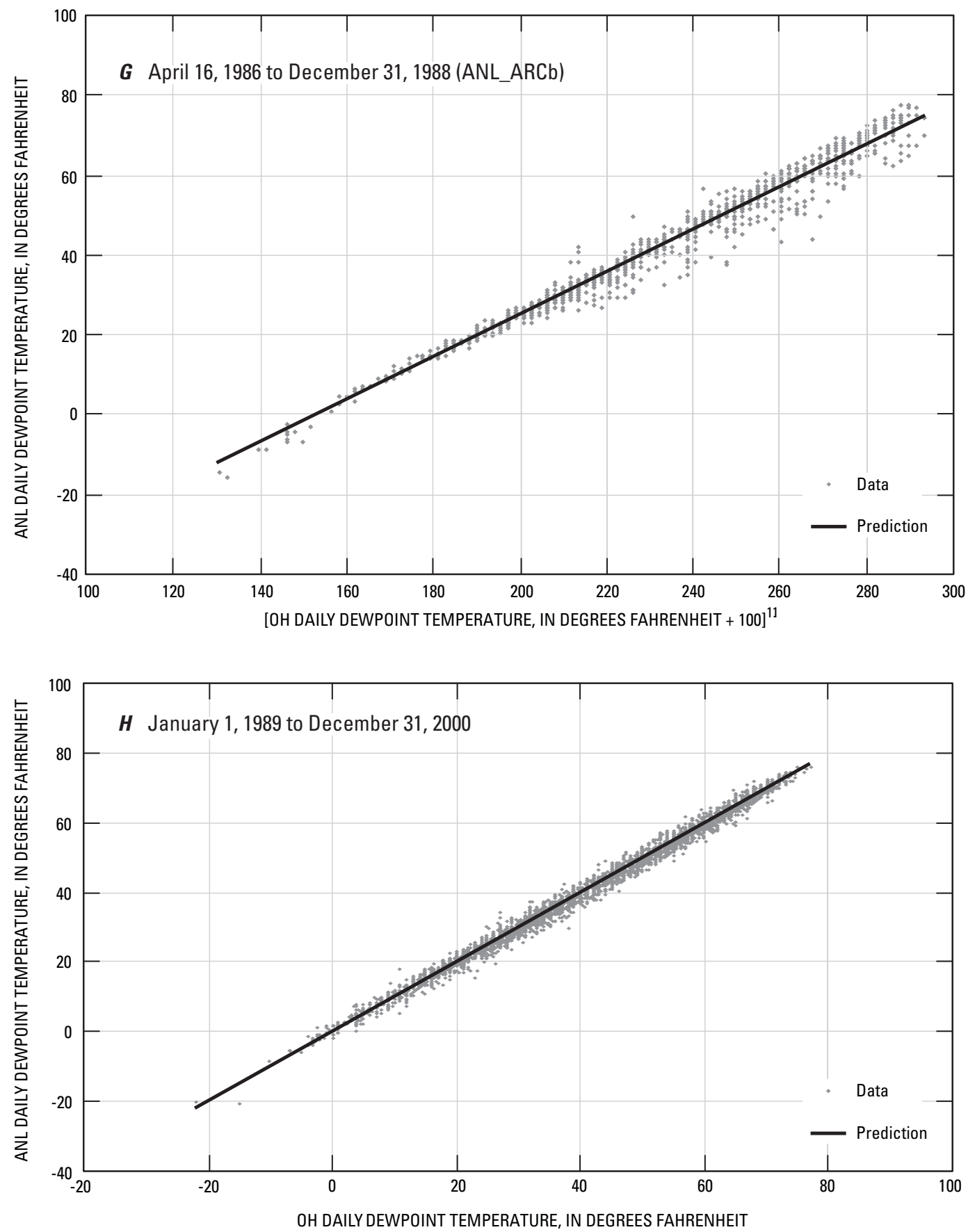

Figure A2-3. Regressions relating daily average dewpoint temperatures at Argonne National Laboratory (ANL) and O'Hare International Airport (OH), Illinois (G:1986-88, H: 1989-2000). See tables 4 and 5 for regression types and statistics.-Continued 

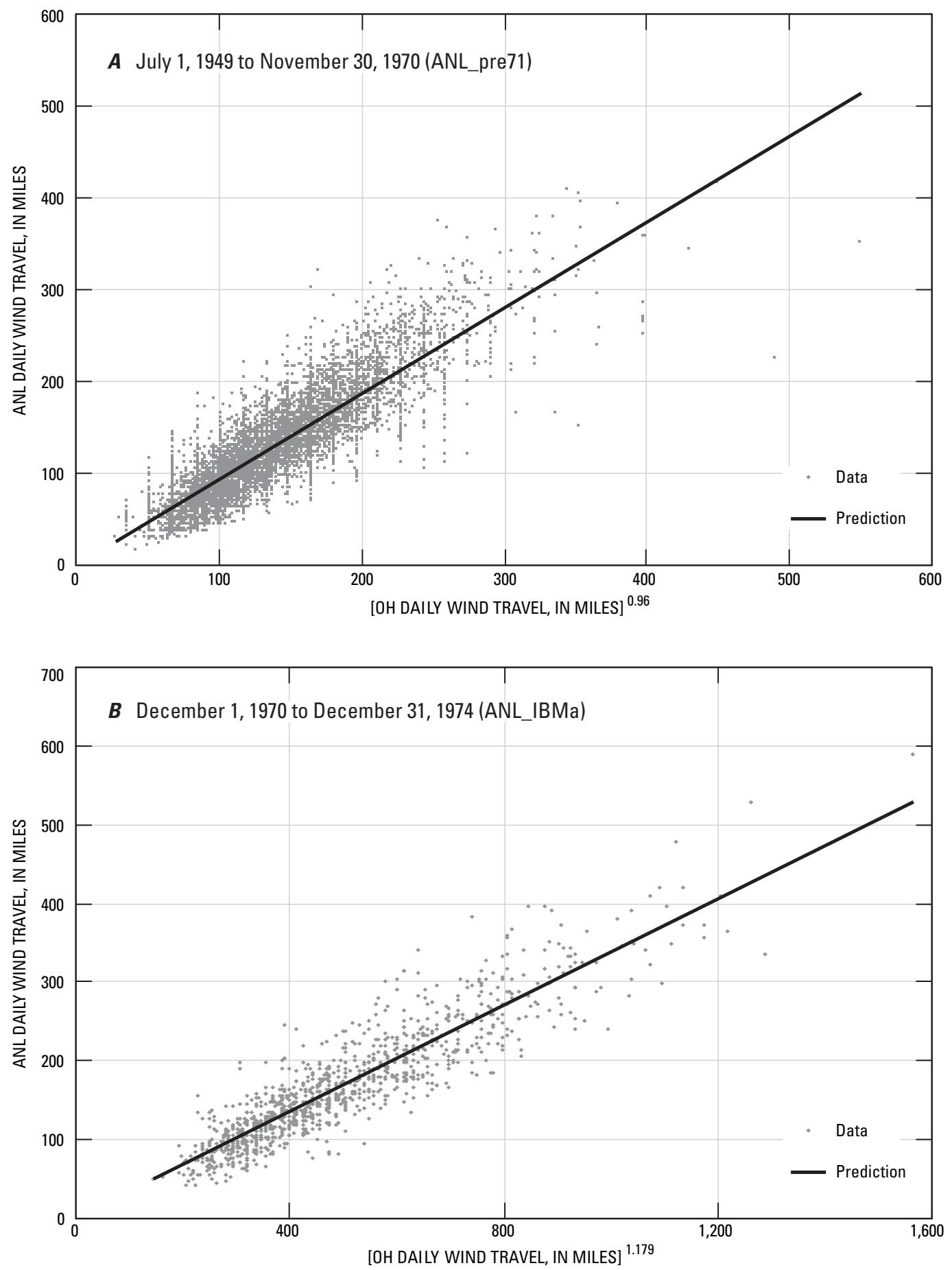

Figure A2-4. Regressions relating daily total wind travel at Argonne National Laboratory (ANL) and O'Hare International Airport (OH), Illinois (A: 1949-70, B: 1970-74). See tables 4 and 5 for regression types and statistics. 

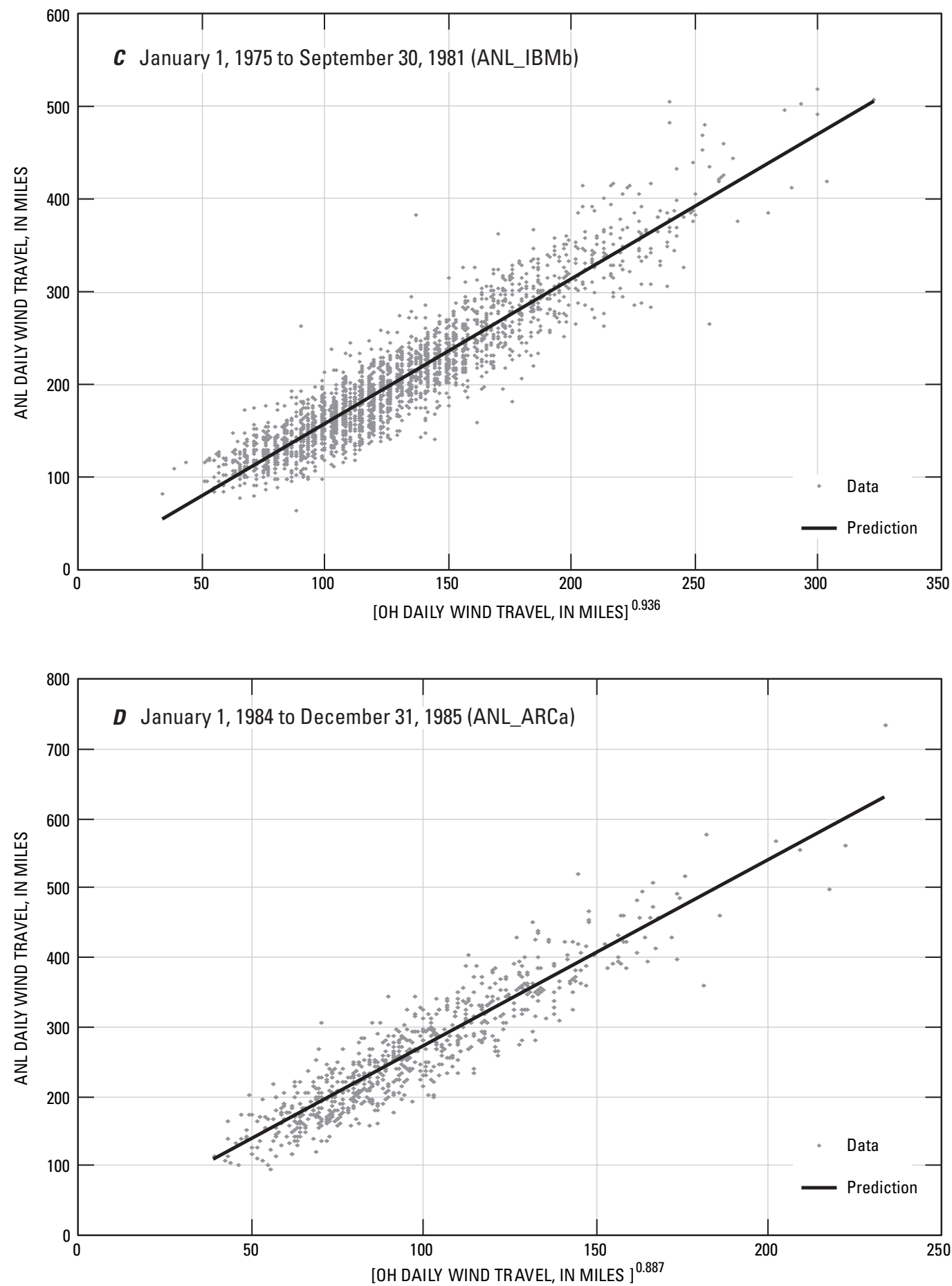

Figure A2-4. Regressions relating daily total wind travel at Argonne National Laboratory (ANL) and O'Hare International Airport (OH), Illinois (C: 1975-81, D: 1984-85). See tables 4 and 5 for regression types and statistics.-Continued 


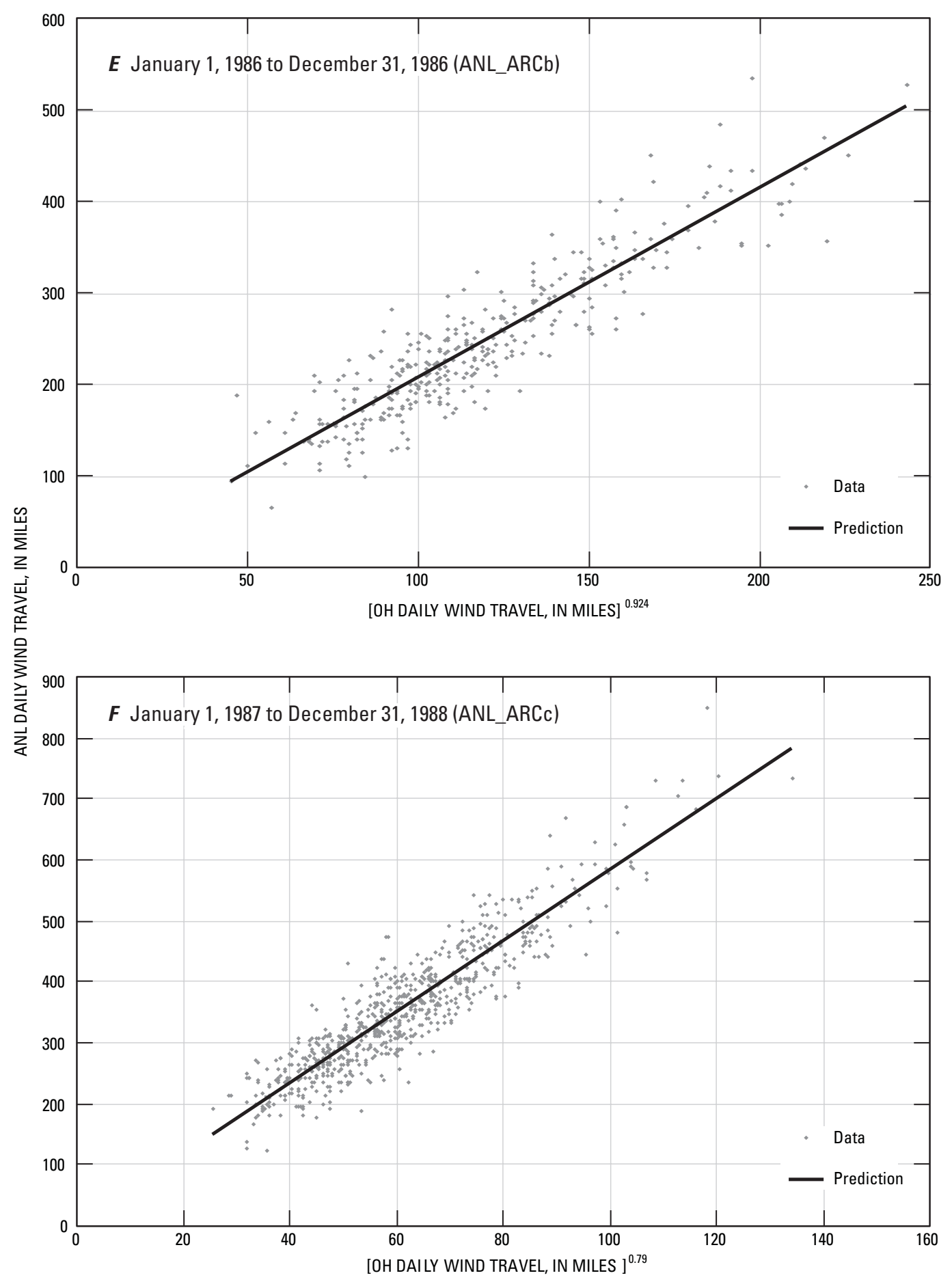

Figure A2-4. Regressions relating daily total wind travel at Argonne National Laboratory (ANL) and O'Hare International Airport (OH), Illinois (E: 1986, F: 1987-88). See tables 4 and 5 for regression types and statistics.-Continued 


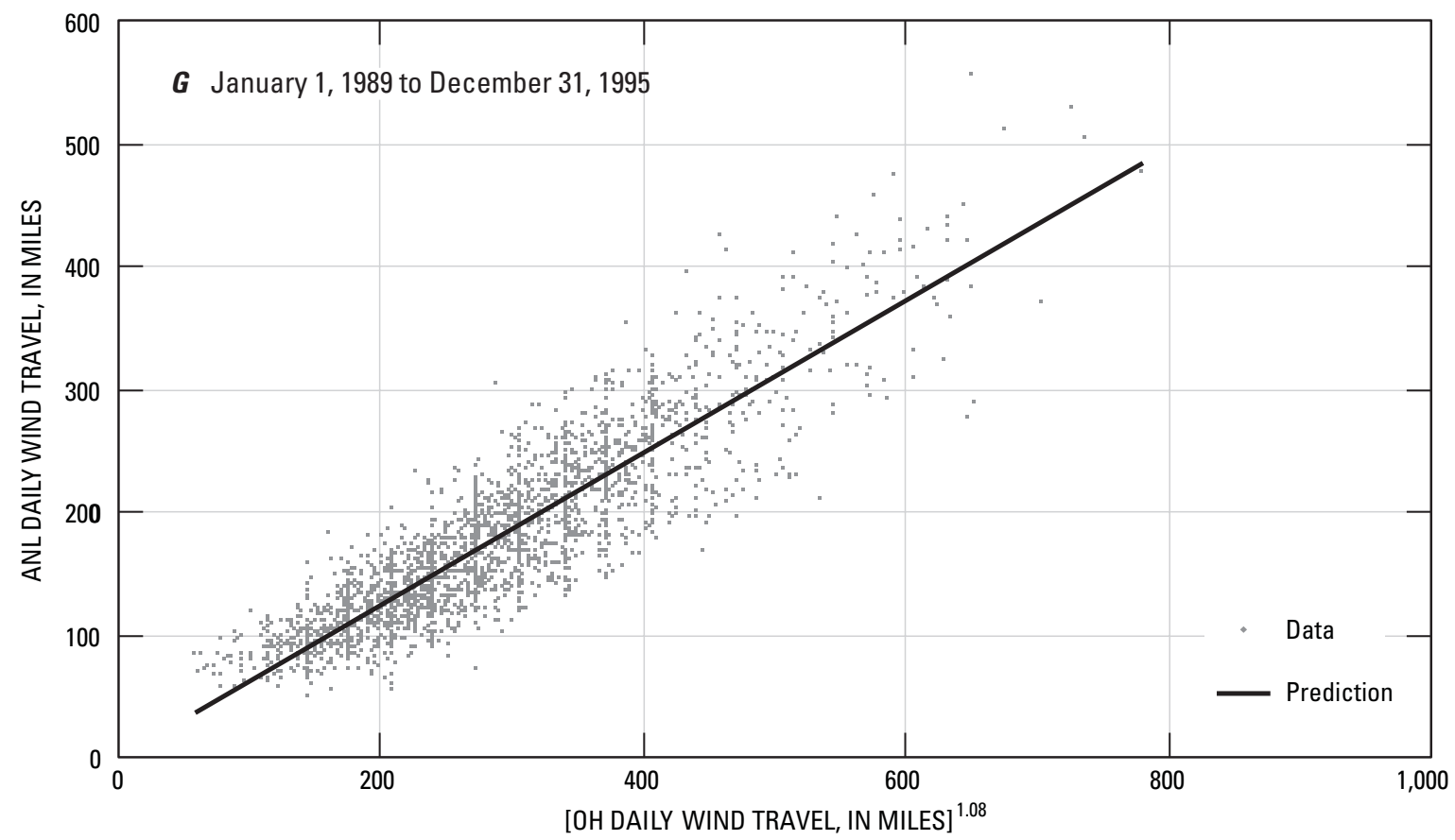

Figure A2-4. Regressions relating daily total wind travel at Argonne National Laboratory (ANL) and O'Hare International Airport (OH), Illinois (G: 1989-95). See tables 4 and 5 for regression types and statistics.-Continued 

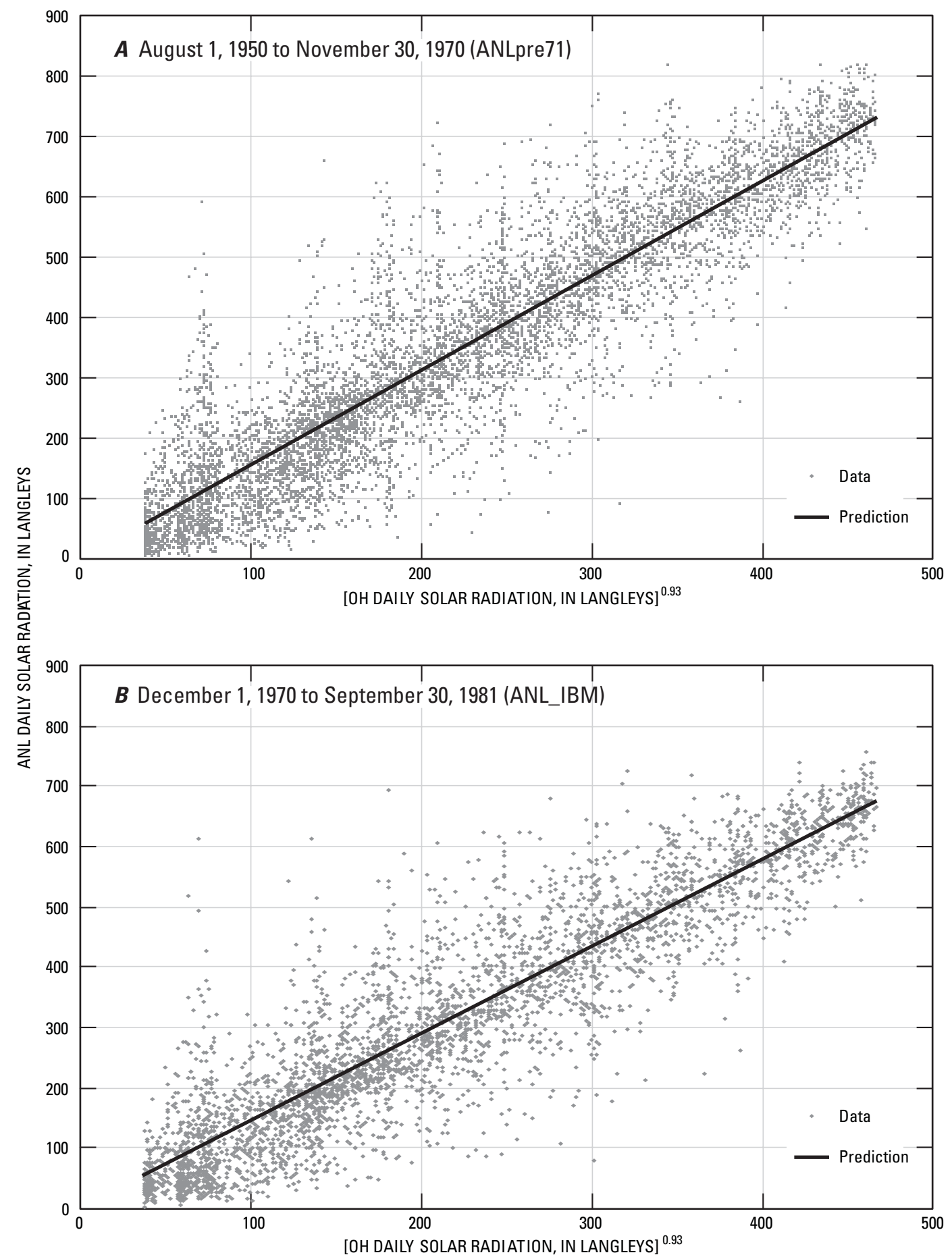

Figure A2-5. Regressions relating daily total solar radiation at Argonne National Laboratory (ANL) and $\mathrm{O}^{\prime}$ Hare International Airport $(\mathrm{OH})$, Illinois (A: 1950-70, B: 1970-81). See tables 4 and 5 for regression types and statistics. 




Figure A2-5. Regressions relating daily total solar radiation at Argonne National Laboratory (ANL) and O'Hare International Airport (OH), Illinois (C: 1984-88, D: 1989-95). See tables 4 and 5 for regression types and statistics.-Continued 


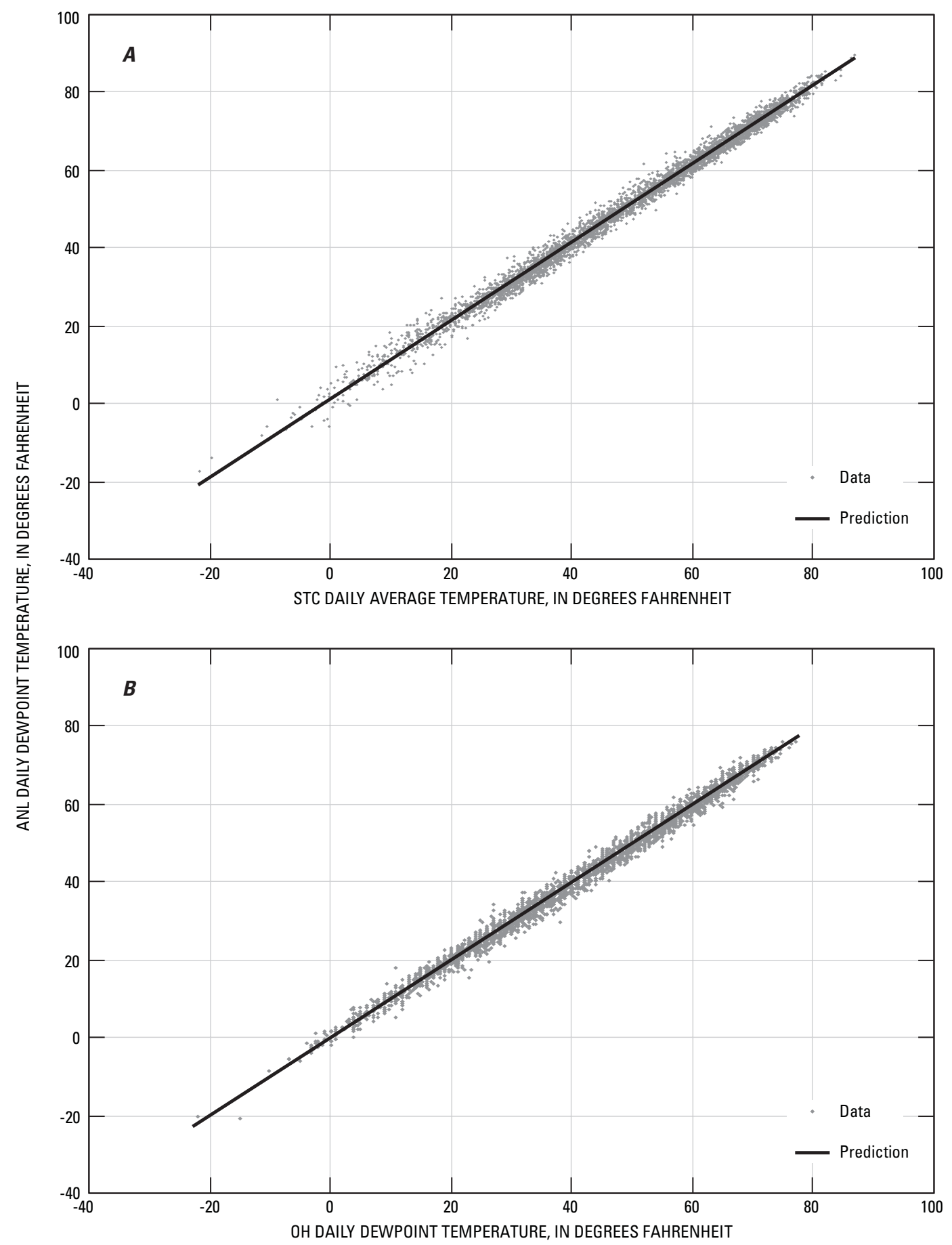

Figure A2-6. Regressions relating daily meteorological data series from Argonne National Laboratory, Illinois (ANL), and 1989-2003 backup stations, using data from January 1, 1989 to December 31, 2000 ( $A$ : average temperature, backup station: St. Charles, Illinois (STC); $B$ : dewpoint temperature, backup station: $\mathrm{O}^{\prime}$ Hare International Airport, Illinois $(\mathrm{OH})$ ). See table 8 for regression type and statistics. 

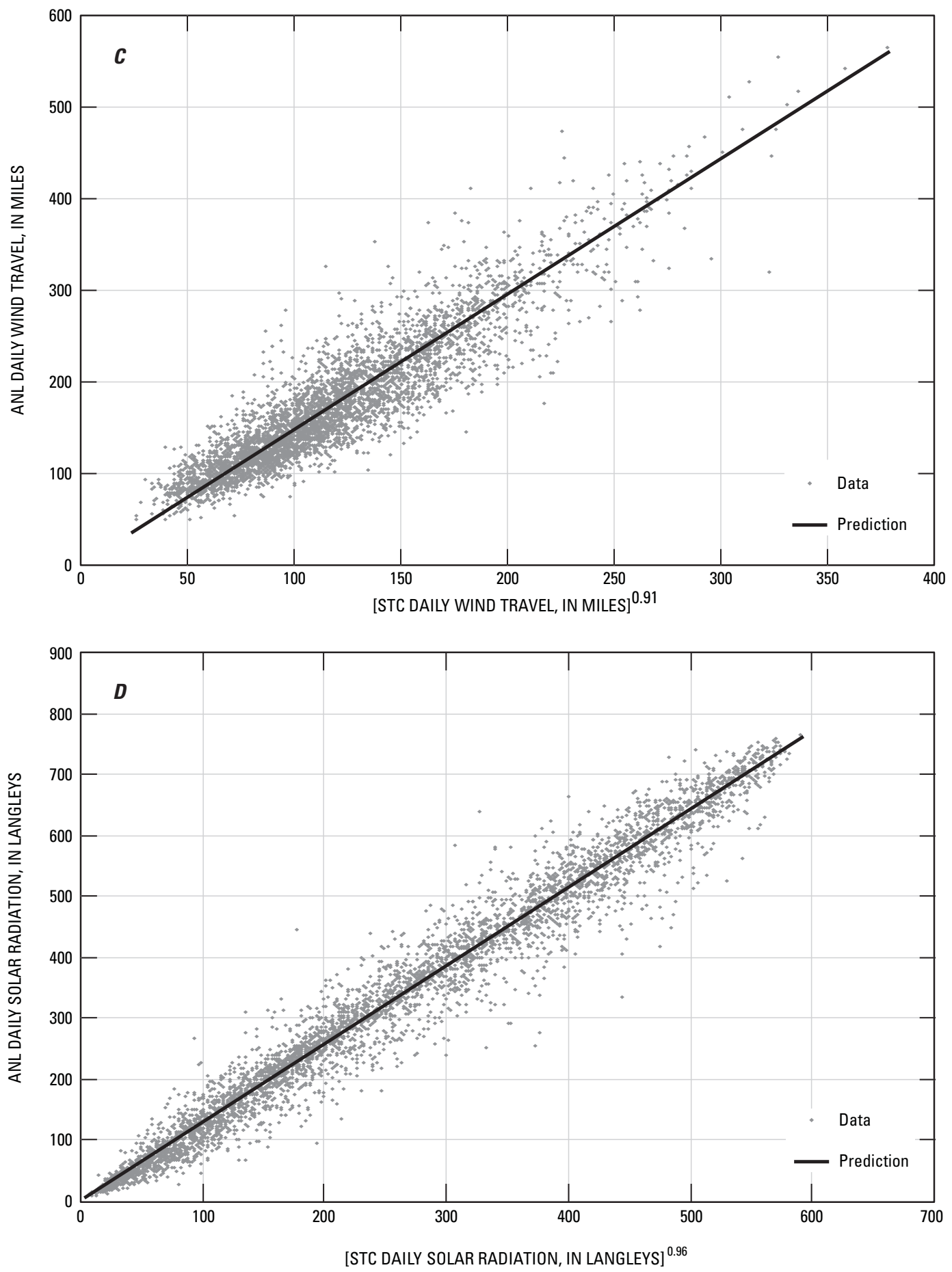

Figure A2-6. Regressions relating daily meteorological data series from Argonne National Laboratory, Illinois (ANL), and 1989-2003 backup stations, using data from January 1, 1989 to December 31, 2000 (C: wind travel, backup station: St. Charles, Illinois (STC), D: solar radiation, backup station: St. Charles, Illinois). See table 8 for regression type and statistics.-Continued 


\section{Reference Cited}

Helsel, D.R., and Hirsch, R.M., 2002, Statistical Methods in Water Resources: Techniques of Water-Resources Investigations of the United States Geological Survey, Book 4, Hydrologic Analysis and Interpretation, Chapter A3, $510 \mathrm{p}$. 
Appendix 3 - Comparisons Between Adjusted and Original Data Series 

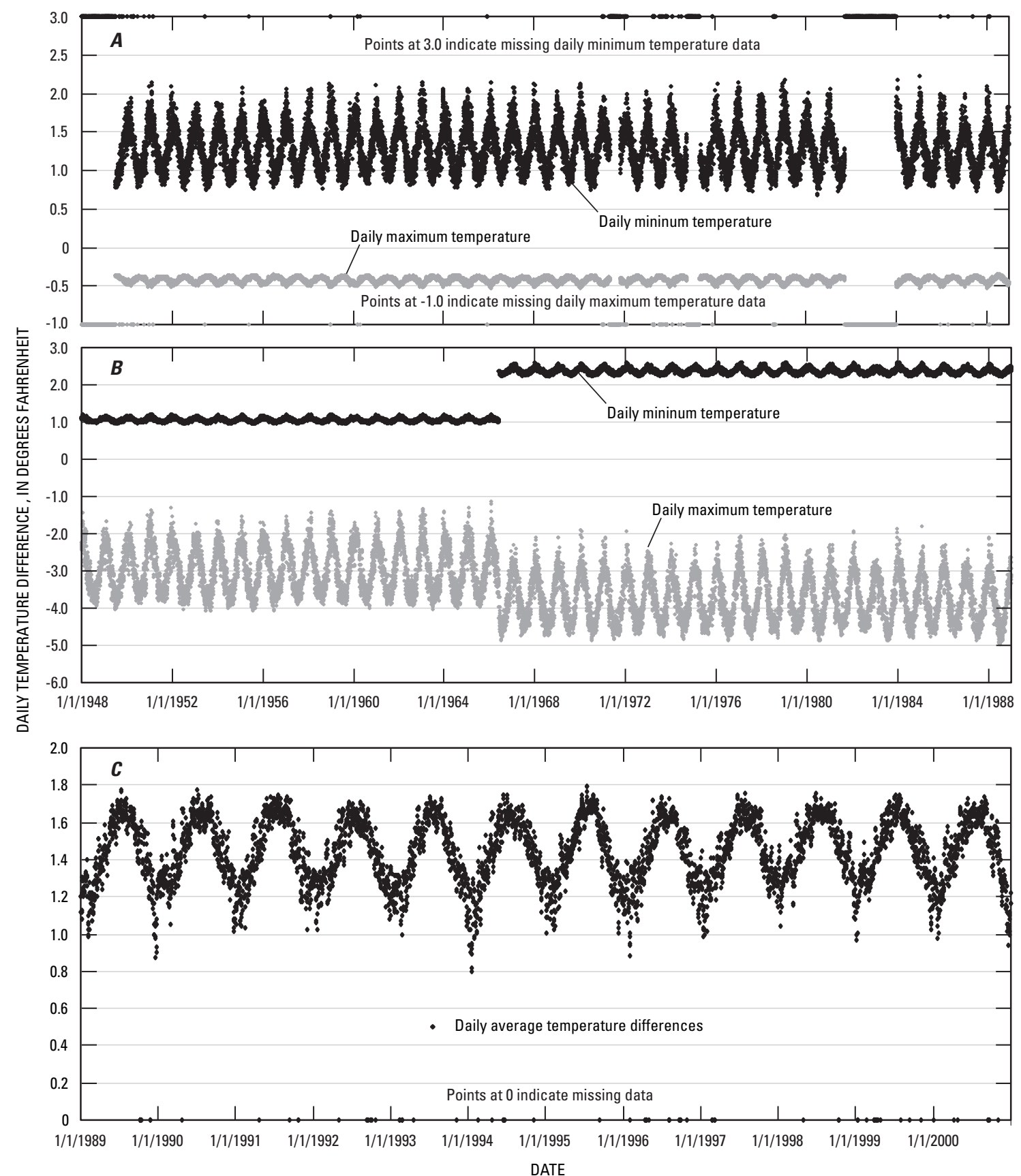

Figure A3-1. Differences (converted minus original) between daily temperature values converted to the ANL_dat base and the original data ( $A$ : Argonne National Laboratory, Illinois, 1948-88; $B$ : Wheaton, Illinois, 1948-88; C: St. Charles, Illinois, 1989-2000). See tables 5, 6, 7, and 8 for equations used for conversion. 

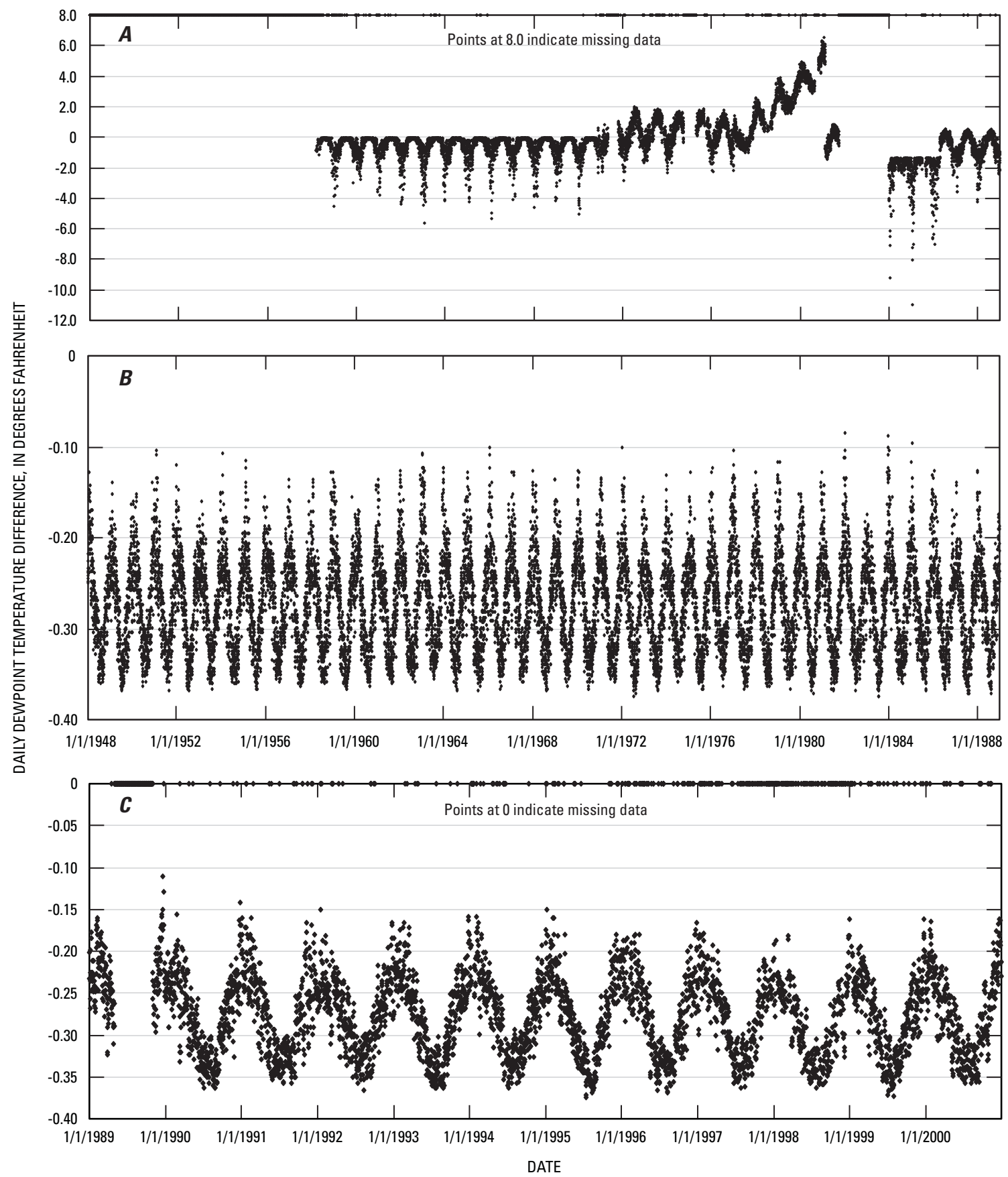

Figure A3-2. Differences (converted minus original) between daily dewpoint temperature values converted to the ANL_dat base and the original data (A: Argonne National Laboratory, Illinois, 1948-88; $B$ : O'Hare International Airport, Illinois, 1948-88; C: 0'Hare International Airport, Illinois, 1989-2000). See tables 5, 7, and 8 for equations used for conversion. 

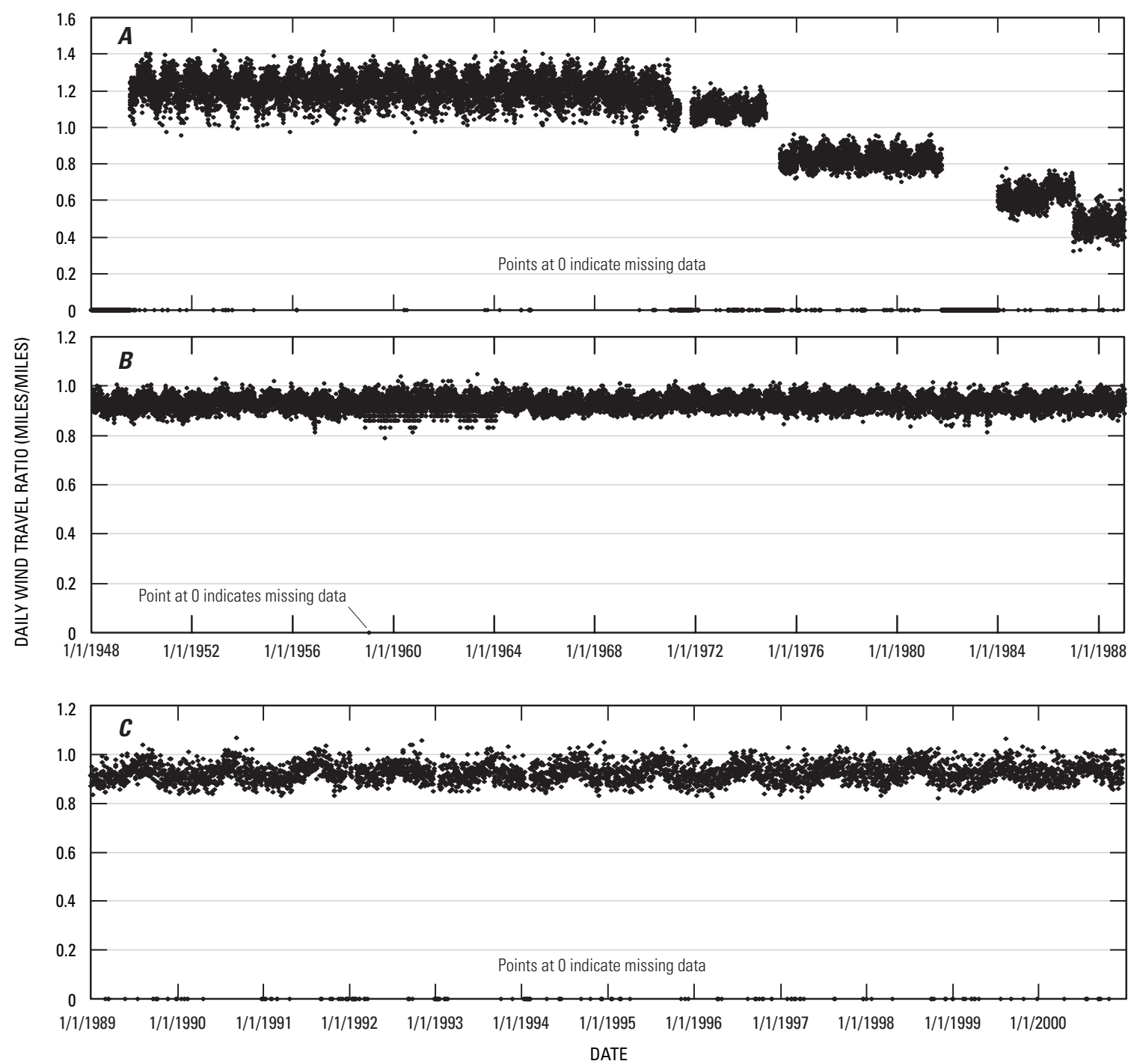

Figure A3-3. Ratios (converted divided by original) between daily wind travel values converted to the ANL_dat base and the original data (A: Argonne National Laboratory, Illinois, 1948-88; $B$ : O'Hare International Airport, Illinois, 1948-88; C: St. Charles, Illinois, 1989-2000). See tables 5, 7, and 8 for equations used for conversion. 

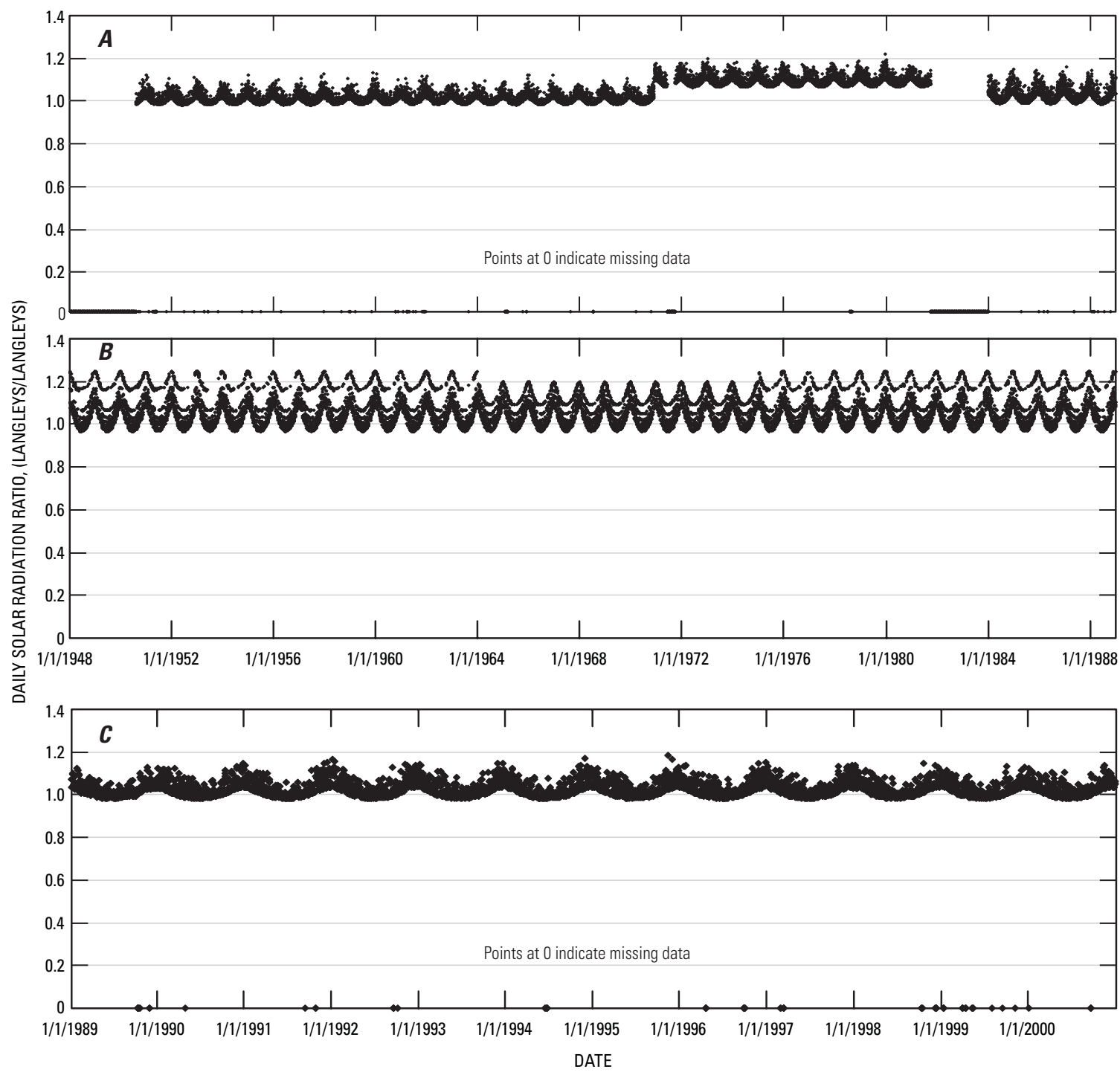

Figure A3-4. Ratios (converted divided by original) between daily solar radiation values converted to the ANL_dat base and the original data (A: Argonne National Laboratory, Illinois, 1948-88; $B$ : O'Hare International Airport, Illinois, 1948-88; C: St. Charles, Illinois, 1989-2000). See tables 5, 7, and 8 for equations used for conversion. 

Appendix 4 - Statistics of Data Sources and

Transformations 
Table A4-1. Fraction of Argonne National Laboratory temperature data from each source, estimated standard error, and description of source and filling method from January 1, 1948, through September 30, 2003, used in this study.

$\left[\%\right.$, percent; ${ }^{\circ}$ F, degrees Fahrenheit; ANL, Argonne National Laboratory; --, no data; QA/QC, quality-assured, quality-controlled; WHT_col, observations made at Wheaton College; WHT_arb, observations made at Morton Arboretum; STC, St. Charles, Illinois]

\begin{tabular}{|c|c|c|c|c|c|c|}
\hline \multirow[b]{2}{*}{$\begin{array}{l}\text { Data-source } \\
\text { flag }\end{array}$} & \multirow[b]{2}{*}{$\begin{array}{l}\text { Number of } \\
\text { hours }\end{array}$} & \multirow[b]{2}{*}{$\begin{array}{l}\text { Fraction of } \\
\text { hours }(\%)\end{array}$} & \multicolumn{3}{|c|}{ Estimated standard error } & \multirow[b]{2}{*}{$\begin{array}{l}\text { Description of source and filling method } \\
\text { (month/day/year) }\end{array}$} \\
\hline & & & $\begin{array}{l}\text { Daily minimum } \\
\left({ }^{\circ} \mathrm{F}\right)\end{array}$ & $\begin{array}{l}\text { Daily maximum } \\
\left({ }^{\circ} \mathrm{F}\right)\end{array}$ & Source & \\
\hline \multicolumn{7}{|c|}{ ANL data } \\
\hline 000 & 126,720 & 25.93 & -- & -- & -- & $1 / 1 / 89$ to $9 / 30 / 03$ \\
\hline 001 & 18,5241 & 37.91 & 4.591 & 4.054 & table 7 & $1 / 1 / 48$ to $11 / 30 / 70$ \\
\hline 002 & 26,511 & 5.42 & 4.468 & 4.251 & table 7 & $12 / 1 / 70$ to $10 / 31 / 74$ \\
\hline 003 & 28,368 & 5.80 & 4.708 & 4.321 & table 7 & $5 / 1 / 75$ to $7 / 31 / 78$ \\
\hline 004 & 27,000 & 5.52 & 4.615 & 4.326 & table 7 & $9 / 1 / 78$ to $9 / 30 / 81$ \\
\hline 005 & 43,446 & 8.89 & 4.577 & 4.318 & table 7 & $1 / 1 / 84$ to $12 / 31 / 88$ \\
\hline 300 & 144 & .03 & -- & -- & -- & Non-QA/QC (1/1/89 to $9 / 30 / 03)$ \\
\hline Sub-total & 437,430 & 89.51 & & & & All ANL data \\
\hline \multicolumn{7}{|c|}{ Missing data } \\
\hline 110 & 157 & 0.032 & -- & -- & -- & Filled by interpolation, $1 / 1 / 89$ to $9 / 30 / 03$ \\
\hline 111 & 3 & .001 & -- & -- & -- & Filled by interpolation, $1 / 1 / 48$ to $11 / 30 / 70$ \\
\hline 112 & 3 & .001 & -- & -- & -- & Filled by interpolation, $12 / 1 / 70$ to $10 / 31 / 74$ \\
\hline 113 & 0 & 0 & -- & -- & -- & Filled by interpolation, $5 / 1 / 75$ to $7 / 31 / 78$ \\
\hline 114 & 0 & 0 & -- & -- & -- & Filled by interpolation, $9 / 1 / 78$ to $9 / 30 / 81$ \\
\hline 115 & 114 & .023 & -- & -- & -- & Filled by interpolation, $1 / 1 / 84$ to $12 / 31 / 88$ \\
\hline 131 & 14,043 & 2.87 & 5.209 & 4.882 & table 6 & Filled by WHT_col data, $1 / 1 / 48$ to $5 / 31 / 66$ \\
\hline 132 & 32,228 & 6.59 & 3.541 & 3.017 & table 5 & $\begin{array}{l}\text { Filled by WHT_arb data, } 6 / 1 / 66 \text { to } \\
12 / 31 / 88\end{array}$ \\
\hline 133 & 2,243 & .46 & $1.744^{\mathrm{a}}$ & -- & table 8 & Filled by STC data, $1 / 1 / 89$ to $9 / 30 / 03$ \\
\hline Sub-total & 48,791 & 9.98 & & & & All missing data \\
\hline \multicolumn{7}{|c|}{ Erroneous data } \\
\hline 210 & 0 & 0 & -- & -- & -- & Filled by interpolation, $1 / 1 / 89$ to $9 / 30 / 89$ \\
\hline 211 & 245 & 0.050 & -- & -- & -- & Filled by interpolation, $1 / 1 / 48$ to $11 / 30 / 70$ \\
\hline 261 & 919 & .188 & -- & -- & -- & $\begin{array}{l}\text { Corrected by inserting a missing negative } \\
\text { sign, } 1 / 1 / 48 \text { to } 11 / 30 / 70\end{array}$ \\
\hline Sub-total & 1,164 & .24 & & & & All erroneous data \\
\hline \multicolumn{7}{|c|}{ Data replaced because of data missing at another time during the day } \\
\hline 431 & 1,303 & 0.267 & 5.209 & 4.882 & table 6 & $1 / 1 / 48$ to $11 / 30 / 70$ \\
\hline \multicolumn{7}{|l|}{ All data } \\
\hline Total & 488,688 & 100.00 & & & & All data \\
\hline
\end{tabular}

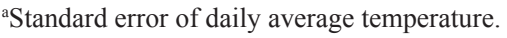


Table A4-2. Fraction of Argonne National Laboratory temperature data from each source and description of source and filling method from January 1, 1948, through December 31, 1988, in this study.

[\%, percent; ANL, Argonne National Laboratory; WHT_col, observations made at Wheaton College; WHT_arb, observations made at Morton Arboretum]

\begin{tabular}{|c|c|c|c|}
\hline $\begin{array}{l}\text { Data-source } \\
\text { flag }\end{array}$ & $\begin{array}{l}\text { Number of } \\
\text { hours }\end{array}$ & $\begin{array}{c}\text { Fraction of } \\
\text { hours }(\%)\end{array}$ & $\begin{array}{l}\text { Description of source and filling method } \\
\text { (month/day/year) }\end{array}$ \\
\hline \multicolumn{4}{|c|}{ ANL data } \\
\hline 001 & 185,241 & 51.54 & ANL, $1 / 1 / 48$ to $11 / 30 / 70$ \\
\hline 002 & 26,511 & 7.38 & ANL, $12 / 1 / 70$ to $10 / 31 / 74$ \\
\hline 003 & 28,368 & 7.89 & ANL, $5 / 1 / 75$ to $7 / 31 / 78$ \\
\hline 004 & 27,000 & 7.51 & ANL, $9 / 1 / 78$ to $9 / 30 / 81$ \\
\hline 005 & 43,446 & 12.09 & ANL, $1 / 1 / 84$ to $12 / 31 / 88$ \\
\hline Sub-total & 310,566 & 86.41 & All ANL data \\
\hline \multicolumn{4}{|c|}{ Missing data } \\
\hline 111 & 3 & 0.001 & Filled by interpolation, $1 / 1 / 48$ to $11 / 30 / 70$ \\
\hline 112 & 3 & .001 & Filled by interpolation, $12 / 1 / 70$ to $10 / 31 / 74$ \\
\hline 115 & 114 & .032 & Filled by interpolation, $1 / 1 / 84$ to $12 / 31 / 88$ \\
\hline 131 & 14,043 & 3.91 & Filled using WHT_col data, $1 / 1 / 48$ to $5 / 31 / 66$ \\
\hline 132 & 32,228 & 8.97 & Filled using WHT_arb data, $6 / 1 / 66$ to $12 / 31 / 88$ \\
\hline Sub-total & 46,391 & 12.91 & All missing data \\
\hline \multicolumn{4}{|c|}{ Erroneous data } \\
\hline 211 & 245 & 0.068 & Filled by interpolation, $1 / 1 / 48$ to $11 / 30 / 70$ \\
\hline 261 & 919 & .256 & $\begin{array}{l}\text { Corrected by inserting a missing negative sign, } \\
1 / 1 / 48 \text { to } 11 / 30 / 70\end{array}$ \\
\hline Sub-total & 1,164 & .32 & All erroneous data \\
\hline \multicolumn{4}{|c|}{ Filled because of missing data sometime else during the day } \\
\hline 431 & 1,303 & 0.363 & $1 / 1 / 48$ to $11 / 30 / 70$ \\
\hline \multicolumn{4}{|c|}{ All data } \\
\hline Total & 359,424 & 100.00 & All data \\
\hline
\end{tabular}


Table A4-3. Fraction of Argonne National Laboratory temperature data from each source and description of source and filling method from January 1, 1989, through September 30, 2003, in this study.

[\%, percent; ANL, Argonne National Laboratory; QA/QC, quality-assured, quality-controlled; STC, St. Charles, Illinois]

\begin{tabular}{crrl}
\hline $\begin{array}{c}\text { Data-source } \\
\text { flag }\end{array}$ & $\begin{array}{c}\text { Number of } \\
\text { hours }\end{array}$ & $\begin{array}{c}\text { Fraction of } \\
\text { hours (\%) }\end{array}$ & \multicolumn{1}{c}{$\begin{array}{c}\text { Description of source and } \\
\text { filling method }\end{array}$} \\
\hline \multicolumn{4}{c}{ ANL data } \\
\hline 300 & 126,720 & 98.03 & ANL QA/QC data \\
Sub-total & 144 & .11 & Non-QA/QC ANL data \\
& $\mathbf{1 2 6 , 8 6 4}$ & $\mathbf{9 8 . 1 4}$ & All ANL data \\
\hline 110 & 157 & Missing data & \\
\hline 133 & 2,243 & 0.12 & Filled by linear interpolation \\
Sub-total & $\mathbf{2 , 4 0 0}$ & 1.74 & Filled by STC data \\
& & $\mathbf{1 . 8 6}$ & All missing data \\
\hline Sub-total & $\mathbf{0}$ & $\mathbf{0}$ & All erroneous data \\
\hline & & All data & \\
\hline Total & $\mathbf{1 2 9 , 2 6 4}$ & $\mathbf{1 0 0 . 0 0}$ & All data \\
\hline
\end{tabular}


Table A4-4. Fraction of Argonne National Laboratory dewpoint temperature data from each source, estimated standard error, and description of source and filling method from January 1, 1948, through September 30, 2003, in this study.

$\left[\%\right.$, percent; ${ }^{\circ}$ F, degrees Fahrenheit; --, no data; ANL, Argonne National Laboratory; QA/QC, quality-assured, quality-controlled; OH, O’Hare International Airport]

\begin{tabular}{|c|c|c|c|c|c|}
\hline \multirow{2}{*}{$\begin{array}{l}\text { Data-source } \\
\text { flag }\end{array}$} & \multirow{2}{*}{$\begin{array}{l}\text { Number of } \\
\text { hours }\end{array}$} & \multirow{2}{*}{$\begin{array}{c}\text { Fraction of } \\
\text { hours }(\%)\end{array}$} & \multicolumn{2}{|c|}{ Estimated standard error } & \multirow{2}{*}{ Description of source and filling method (month/day/year) } \\
\hline & & & Value $\left({ }^{\circ} \mathrm{F}\right)$ & Source & \\
\hline \multicolumn{6}{|c|}{ ANL data } \\
\hline 000 & 120,545 & 24.67 & -- & -- & ANL, $1 / 1 / 89$ to $9 / 30 / 03$ \\
\hline 001 & 107,399 & 21.98 & 2.349 & table 7 & ANL, $1 / 1 / 48$ to $11 / 30 / 70$ \\
\hline 002 & 40,919 & 8.37 & 2.439 & table 7 & ANL, $12 / 1 / 70$ to $12 / 31 / 76$ \\
\hline 003 & 32,121 & 6.57 & 2.832 & table 7 & ANL, $1 / 1 / 77$ to $2 / 19 / 81$ \\
\hline 004 & 5,307 & 1.09 & 2.102 & table 7 & ANL, $2 / 20 / 81$ to $9 / 30 / 81$ \\
\hline 005 & 18,606 & 3.81 & 2.357 & table 7 & ANL, $1 / 1 / 84$ to $4 / 15 / 86$ \\
\hline 006 & 23,522 & 4.81 & 3.361 & table 7 & ANL, $4 / 16 / 86$ to $12 / 31 / 88$ \\
\hline 300 & 144 & .029 & -- & -- & Original data (non-QA/QC) \\
\hline Sub-total & 348,563 & 71.33 & & & All ANL data \\
\hline \multicolumn{6}{|c|}{ Missing data } \\
\hline 110 & 210 & 0.043 & -- & -- & Filled by linear interpolation, $1 / 1 / 89$ to $9 / 30 / 03$ \\
\hline 111 & 119 & .024 & -- & -- & Filled by interpolation, $1 / 1 / 48$ to $11 / 30 / 70$ \\
\hline 112 & 7 & .001 & -- & -- & Filled by interpolation, $12 / 1 / 70$ to $12 / 31 / 76$ \\
\hline 113 & 5 & .001 & -- & -- & Filled by interpolation, $1 / 1 / 77$ to $2 / 19 / 81$ \\
\hline 114 & 0 & 0 & -- & -- & Filled by interpolation, $2 / 20 / 81$ to $9 / 30 / 81$ \\
\hline 115 & 79 & .016 & -- & -- & Filled by interpolation, $1 / 1 / 84$ to $4 / 15 / 86$ \\
\hline 116 & 41 & .008 & -- & -- & Filled by interpolation, $4 / 16 / 86$ to $12 / 31 / 88$ \\
\hline 131 & 131,835 & 26.98 & 1.578 & table 5 & Filled with $\mathrm{OH}$ data using regression equation \\
\hline 171 & 4 & .001 & -- & -- & Filled by extrapolation, $1 / 1 / 48$ to $11 / 30 / 70$ \\
\hline 180 & 1,711 & .350 & -- & -- & $\begin{array}{l}\text { Marked with } 777.7 \text { as missing in "NUMERIC" ANL data } \\
\text { but filled with "TEXT" ANL data }\end{array}$ \\
\hline Sub-total & 134,011 & 27.42 & & & All missing data \\
\hline \multicolumn{6}{|c|}{ Erroneous data } \\
\hline 210 & 25 & 0.005 & -- & -- & Filled by interpolation, $1 / 1 / 89$ to $9 / 30 / 03$ \\
\hline 211 & 373 & .076 & -- & -- & Filled by interpolation, $1 / 1 / 48$ to $11 / 30 / 70$ \\
\hline 212 & 4 & .001 & -- & -- & Filled by interpolation, $12 / 1 / 70$ to $12 / 31 / 76$ \\
\hline 213 & 0 & 0 & -- & -- & Filled by interpolation, $1 / 1 / 77$ to $2 / 19 / 81$ \\
\hline 214 & 0 & 0 & -- & -- & Filled by interpolation, $2 / 20 / 81$ to $9 / 30 / 81$ \\
\hline 215 & 2 & 0 & -- & -- & Filled by interpolation, $1 / 1 / 84$ to $4 / 15 / 86$ \\
\hline 216 & 6 & .001 & -- & -- & Filled by interpolation, $4 / 16 / 86$ to $12 / 31 / 88$ \\
\hline 231 & 4,508 & .92 & 1.578 & table 5 & Filled with $\mathrm{OH}$ data using regression equation \\
\hline 261 & 1,189 & .24 & -- & -- & $\begin{array}{l}\text { Corrected by adding a missing negative sign, } 1 / 1 / 48 \text { to } \\
11 / 30 / 70\end{array}$ \\
\hline 271 & 7 & .001 & -- & -- & Filled by extrapolation, $1 / 1 / 48$ to $11 / 30 / 70$ \\
\hline Sub-total & 6,114 & 1.25 & & & All erroneous data \\
\hline \multicolumn{6}{|c|}{ Data replaced because of missing or erroneous data at another time during the same day } \\
\hline 431 & 0 & 0 & -- & -- & -- \\
\hline \multicolumn{6}{|c|}{ All data } \\
\hline Total & 488,688 & 100.00 & & & All data \\
\hline
\end{tabular}


Table A4-5. Fraction of Argonne National Laboratory dewpoint temperature data from each source and description of source and filling method from January 1, 1948, through December 31, 1988, in this study.

[\%, percent; ANL, Argonne National Laboratory; OH, O’Hare International Airport]

\begin{tabular}{|c|c|c|c|}
\hline $\begin{array}{l}\text { Data-source } \\
\text { flag }\end{array}$ & $\begin{array}{l}\text { Number of } \\
\text { hours }\end{array}$ & $\begin{array}{l}\text { Fraction of } \\
\text { hours }(\%)\end{array}$ & Description of source and filling method (month/day/year) \\
\hline \multicolumn{4}{|r|}{ ANL data } \\
\hline 001 & 107,399 & 29.88 & ANL, $1 / 1 / 48$ to $11 / 30 / 70$ \\
\hline 002 & 40,919 & 11.38 & ANL, $12 / 1 / 70$ to $12 / 31 / 76$ \\
\hline 003 & 32,121 & 8.94 & ANL, $1 / 1 / 77$ to $2 / 19 / 81$ \\
\hline 004 & 5,307 & 1.48 & ANL, $2 / 20 / 81$ to $9 / 30 / 81$ \\
\hline 005 & 18,606 & 5.18 & ANL, $1 / 1 / 84$ to $4 / 15 / 86$ \\
\hline 006 & 23,522 & 6.54 & ANL, $4 / 16 / 86$ to $12 / 31 / 88$ \\
\hline Sub-total & 227,874 & 63.40 & All ANL data \\
\hline \multicolumn{4}{|c|}{ Missing data } \\
\hline 111 & 119 & 0.033 & Filled by interpolation, $1 / 1 / 48$ to $11 / 30 / 70$ \\
\hline 112 & 7 & .002 & Filled by interpolation, $12 / 1 / 70$ to $12 / 31 / 76$ \\
\hline 113 & 5 & .001 & Filled by interpolation, $1 / 1 / 77$ to $2 / 19 / 81$ \\
\hline 115 & 79 & .022 & Filled by interpolation, $1 / 1 / 84$ to $4 / 15 / 86$ \\
\hline 116 & 41 & .011 & Filled by interpolation, $4 / 16 / 86$ to $12 / 31 / 88$ \\
\hline 131 & 129,680 & 36.08 & Filled from $\mathrm{OH}$ data using regression equation \\
\hline 171 & 4 & .001 & Filled by extrapolation, $1 / 1 / 48$ to $11 / 30 / 70$ \\
\hline Sub-total & 129,935 & 36.15 & All missing data \\
\hline \multicolumn{4}{|c|}{ Erroneous data } \\
\hline 211 & 373 & 0.104 & Filled by interpolation, $1 / 1 / 48$ to $11 / 30 / 70$ \\
\hline 212 & 4 & .001 & Filled by interpolation, $12 / 1 / 70$ to $12 / 31 / 76$ \\
\hline 215 & 2 & .001 & Filled by interpolation, $1 / 1 / 84$ to $4 / 15 / 86$ \\
\hline 216 & 6 & .002 & Filled by interpolation, $4 / 16 / 86$ to $12 / 31 / 88$ \\
\hline 231 & 34 & .009 & Filled with $\mathrm{OH}$ data using regression equation \\
\hline 261 & 1,189 & .331 & $\begin{array}{l}\text { Corrected by adding a missing negative sign, } 1 / 1 / 48 \text { to } \\
11 / 30 / 70\end{array}$ \\
\hline 271 & 7 & .002 & Filled by extrapolation, $1 / 1 / 48$ to $11 / 30 / 70$ \\
\hline Sub-total & 1,615 & .449 & All erroneous data \\
\hline \multicolumn{4}{|r|}{ All data } \\
\hline Total & 359,424 & 100.00 & All data \\
\hline
\end{tabular}


Table A4-6. Fraction of Argonne National Laboratory dewpoint temperature data from each source and description of source and filling method from January 1, 1989, through September 30, 2003, in this study.

[\%, percent; ANL, Argonne National Laboratory; QA/QC, quality-assured, quality-controlled; OH, O’Hare International Airport]

\begin{tabular}{|c|c|c|c|}
\hline $\begin{array}{l}\text { Data-source } \\
\text { flag }\end{array}$ & $\begin{array}{l}\text { Number of } \\
\text { hours }\end{array}$ & $\begin{array}{l}\text { Fraction of } \\
\text { hours }(\%)\end{array}$ & Description of source and filling method \\
\hline \multicolumn{4}{|r|}{ ANL data } \\
\hline 000 & 120,545 & 93.25 & Original QA/QC ANL data \\
\hline 300 & 144 & .111 & Original non-QA/QC ANL data \\
\hline Sub-total & 120,689 & 93.37 & All ANL data \\
\hline \multicolumn{4}{|r|}{ Missing data } \\
\hline 110 & 210 & 0.16 & Filled by linear interpolation \\
\hline 131 & 2,155 & 1.67 & Filled with $\mathrm{OH}$ data with the regression equation \\
\hline 180 & 1,711 & 1.32 & $\begin{array}{l}\text { Marked with } 777.7 \text { as missing in "NUMERIC" ANL data but filled with "TEXT" } \\
\text { ANL data }\end{array}$ \\
\hline Sub-total & 4,076 & 3.15 & All missing data \\
\hline \multicolumn{4}{|r|}{ Erroneous data } \\
\hline 210 & 25 & 0.02 & Filled by interpolation \\
\hline 231 & 4,474 & 3.46 & Filled from $\mathrm{OH}$ data using regression equation \\
\hline Sub-total & 4,499 & 3.48 & All erroneous data \\
\hline \multicolumn{4}{|r|}{ All data } \\
\hline Total & 129,264 & 100.00 & All data \\
\hline
\end{tabular}


Table A4-7. Fraction of Argonne National Laboratory wind travel data from each source, estimated standard error, and description of source and filling method from January 1, 1948, through September 30, 2003, in this study.

[\%, percent; ANL, Argonne National Laboratory; --, no data, QA/QC, quality-assured, quality-controlled; OH, O’Hare International Airport; STC, St. Charles, Illinois]

\begin{tabular}{|c|c|c|c|c|c|}
\hline \multirow{2}{*}{$\begin{array}{c}\text { Data-source } \\
\text { flag }\end{array}$} & \multirow{2}{*}{$\begin{array}{c}\text { Number of } \\
\text { hours }\end{array}$} & \multirow{2}{*}{$\begin{array}{l}\text { Fraction of } \\
\text { hours }(\%)\end{array}$} & \multicolumn{2}{|c|}{ Estimated standard error } & \multirow[b]{2}{*}{ Description of source and filling method (month/day/year) } \\
\hline & & & $\begin{array}{l}\text { Value } \\
\text { (miles) }\end{array}$ & Source & \\
\hline \multicolumn{6}{|c|}{ ANL data } \\
\hline 000 & 126,156 & 25.82 & -- & -- & Original QA/QC data \\
\hline 001 & 186,032 & 38.07 & 43.20 & table 7 & $1 / 1 / 48$ to $11 / 30 / 70$ \\
\hline 002 & 25,886 & 5.30 & 45.88 & table 7 & Argonne/IBM period a, $12 / 1 / 70$ to $12 / 31 / 74$ \\
\hline 003 & 52,873 & 10.82 & 42.14 & table 7 & Argonne/IBM period $b, 1 / 1 / 75$ to $12 / 31 / 81$ \\
\hline 004 & 17,231 & 3.53 & 47.19 & table 7 & Argonne/ARC period a, $1 / 1 / 84$ to $12 / 31 / 85$ \\
\hline 005 & 8,517 & 1.74 & 46.89 & table 7 & Argonne/ARC period $b, 1 / 1 / 86$ to $12 / 31 / 86$ \\
\hline 006 & 17,196 & 3.52 & 53.39 & table 7 & Argonne/ARC period a, $1 / 1 / 87$ to $12 / 31 / 88$ \\
\hline 300 & 144 & .03 & -- & -- & Original data (non/QA/QC) \\
\hline Sub-total & 434,035 & 88.82 & & & All ANL data \\
\hline \multicolumn{6}{|c|}{ Missing data } \\
\hline 110 & 149 & 0.03 & -- & -- & Filled by linear interpolation $1 / 1 / 89$ to $9 / 30 / 03$ \\
\hline 111 & 16 & .003 & -- & -- & Filled by interpolation, $1 / 1 / 48$ to $11 / 30 / 70$ \\
\hline 112 & 3 & .001 & -- & -- & Filled by interpolation, $12 / 1 / 70$ to $12 / 31 / 74$ \\
\hline 113 & 0 & 0 & -- & -- & Filled by interpolation, $1 / 1 / 75$ to $12 / 31 / 81$ \\
\hline 114 & 65 & .013 & -- & -- & Filled by interpolation, $1 / 1 / 84$ to $12 / 31 / 85$ \\
\hline 115 & 24 & .005 & -- & -- & Filled by interpolation, $1 / 1 / 86$ to $12 / 31 / 86$ \\
\hline 116 & 36 & .007 & -- & -- & Filled by interpolation, $1 / 1 / 87$ to $12 / 31 / 88$ \\
\hline 131 & 48,358 & 9.90 & 33.04 & table 5 & Filled from $\mathrm{OH}$ regression equation, $1 / 1 / 48$ to $12 / 31 / 88$ \\
\hline 132 & 2,480 & .51 & 29.64 & table 8 & Filled with the STC regression equation \\
\hline Sub-total & 51,131 & 10.46 & & & All missing data \\
\hline \multicolumn{6}{|c|}{ Erroneous data } \\
\hline 210 & 0 & 0 & -- & -- & Filled by interpolation, $1 / 1 / 89$ to $9 / 30 / 03$ ) \\
\hline 211 & 0 & 0 & -- & -- & Filled by interpolation, $1 / 1 / 48$ to $11 / 30 / 70$ ) \\
\hline 212 & 109 & .022 & -- & -- & Filled by interpolation, $12 / 1 / 70$ to $12 / 31 / 74$ ) \\
\hline 213 & 0 & 0 & -- & -- & Filled by interpolation, $1 / 1 / 75$ to $12 / 31 / 81$ ) \\
\hline 214 & 8 & .002 & -- & -- & Filled by interpolation, $1 / 1 / 84$ to $12 / 31 / 85$ ) \\
\hline 215 & 3 & .001 & -- & -- & Filled by interpolation, $1 / 1 / 86$ to $12 / 31 / 86$ ) \\
\hline 216 & 0 & 0 & -- & -- & Filled by interpolation, $1 / 1 / 87$ to $12 / 31 / 88$ ) \\
\hline 231 & 274 & .056 & 33.04 & table 5 & Filled from $\mathrm{OH}$ data, $1 / 1 / 48$ to $12 / 31 / 88$ \\
\hline 232 & 45 & .009 & 29.64 & table 8 & Filled with the STCregression equation \\
\hline Sub-total & 439 & .090 & & & All erroneous data \\
\hline \multicolumn{6}{|c|}{ Data filled because of missing or erroneous data at another time during the same day } \\
\hline 431 & 3,083 & 0.63 & 33.04 & table 5 & Filled from $\mathrm{OH}, 1 / 1 / 48$ to $12 / 31 / 88$ \\
\hline \multicolumn{6}{|c|}{ All data } \\
\hline Total & 488,688 & 100.00 & & & All data \\
\hline
\end{tabular}


Table A4-8. Fraction of Argonne National Laboratory wind travel data from each source and description of source and filling method from January 1, 1948, through December 31, 1988 , in this study.

[\%, percent; ANL, Argonne National Laboratory; OH, O’Hare International Airport]

\begin{tabular}{|c|c|c|c|}
\hline $\begin{array}{l}\text { Data-source } \\
\text { flag }\end{array}$ & $\begin{array}{c}\text { Number of } \\
\text { hours }\end{array}$ & $\begin{array}{l}\text { Fraction of } \\
\text { hours }(\%)\end{array}$ & $\begin{array}{l}\text { Description of source and filling method } \\
\text { (month/day/year) }\end{array}$ \\
\hline \multicolumn{4}{|c|}{ ANL data } \\
\hline 001 & 186,032 & 51.76 & $1 / 1 / 48$ to $11 / 30 / 70$ \\
\hline 002 & 25,886 & 7.20 & Argonne/IBM period a $(12 / 1 / 70$ to $12 / 31 / 74)$ \\
\hline 003 & 52,873 & 14.71 & Argonne/IBM period $\mathrm{b}(1 / 1 / 75$ to $12 / 31 / 81)$ \\
\hline 004 & 17,231 & 4.79 & Argonne/ARC period a (1/1/84 to $12 / 31 / 85)$ \\
\hline 005 & 8,517 & 2.37 & Argonne/ARC period $\mathrm{b}(1 / 1 / 86$ to $12 / 31 / 86)$ \\
\hline 006 & 17,196 & 4.78 & Argonne/ARC period a (1/1/87 to $12 / 31 / 88)$ \\
\hline Sub-total & $\mathbf{3 0 7 , 7 3 5}$ & 85.62 & All ANL data \\
\hline \multicolumn{4}{|c|}{ Missing data } \\
\hline 111 & 16 & 0.004 & Filled by interpolation $(1 / 1 / 48$ to $11 / 30 / 70)$ \\
\hline 112 & 3 & .001 & Filled by interpolation $(12 / 1 / 70$ to $12 / 31 / 74)$ \\
\hline 114 & 65 & .018 & Filled by interpolation $(1 / 1 / 84$ to $12 / 31 / 85)$ \\
\hline 115 & 24 & .007 & Filled by interpolation $(1 / 1 / 86$ to $12 / 31 / 86)$ \\
\hline 116 & 36 & .010 & Filled by interpolation $(1 / 1 / 87$ to $12 / 31 / 88)$ \\
\hline 131 & 48,072 & 13.37 & Filled from $\mathrm{OH}$ data $(1 / 1 / 48$ to $12 / 31 / 88)$ \\
\hline Sub-total & 48,216 & 13.41 & All missing data \\
\hline \multicolumn{4}{|c|}{ Erroneous data } \\
\hline 212 & 109 & 0.030 & Filled by interpolation $(12 / 1 / 70$ to $12 / 31 / 74)$ \\
\hline 214 & 8 & .002 & Filled by interpolation $(1 / 1 / 84$ to $12 / 31 / 85)$ \\
\hline 215 & 3 & .001 & Filled by interpolation $(1 / 1 / 86$ to $12 / 31 / 86)$ \\
\hline 231 & 270 & .075 & Filled from $\mathrm{OH}$ data $(1 / 1 / 48$ to $12 / 31 / 88)$ \\
\hline Sub-total & 390 & .109 & All erroneous data \\
\hline \multicolumn{4}{|c|}{ Data replaced because of missing or erroneous data at another time during the same day } \\
\hline 431 & 3,083 & 0.86 & Filled from $\mathrm{OH}$ data $(1 / 1 / 48$ to $12 / 31 / 88)$ \\
\hline Total & 359,424 & 100.00 & All data \\
\hline
\end{tabular}


Table A4-9. Fraction of Argonne National Laboratory wind travel data from each source and description of source and filling method from January 1, 1989, through September 30, 2003, in this study.

[\%, percent; ANL, Argonne National Laboratory; QA/QC, quality-assured, quality-controlled; OH, O'Hare International Airport; STC, St. Charles, Illinois]

\begin{tabular}{crrr}
\hline $\begin{array}{c}\text { Data-source } \\
\text { flag }\end{array}$ & $\begin{array}{c}\text { Number of } \\
\text { hours }\end{array}$ & $\begin{array}{c}\text { Fraction of } \\
\text { hours (\%) }\end{array}$ & Description of source and filling method \\
\hline 000 & 126,156 & 97.60 & QA/QC data \\
300 & 144 & .11 & Non-QA/QC data \\
Sub-total & $\mathbf{1 2 6 , 3 0 0}$ & $\mathbf{9 7 . 7 1}$ & All ANL data \\
\hline & & \multicolumn{2}{c}{ Missing data } \\
\hline 110 & 149 & 0.12 & Filled by linear interpolation $(1 / 1 / 89$ to $9 / 30 / 03)$ \\
131 & 286 & .22 & Filled from OH regression equation \\
132 & 2,480 & 1.92 & Filled with the STC regression equation \\
Sub-total & $\mathbf{2 , 9 1 5}$ & $\mathbf{2 . 2 6}$ & All missing data \\
\hline & & \multicolumn{2}{c}{ Erroneous data } \\
\hline 231 & 4 & 0.003 & Filled from OH regression equation \\
232 & 45 & .035 & Filled with the STC regression equation \\
Sub-total & $\mathbf{4 9}$ & $\mathbf{. 0 3 8}$ & All erroneous data \\
\hline & & \multicolumn{3}{c}{ All data } \\
\hline Total & $\mathbf{1 2 9 , 2 6 4}$ & $\mathbf{1 0 0 . 0 0}$ & All data \\
\hline
\end{tabular}


Table A4-10. Fraction of Argonne National Laboratory solar radiation data from each source, estimated standard error, and description of source and filling method from January 1, 1948, through September 30, 2003, in this study.

[\%, percent; Lg/day, Langleys per day; ANL, Argonne National Laboratory; --, no data; QA/QC, quality-assured, quality-controlled; OH, O’Hare International Airport; STC, St. Charles, Illinois; ET, extraterrestrial]

\begin{tabular}{|c|c|c|c|c|c|}
\hline \multirow{2}{*}{$\begin{array}{l}\text { Data-source } \\
\text { flag }\end{array}$} & \multirow{2}{*}{$\begin{array}{l}\text { Number of } \\
\text { hours }\end{array}$} & \multirow{2}{*}{$\begin{array}{l}\text { Fraction of } \\
\text { hours (\%) }\end{array}$} & \multicolumn{2}{|c|}{$\begin{array}{l}\text { Estimated standard } \\
\text { error }\end{array}$} & \multirow{2}{*}{ Description of source and filling method (month/day/year) } \\
\hline & & & $\begin{array}{l}\text { Value } \\
\text { (Lg/day) }\end{array}$ & Source & \\
\hline \multicolumn{6}{|c|}{ ANL data } \\
\hline 000 & 125,025 & 25.58 & -- & -- & QA/QC data \\
\hline 003 & 43,398 & 8.88 & 117.42 & table 7 & Argonne-ARC period $(1 / 1 / 84$ to $12 / 31 / 88)$ \\
\hline 300 & 154 & .03 & -- & -- & Non-QA/QC data \\
\hline Sub-total & 434,246 & 88.86 & & & All ANL data \\
\hline \multicolumn{6}{|c|}{ Missing data } \\
\hline 141 & 133 & .027 & -- & -- & $\begin{array}{l}\text { Filled by interpolation on fraction of observed to ET solar radiation } \\
\qquad(1 / 1 / 48 \text { to } 11 / 30 / 70)\end{array}$ \\
\hline 142 & 2 & .0004 & -- & -- & $\begin{array}{l}\text { Filled by interpolation on fraction of observed to ET solar radiation } \\
(12 / 1 / 70 \text { to } 12 / 31 / 81)\end{array}$ \\
\hline 143 & 61 & .012 & -- & -- & $\begin{array}{l}\text { Filled by interpolation on fraction of observed to ET solar radiation } \\
\qquad(1 / 1 / 84 \text { to } 12 / 31 / 88)\end{array}$ \\
\hline 150 & 164 & .034 & -- & -- & Nighttime periods that were filled with zero \\
\hline Sub-total & 50,511 & 10.34 & & & All missing data \\
\hline 243 & 5 & .001 & -- & -- & $\begin{array}{l}\text { Filled by interpolation on fraction of observed to ET solar radiation } \\
\qquad(1 / 1 / 84 \text { to } 12 / 31 / 88)\end{array}$ \\
\hline 250 & 2,308 & .472 & -- & -- & Positive value at night set to zero (1/1/89 to $9 / 30 / 03)$ \\
\hline 251 & 262 & .054 & -- & -- & Positive value at night set to zero $(1 / 1 / 48$ to $11 / 30 / 70)$ \\
\hline 252 & 2 & .0004 & -- & -- & Positive value at night set to zero $(12 / 1 / 70$ to $12 / 31 / 81)$ \\
\hline 253 & 48 & .010 & -- & -- & Positive value at night set to zero (1/1/84 to $12 / 31 / 88)$ \\
\hline Sub-total & 3,062 & .63 & & & All erroneous data \\
\hline \multicolumn{6}{|c|}{ Data replaced because of missing or erroneous data at some other time during the day } \\
\hline 431 & 869 & 0.18 & 81.93 & table 5 & Filled from $\mathrm{OH}$ data set $(1 / 1 / 48$ to $12 / 31 / 88)$ \\
\hline \multicolumn{6}{|c|}{ All data } \\
\hline Total & 488,688 & 100.00 & & & All data \\
\hline
\end{tabular}


Table A4-11. Fraction of Argonne National Laboratory solar radiation data from each source and description of source and filling method from January 1, 1948, through December 31, 1988, in this study.

[\%, percent; ANL, Argonne National Laboratory; OH, O’Hare International Airport; ET, extraterrestrial]

\begin{tabular}{|c|c|c|c|}
\hline $\begin{array}{c}\text { Data-source } \\
\text { flag }\end{array}$ & $\begin{array}{c}\text { Number of } \\
\text { hours }\end{array}$ & $\begin{array}{c}\text { Fraction of } \\
\text { hours }(\%)\end{array}$ & Description of source and filling method (month/day/year) \\
\hline & & & ANL data \\
\hline 001 & 174,386 & 48.52 & Original data $(1 / 1 / 48$ to $11 / 30 / 70)$ \\
\hline 002 & 91,283 & 25.40 & Argonne-IBM period $(12 / 1 / 70$ to $12 / 31 / 81)$ \\
\hline 003 & 43,398 & 12.07 & Argonne-ARC period $(1 / 1 / 84$ to $12 / 31 / 88)$ \\
\hline Sub-total & 309,067 & 85.99 & All ANL data \\
\hline & & & Missing data \\
\hline 131 & 48,540 & 13.50 & Filled from $\mathrm{OH}$ data set $(1 / 1 / 48$ to $12 / 31 / 88)$ \\
\hline 141 & 133 & .037 & Filled by interpolation on fraction of observed to ET solar radiation $(1 / 1 / 48$ to $11 / 30 / 70)$ \\
\hline 142 & 2 & .001 & Filled by interpolation on fraction of observed to ET solar radiation $(12 / 1 / 70$ to $12 / 31 / 81)$ \\
\hline 143 & 61 & .017 & Filled by interpolation on fraction of observed to ET solar radiation $(1 / 1 / 84$ to $12 / 31 / 88)$ \\
\hline Sub-total & 48,736 & 13.56 & All missing data \\
\hline & & & Erroneous data \\
\hline 231 & 266 & 0.074 & Filled from $\mathrm{OH}$ data set $(1 / 1 / 48$ to $12 / 31 / 88)$ \\
\hline 241 & 160 & .045 & Filled by interpolation on fraction of observed to ET solar radiation $(1 / 1 / 48$ to $11 / 30 / 70)$ \\
\hline 242 & 9 & .003 & Filled by interpolation on fraction of observed to ET solar radiation $(12 / 1 / 70$ to $12 / 31 / 81)$ \\
\hline 243 & 5 & .001 & Filled by interpolation on fraction of observed to ET solar radiation $(1 / 1 / 84$ to $12 / 31 / 88)$ \\
\hline 251 & 262 & .073 & Positive value at night set to zero (1/1/48 to $11 / 30 / 70)$ \\
\hline 252 & 2 & .001 & Positive value at night set to zero $(12 / 1 / 70$ to $12 / 31 / 81)$ \\
\hline 253 & 48 & .013 & Positive value at night set to zero $(1 / 1 / 84$ to $12 / 31 / 88)$ \\
\hline Sub-total & 752 & .21 & \\
\hline \multicolumn{4}{|c|}{ Data replaced because of missing or erroneous data at some other time during the day } \\
\hline 431 & 869 & 0.24 & Filled from $\mathrm{OH}$ data set $(1 / 1 / 48$ to $12 / 31 / 88)$ \\
\hline \multicolumn{4}{|r|}{ All data } \\
\hline Total & 359,424 & 100.00 & All data \\
\hline
\end{tabular}


Table A4-12. Fraction of Argonne National Laboratory solar radiation data from each source and description of source and filling method from January 1, 1989, through September 30, 2003, in this study.

[\%, percent; QA/QC, quality-assured, quality-controlled; STC, St. Charles, Illinois; ET, extraterrestrial]

\begin{tabular}{crrl}
$\begin{array}{c}\text { Data-source } \\
\text { flag }\end{array}$ & $\begin{array}{c}\text { Number of } \\
\text { hours }\end{array}$ & $\begin{array}{c}\text { Fraction of } \\
\text { hours (\%) }\end{array}$ & \multicolumn{1}{c}{ ANL data } \\
\hline 000 & 125,025 & 96.72 & QA/QC data \\
300 & 154 & .12 & Non-QA/QC data \\
Sub-total & $\mathbf{1 2 5 , 1 7 9}$ & $\mathbf{9 6 . 8 4}$ & All ANL data \\
\hline & & & \multicolumn{1}{c}{ Missing data } \\
\hline 132 & 1,446 & 1.12 & Filled using the STC data $(1 / 1 / 89$ to $9 / 30 / 03)$ \\
140 & 165 & .13 & Filled by interpolation on fraction of observed to ET solar radiation $(1 / 1 / 89$ to 9/30/03) \\
150 & 164 & .13 & Nighttime periods that were filled with zero. \\
Sub-total & $\mathbf{1 , 7 7 5}$ & $\mathbf{1 . 3 7}$ & All missing data \\
\hline & & & \multicolumn{1}{c}{ Erroneous data } \\
\hline 240 & 2 & 0.002 & Filled by interpolating on the ratios of measured solar radiation values. \\
250 & 2,308 & 1.79 & Positive solar radiation value at night set to zero (1/1/89 to 9/30/03) \\
Sub-total & $\mathbf{2 , 3 1 0}$ & $\mathbf{1 . 7 9}$ & All erroneous data \\
\hline & & & All data \\
\hline Total & $\mathbf{1 2 9 , 2 6 4}$ & $\mathbf{1 0 0 . 0 0}$ & All data \\
\hline
\end{tabular}


Publishing support provided by:

Rolla Publishing Service Center

For additional information concerning this publication, contact:

Director, USGS Illinois Water Science Center

1201 W. University Avenue, Suite 100, Urbana, IL 61801, (217) 328-8747

Or visit the Illinois Water Science Center Web Site at:

http://il.water.usgs.gov 

